\title{
PRODUCTION OF GREEN BACTERIAL CELLULOSE NANOFIBERS BY UTILIZING RENEWABLE RESOURCES OF ALGAE IN COMPARISON WITH AGRICULTURAL RESIDUE
}

\author{
by \\ MINAKSHI GOYAT \\ Bachelor of Chemical Engineering \\ Kurukshetra University, Kurukshetra, INDIA, 2012
}

\author{
A thesis \\ presented to Ryerson University \\ in partial fulfillment of the requirements \\ for the degree of \\ Master of Applied Science \\ in the Program of \\ Chemical Engineering
}

Toronto, Ontario, Canada, 2016

(C) Minakshi Goyat, 2016 


\begin{abstract}
AUTHOR'S DECLARATION
I hereby declare that I, Minakshi Goyat, am the sole author of this thesis. This is a true copy of the thesis, including any required final revisions, as accepted by my examiners.

I authorize Ryerson University to lend this thesis to other institutions or individuals for the purpose of scholarly research.

I further authorize Ryerson University to reproduce this thesis by photocopying or by other means, in total or in part, at the request of other institutions or individuals for the purpose of scholarly research.
\end{abstract}

I understand that my thesis may be made electronically available to the public. 


\begin{abstract}
Production of Green Bacterial Cellulose Nanofibers by Utilizing Renewable Resources of Algae in Comparison with Agricultural Residue
\end{abstract}

\author{
Minakshi Goyat \\ Master of Applied Science \\ Department of Chemical Engineering \\ RYERSON UNIVERSITY
}

2016

Bacterial Cellulose (BC) was synthesized through utilizing algae as a sustainable and renewable carbon source in comparison with agriculture residues (i.e., Wheat Straws (WS)). BC was produced in separate hydrolysis and fermentation method (SHF) using Gluconacetobacter xylinum (G.xylinum). Results for the individual and total sugars were analyzed in comparison with corresponding results from WS hydrolysis. Results show that highest total sugars content was obtained with algae samples that were hydrolyzed using enzymes (Cellulase, $\beta$-glycosidase, and Xylanase) and produced $27.58 \mathrm{~g} / \mathrm{L}$. Similarly, WS hydrolysis under same conditions produced $52.12 \mathrm{~g} / \mathrm{L}$. The lowest total sugars production was obtained with algae sample that was hydrolyzed using $1 \%$ of acid at $121^{\circ} \mathrm{C}$. Produced sugars were utilized in SHF to produce BC, with highest production of $4.86 \mathrm{~g} / \mathrm{L} \mathrm{BC}$ was achieved with algae sample that went through enzymatic hydrolysis. The equivalent production that was obtained from WS hydrolysis was $10.6 \mathrm{~g} / \mathrm{L} \mathrm{Results}$ obtained from individual sugars indicated that among all individual sugars glucose was maximum consumed i.e. $80-85 \%$ of glucose sugar was consumed where the lowest was arabinose which was 
only $50 \%$ consumed during fermentation. The lower production of $\mathrm{BC}$ using algae compared to WS (approximately half) as algae we used was unprocessed means it had oil content in it. About $30-60 \%$ of algae dry weight was utilized for production of oil and rest amount of feedstock was only used for hydrolysis and fermentation.

Keywords: Bacterial cellulose (BC), Algae, Wheat straw (WS), Separate hydrolysis and fermentation and Agricultural residues. 


\section{ACKNOWLEDGEMENTS}

Firstly, I would like to express my sincere gratitude to my master's thesis advisor, Prof. Yaser Dahman, for his continuous support, patience, motivation and immense knowledge. I have learned various things since I became Dr. Yaser Dahman's student. His guidance has helped me in all the time of research and writing of this thesis. He spent much time instructing me how to search literature and how to collect data. I could not have imagined having a better supervisor and mentor for my master's study.

Besides my advisor, I would like to thank the rest of my thesis committee: Prof. Farhad EinMozaffri, Prof. Simant Upreti, Prof. Jiangning (Jenny) Wu and Prof. Yaser Dahman for their insightful comments and encouragement, and also for the hard questions which incented me to widen my research from various perspectives.

My sincere thanks also goes to Dr. Yaser Dahman, Dr. Simant Upreti, Dr. Dae Kun Hwang, Dr. Ramdhane Dhib and Dr. Ginette Turcotte, who provided me an opportunity to work with them as a Graduate Assistant. I would also like to thank Shawn McFadden at the Analytical Centre for helping in HPLC analysis, administrative assistants Alison MacLeod and Isabella Fernandes, and engineering specialist Ali Hemmati for nonstop support. Without their precious support it would not have been possible to conduct this research.

I would like to thank all the members of the Chemical Engineering department who directly or indirectly helped me. And last but not the least, I would like to thank my family i.e. my parents and my uncle for their support and encouragement during my degree, and my cousins for making my stay a memorable one. 
1 dedicate this thesis to my

\section{PARENTS \& UNCLE (DM. Azad Goyat)}

whose unconditional love has always supported me. 


\section{TABLE OF CONTENTS}

AUTHOR'S DECLARATION ii

ABSTRACT iii-iv

ACKNOWLEDGEMENTS V

DEDICATION vi

TABLE OF CONTENTS vii-x

NOMENCLATURE xi

LIST OF TABLES xii-xiii

LIST OF FIGURES xiv-xv

1. INTRODUCTION $1-5$

1.1 Background 1

1.2 Problem Statement 5

1.3 Outline of the Thesis 5

2. THEORETICAL BACKGROUND 6-29

$2.1 \quad$ Diversity of Cellulose

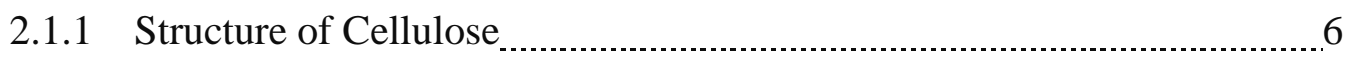

2.1.2 Different Ways to Produce Cellulose _............................................... 7

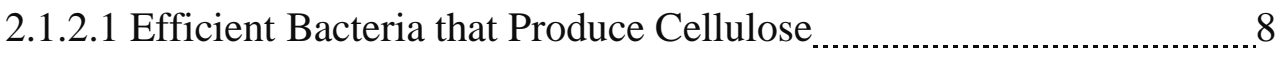

2.1.2.2 BC Cultivation Process

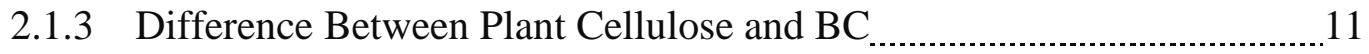

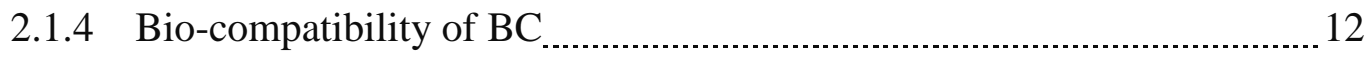

2.2 Algae Bio-refinery

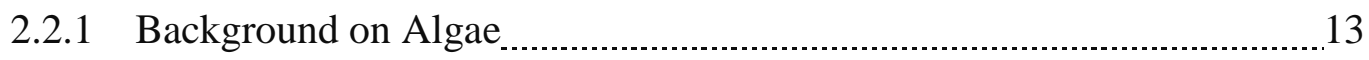




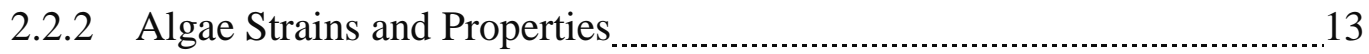

2.2.3 Advantage of Using Algal Biomass _................................................... 15

2.2.3.1 High Productivity $\ldots \ldots \ldots \ldots$

2.2.3.2 Feedstock and Land Usage _...................................................... 15

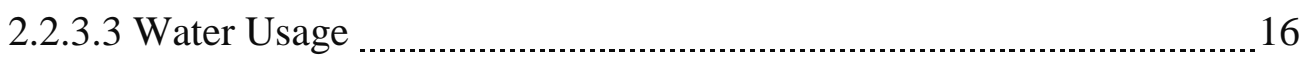

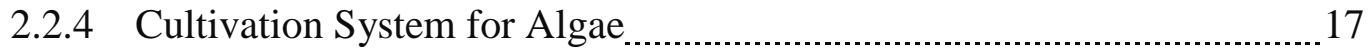

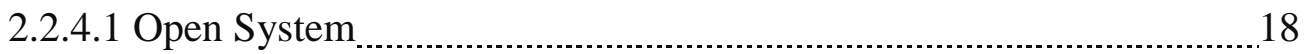

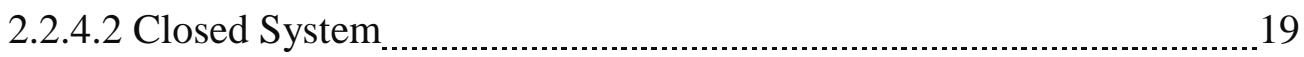

2.2.4.3 Sea Based System

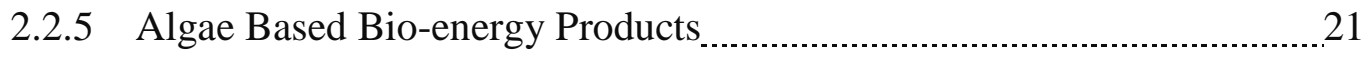

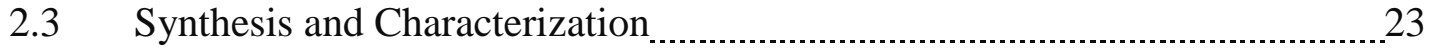

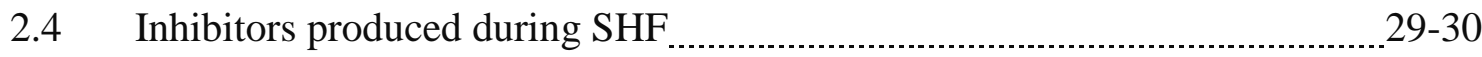

3. EXPERIMENTAL PART__ $31-42$

$3.1 \quad$ Materials $\quad 31$

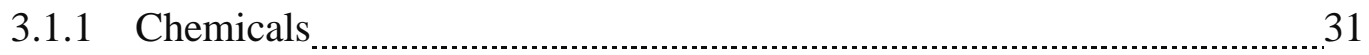

3.1.2 Biomass $\ldots \ldots$

3.2 Methods and Procedures $\quad 32$

3.2.1 Pretreatment and Hydrolysis of Algae

3.2.2 Bacterial Strain and Cultural Growth Conditions _................................. 35

3.2.3 Production of BC Nanofibers _ _ _

3.2.4 Recover and Calculation of BC Yield

3.2.5 Lignocellulosic Composition Calculation _ _ $\quad 37$

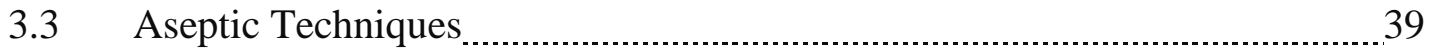




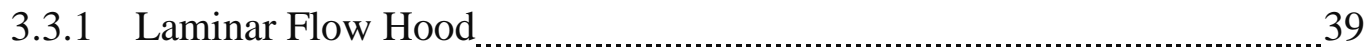

3.4.2 Streaking $\quad 40$

3.4 Analytical Methods _ _ _ _ $\quad 41$

3.4.1 High-Performance Liquid Chromatography (HPLC) _.......................... 41

4. RESULTS AND DISCUSSIONS__ $43-63$

4.1 Lignocellulosic Composition of Algae and WS _ _ _ 43

4.2 Hydrolysis of Algae $\ldots \ldots \ldots$

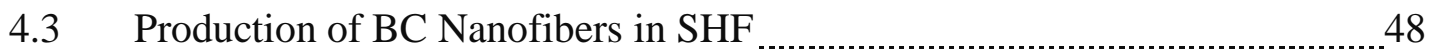

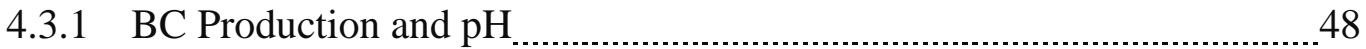

4.3.2 Sugar Concentration profiles $\ldots$

4.3.3 Change in Bacterium Cell Concentrations _.................................. 54

4.4 Comparison between Algae and WS

4.4.1 Production of Individual and Total sugar from Algae and WS _............ 56

4.4.2 Production of BC Nanofibers Algae and WS

4.5 Inhibitors during SHF process

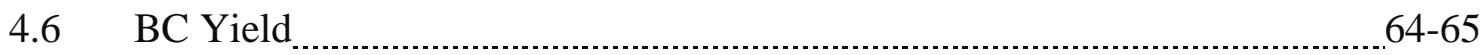

5. ERROR ANALYSIS _

6. CONCLUSION AND RECOMMENDATIONS__ 69-70

7. APPENDICES

Appendix A: Chemicals Used $\quad 71-72$

Appendix B: HPLC Analysis Results _.........................................................

Appendix C. HPLC Standard Calibration Curve $\quad \quad$ _ $\quad$ 78-80

Appendix D. Graphs and Tables Related to SHF and Hydrolysis _...........................81-84 
8. REFERENCES

85-97 


\section{NOMENCLATURE}

$\begin{array}{ll}\text { BC } & \text { Bacterial cellulose } \\ \text { G.xylinum } & \text { Gluconacetobacter xylinum } \\ \text { SSF } & \text { Separate hydrolysis and fermentation } \\ \text { CSL } & \text { Simultaneous saccharification and fermentation } \\ \text { WS } & \text { Wheat straw } \\ \text { STDEV } & \text { Standard deviation } \\ \% \text { RSD } & \text { Percent relative standard deviation } \\ \text { HPLC } & \text { High pressure liquid chromatography } \\ x & \text { Data point } \\ \bar{x} & \text { Sample mean value } \\ \mathrm{n} & \text { Sample size }\end{array}$




\section{LIST OF TABLES}

Table 2.1. Various micro-organisms used for synthesizing BC.

Table 2.2. Different components of microalgae.

Table 2.3. Productivity of selected crops.

Table 2.4. Common pretreatments of lignocellulose.

Table 2.5. Chemical compositions of used mediums.

Table 2.6. Compositions of the different feedstock's of sugar mixtures that were used in BC production by G. xylinum (Dahman Y. J., 2010).

Table 3.1. Pretreatment condition of different algae samples used for hydrolysis of algae and WS.

Table 3.2. Pretreatment and hydrolysis conditions of the different algae samples that were utilized in the production fermentation of $\mathrm{BC}$.

Table 4.1. Lignocellulose composition of WS and algae.

Table 4.2. Individual and total sugars concentration from algae hydrolysis.

Table 4.3. Results obtained from the fermentation experiments using algal hydrolysate as a feedstock to produce BC by G. xylinum.

Table 4.4.Concentration of individual sugars before and after production fermentation of $\mathrm{BC}$ through utilizing algae hydrolysate in the feedstock.

Table 4.5. Concentration of individual sugars produced during hydrolysis of algae and WS.

Table 4.6. BC yield from algae and WS.

Table A1. List of chemicals used and their chemical formulas.

Table B1. Sample A1, area of absorbance.

Table B2. Sample A2, area of absorbance.

Table B3. Sample A3, area of absorbance.

Table B4. Sample A4, area of absorbance.

Table B5. Retention times for standard solutions used in HPLC. 
Table D1. Production of BC nanofibers.

Table D2. Percentage of sugar available during fermentation. 


\section{LIST OF FIGURES}

Figure 2.1. Structural formula of cellulose. The arrows point to the basic repeat unit, which is a cellobiose molecule.

Figure 2.2. BC and plant cellulose (www.res.titech.ac.jp).

Figure 2.3. Algae in seawater.

Figure 2.4. Classification of algae.

Figure 2.5. Overview of different products obtained from algae using different methods.

Figure 2.6. The main goal of pretreatment is to increase the accessibility of cellulose to cellulolytic enzymes in subsequent enzymatic hydrolysis stage.

Figure 2.7. Depiction of enzymatic hydrolysis of cellulose by respective enzymes.

Figure 2.8. BC product from various fruit juices on medium I and II. (A) Orange (B) Pineapple (C) Apple

(D) Japanese Pear (E) Grape. (1) Fruit juice adjusted pH 6 + nitrogen source in HS medium.

(2) Fruit juice adjusted pH 6 (Kurosumi, 2009).

Figure 3.1. Petri dish showing growth of bacteria.).

Figure 3.2. HPLC (Model \# 600 by Perklin Elmer) equipped with refractive index (Model \# Hp1047 A, Hewlett Packard

Figure 4.1. Individual sugars concentration produced by different algal hydrolysis samples under different pretreatments.

Figure 4.2. Total sugars concentration produced by different algal hydrolysis samples under different pretreatments conditions.

Figure 4.3. Final BC production obtained using the different cultures prepared with conditions in Table 7, in addition to the final $\mathrm{pH}$ of the culture media.

Figure 4.4. Changes in the percentage of total sugars concentration in the fermentation medium during SHF for all samples

Figure 4.5. Change in G. xylinum bacterial cell concentration during the SHF method. 
Figure 4.6. Total sugars concentration from algae and WS hydrolysis.

Figure 4.7. Final BC production from algae and WS.

Figure 4.8. Changes in the percentage of total sugars concentrations in the fermentation medium during SHF method (A) For algae (B) For WS.

Figure 4.9. Change in G. xylinum cell counts during the fermentation process for different samples (a) Algae and (b) WS.

Figure C1. HPLC calibration curve for glucose.

Figure C2. HPLC calibration curve for xylose.

Figure C3. HPLC calibration curve for galactose.

Figure C4. HPLC calibration curve for arabinose.

Figure C5. HPLC calibration curve for mannose.

Figure C6. HPLC calibration curve for furfural.

Figure D3. Lignocellulose composition from WS and algae.

Figure D4. Glucose sugar concentration.

Figure D5. Xylose sugar concentration.

Figure D6. Arabinose sugar concentration.

Figure D7. Mannose sugar concentration. 


\section{INTRODUCTION}

\subsection{Background}

Cellulose is a linear polysaccharide homo-polymer of D-glucose with a disaccharide repeat unit consisting of two glucose residues joined by a $\beta$ (1-4) glycosidic bond (Wertz, 2010). Its chemical formula is $\left(\mathrm{C}_{6} \mathrm{H}_{10} \mathrm{O}_{5}\right)_{n}$.

Bacterial cellulose (BC) is an important bio-material and has a versatile structure. $\mathrm{BC}$ is a most promising biomaterial possessing unique properties for applications in different fields i.e. composite membrane, artificial skins, blood vessels and binding agents (Pommet, 2008). BC can be synthesized by plants, some animals and a large number of microorganisms (Castro, 2011). BC can be produced by different strains of bacteria i.e. Gluconacetobacter, Agrobacterium, Achromobacter, Aerobacter, Salmonella, Sarcina, Escherichia, and Rhizobium (Dahman, 2010). Among them, G. xylinum is the most efficient BC producer that can produce it in abundance for industrial application (Brown A. J., 1886).

The cellulose obtained from plants contains many impurities whereas BC produced by microorganisms are pure and very beneficial with excellent properties i.e. transparency, tensile strength, ductility, oxygen permeability, biocompatibility, water-binding capability, adaptability to the living body, high degree of crystallinity, swelling capacity, degree of polymerization and biodegradability. All those superior properties of BC make it a highly potential precursor for breakthrough technologies in many vital fields, such as membrane technologies, green biotechnology, and hybrid nanocomposites (Dahman Y., 2009). 
Cellulose is also known as native cellulose; (Brown R. M., 2004). Native cellulose is found in two crystalline forms: cellulose $I$ and cellulose $I I$. But so far, native cellulose exists as cellulose I where glucan chains are oriented parallel; (Kuga, 1988), whereas, in cellulose II, the chains are antiparallel (Brown R. M., 2004). The dimensions of cellulose of ribbons vary depending on the study source. According to (Brown R. M., 1976), it is $3.2 \mathrm{~nm}$ (thickness) x $133 \mathrm{~nm}$ (length) while according to (Zaar, 2000), its dimensions as $3-4 \times 70-80 \mathrm{~nm}$ and according to (Yamanaka, 2000) it is $4.1 \times 117 \mathrm{~nm}$. The differences in ribbons dimensions may be reasoned to the differences in production processes over time.

Due to its network or structure, $\mathrm{BC}$ has been used for making biomaterials of high mechanical strength and high water retention capacity (Lee J. W., 2001). BC has a wide range of applications in the medical field such as artificial skin for humans with extensive burns, artificial blood vessels for microsurgery, scaffolds for tissue engineering of cartilage (Svensson, 2005), and wounddressing (Alvarez, 2004). BC is used in wound dressing, but it does not possess antimicrobial activity to prevent wound infection.

During BC production, there was a problem with the high cost of culture medium. As a result, lower cost carbon source were examined in current years to produce BC. The lower cost substrates that were examined recently include agricultural products or waste (Kongruang, 2008), food process effluents, hemicelluloses in waste liquor from atmospheric acetic acid pulping (Uraki, 2002), molasses (Bae, 2004), konjak glucomannan (Hong, 2008), fruit juices (Kurosumi, 2009), rice bark (Goelzer, 2009).

In recent years, interest in algae is continuously increasing since algae have potential to meet global demand in addition to that microalgae have various advantages over other agricultural raw material 
(Szulczyk, 2010). Most significant is that they can be grown anywhere and under any weather conditions because algae have variety of species with different properties and adaptations ability. It can grow in open ponds, sea water, fresh water, deserts, arid lands, etc. For growth of algae, some parameters such as $\mathrm{pH}$, light, salinity, temperature and quality of ingredients are important (Szulczyk, 2010).

Moreover, microalgae have high productivity per unit area in contrast to other crops and do not require fields to grow. Algae can produce 2, 500,000 liter of oil $/ \mathrm{km}^{2}$ whereas soybeans produce 59,000 liter of oil $/ \mathrm{km}^{2}$ at medium productivity (Pienkos, 2009). The algae constitute of lignocellulose biomass i.e. cellulose, hemicellulose and lignin. Moreover, algae have short doubling time (around 12-24 hours), simple structure, contains more oil and are capable of greater photosynthetic efficiency than other raw materials or oil crops. In today's scenario, more work is focused on reducing the cost of biodiesel and can be improved with some of the innovations. The $1^{\text {st }}$ and most important is the selection of algae strain, and this is also the $1^{\text {st }}$ step for biodiesel production. Algae strain should be enriched in lipid productivity so that it produces more oil content (Jiang, 2011) (Yoo, 2010).

In addition, algal fuel has gained lots of interest in the recent years (i.e., starting 2010). This interest has been driven by the following reasons (Lundquist, 2010):

- Algal fuel can be produced using freshwater, saltwater and wastewater.

- The oil is biodegradable so it is harmless to the environment if spilled.

- The bio-oil production is around $60 \%$ of the biomass much higher than the $2-3 \%$ produced from soybean.

Algae use $\mathrm{CO}_{2}$ and convert it to lipids, which are extracted using organic solvents and converted 
to biodiesel by esterification or trans-esterification process. The growing of algae, extraction of lipids and conversion to biodiesel is collectively known as bio-refinery. Carbon dioxide emitted from combustion processes can be used as a source of carbon for algal growth $(1 \mathrm{~kg}$ of the algal biomass requiring about $1.8 \mathrm{~kg}$ of $\mathrm{CO}_{2}$ ) (Y., Chisti., 2007). Depending on the technology used and the location of production, algal biomass can be utilized to produce proteins (feed and food), carbohydrates (bioenergy and biofuels) lipids and valuable compounds. Nowadays, algae have been used in industry for energy production (alternative source for fossil fuels) and the production of biodiesel (Burton T., 2009) (Chisti, 2007). The other innovation is the cultivation of algae. Last innovation is to synthesize valuable products from by-products i.e. biogas (Vergara-Fernandez, 2008), bio-butanol (Nakas, 1983), omega 3 oil (Belarbi, 2000), livestock feed (Besada, 2009), and cosmetic (Spolaore, 2006).

Once the oil is extracted from algae, remaining biomass can be further utilized as a renewable and sustainable resource for carbon that can replace agriculture residues to produce biofuels such as ethanol and butanol (Potts, 2012). Algae are known to produce biomass faster and on reduced land surface as compared with lignocellulosic biomass (Lee R. A., 2013). The cell wall of algae consists of polysaccharides that can be hydrolyzed to produce sugar. Therefore, algae can be used as a carbon source in fermentation processes. All these characteristics make algae a promising alternative for agricultural residues.

The present research is focused on utilizing algae in comparison with agriculture wastes to produce BC. This includes investigating the pretreatment hydrolysis of algae followed by fermentation production of BC in comparison with WS. 


\subsection{Problem Statement}

The aim of this thesis is to investigate the potential to produce the green Bacterial cellulose nanofibers by utilizing renewable resources of algae in separate hydrolysis and fermentation (SHF). Results obtained were compared with corresponding results that were obtained earlier for $\mathrm{BC}$ production experiments using WS from agriculture residues. The experiments mainly focused on hydrolysis and fermentation process and the following areas were investigated:

- Individual and total sugars produced by hydrolysis of the renewable resources of algae using different pretreatment conditions (i.e. acidic treatment, thermal treatment and enzymatic treatment).

- Production of green BC nanofibers by utilizing green renewable resources of algae using SHF.

- Comparison was established with respect to hydrolysis and $\mathrm{BC}$ production results that were obtained earlier from agricultural residue (i.e., WS).

\subsection{Outline of Thesis}

The following content describes the $\mathrm{BC}$ nanofibers, with focus on separate hydrolysis and fermentation process. The following chapters contain the theoretical background, materials and methods used during hydrolysis and fermentation process in this thesis, which is followed by results and discussion. At the end of the thesis, conclusion, recommendations for future work, references and appendices are included. 


\section{THEORETICAL BACKGROUND}

\subsection{Diversity of Cellulose}

Cellulose can be synthesized by a great diversity of living organisms i.e. trees, cotton plants, and moreover, these are major sources for the industrial production of cellulose. Cellulose can be synthesized by bacteria and prokaryotes as well (e.g., Acetobacter, Rhizobium, and Agrobacterium). Even some pathogenic bacteria have been found to synthesize cellulose (Brown R. M., 2004). One of the most interesting recent discoveries is that the most ancient forms of life on earth, represented by the cyanobacteria, also synthesize cellulose (Nobles, 2001). Of course, eukaryotic organisms produce cellulose, and certain fungi, amoebae, cellular slime molds, and green algae have representatives that produce perfectly pure cellulose (Wiessner, 2012).

\subsubsection{Structure of Cellulose}

$\mathrm{BC}$ is an important material that has versatile structure. Cellulose is chemically composed of glucose monomers as shown in figure 2.1 (Brown R. M., 2004). Cellulose is a linear polysaccharide homo-polymer of D-glucose with a disaccharide repeat unit consisting of two glucose residues joined by a $\beta$ (1-4) glycosidic bond (Wertz, 2010). Its chemical formula is $\left(\mathrm{C}_{6} \mathrm{H}_{10} \mathrm{O}_{5}\right)_{\mathrm{n}}$. The number of glucose units in native cellulose (Cellulose made by living organism) depends on the source, such as primary or secondary cell walls. Primary cell wall cellulose polymers have about 8000 glucose units per chain (dp 8000). Secondary wall cellulose has a higher dp, up to 15,000 (Brown R. M., 2004). 


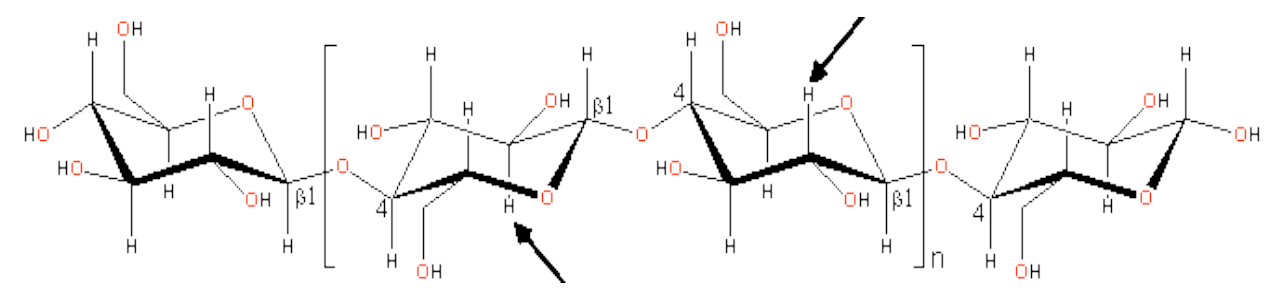

Figure 2.1. Structural formula of Cellulose. The arrows point to the basic repeat unit, which is a cellobiose molecule (Brown R. M., 2004).

Cellulose is found in two crystalline forms i.e. Cellulose I and Cellulose II (Brown R. M., 2004). The difference between these two is based on orientation. In cellulose I, glucan chains are oriented in parallel (Kuga, 1988), whereas, in Cellulose II, the chains are anti-parallel. Micro-fibril is the basic structural unit of Cellulose. Factors that influence cellulose hydrolysis by cellulase enzymes include degree of polymerization, crystallinity, accessible surface area, and the presence of lignin and structural polysaccharides. Moreover, thermodynamically cellulose II is more stable than Cellulose I because it has an additional hydrogen bond per glucose residue (Brown R. M., 2004). Native cellulose II is rare and is found only in several algae as well as some bacteria. The structure of Cellulose is for the protection of the cell. Moreover, coating or covering of cellulose to produce a cell wall is of great importance in protecting the delicate protoplasm from the environment (Brown R. M., 2004).

\subsubsection{Different ways to produce Cellulose}

Up until now, four main different pathways have been used to prepare cellulose. This first pathway includes the chemical pulping, separation, and purification processes to remove lignin and other polysaccharides (hemicelluloses) and is the most popular and industrially important pathway for isolating cellulose. Second pathway consists of the biosynthesis of cellulose from different types 
of microorganisms, such as algae (Vallonia), fungi (Saprolegnia, Dictystelium discoideum), or certain bacteria (Acetobater, Achromobacter, Aerobacter, Agrobacterium, Pseudomonas, Rhizobium, Sarcina, Alcaligenes, Zoogloea) (Vandamme, 1998). The last pathway is a chemical synthesis (without the use of any biologically-derived enzymes), that produces cellulose through a ring opening polymerization of the benzylated and pivaloylated derivatives of glucose (Nakatsubo, 1996).

Among the different sources of $\mathrm{BC}$, the production of cellulose using microorganisms, also known as "microbial cellulose", is considered one of the most beneficial methods of synthesis and has been widely studied to fulfill the environmental requirements placed on the paper and cellulose industries. Recently, BC has been adopted in research as the specialized name for microbial cellulose.

\subsubsection{Efficient Bacteria that Produces Cellulose}

Cellulose is a natural polymer and a source of novel material for many applications (Trovatti, 2011) (Klemm D. S., 2001). It can be produced by different plants, trees like corn roots, mung bean hypocotyls, radish roots, mosses, amoebae, ferns, certain fungi (the Oomycetes), angiosperms and gymnosperms, cellular slime molds (Dictyostelium discoideum) and a great diversity of algae (Vaucheria Glaucocystis, Pleurochrysis, Oocystis, Valonia, and Eremosphaera), plankton and marine algae (Brown Jr, 1978)and by several bacteria (Klemm D. S., 2001). BC is produced by several bacteria belonging to the Gluconacetobacter genus, which comprises of several species like Gluconacetobacter xylinum, Gluconacetobacter hansenii and Gluconacetobacter nataicola (Dutta, 2007). These are well known BC producers. Among all, Gluconacetobacter xylinum is the 
most capable microorganism for synthesizing cellulose. A summary of the most common BC producers is given in Table 2.1.

Table 2.1. Various micro-organisms used for synthesizing BC (Jonas, 1998) (Sheykhnazari, 2011) (El-Saied, 2004).

\begin{tabular}{|c|c|c|}
\hline Organism (Genus) & Cellulose Produced & Biological Role \\
\hline Acetobacter & Extracellular Pellicle & To keep in aerobic \\
\hline Acetobacter & Cellulose Ribbons & Environment \\
\hline Achromobacter & Cellulose Fibrils & Flocculation in waste water \\
\hline Aerobacter & Cellulose Fibrils & Flocculation in waste water \\
\hline Agrobacterium & Short Fibrils & Attach of plant tissues \\
\hline Alcali-genes & Cellulose Fibrils & Flocculation in waste water \\
\hline Pseudomonas & No Distinct Fibrils & Flocculation in waste water \\
\hline Rhizobium & Short Fibrils & Attached to most plants \\
\hline Sarcina & Amorphous Cellulose & Unknown \\
\hline Zoogoloea & Not Well Defined & Flocculation in waste water \\
\hline
\end{tabular}


By varying method or concentration of culture, different phonological BC can be produced (Keshk, 2005). BC can be produced by different strains of bacteria i.e. Acetobacter, Agrobacterium, Achromobacter, Aerobacter, Salmonella, Escherichia, Azotobacter and Rhizobium (Colvin, 1963) (P. Ross, 2002) (Brown A. J., 1886). The structural feature of BC can depend on the type of bacteria strain used (shown in Table 2.1) (Sani, 2010). It has been reported that A. xylinum can produce sugars and BC (Adejoye, 2006) (Bae, 2004) (Ishihara, 2002) (Verschuren, 2000). The G. xylinum is a gram-negative bacteria belonging to family of Acetobacteraceae (Yamada, 1997). This micro-organism has a unique feature of its ability to produce Cellulose with high degree of crystallinity which distinguish it from plant cellulose (Cannon, 1991) (Ross, 1991).

\subsubsection{BC Cultivation Process}

$\mathrm{BC}$ can be produced using either using static or agitated cultivation. The following procedure is used during the static cultivation process. First, the bacteria are transplanted into a culture medium and then grown in an Erlenmeyer flask. The produced cellulose pellicles are washed with a $1 \mathrm{M}$ sodium hydroxide solution $(\mathrm{NaOH})$ and then repeatedly washed with deionized water to remove the bacteria wand the remaining media. The washed $\mathrm{BC}$ is stored in deionized water in a refrigerator to prevent drying and contamination (Hamad, 2002). The general agitated culture method is carried out by transferring the bacteria into a liquid medium in a flask where it is then agitated for several days. The culture liquid is transferred into a liquid medium in a Roux flask where it is cultivated under continuous agitation for several days. In the static cultivation method, $\mathrm{BC}$ has produced a gelatinous sheet, whereas in the agitated cultivation method, $\mathrm{BC}$ accumulates in a dispersed suspension containing irregular masses, such as granules, stellates, and fibrous strands (Chen, 2010). 


\subsubsection{Difference between Plant Cellulose and BC}

Plant cellulose and $\mathrm{BC}$ have the same chemical structure but different physical and chemical properties. The chemical purity of $\mathrm{BC}$ is another important feature that distinguishes it from plant cellulose and is usually associated with hemicelluloses and lignin. Figure 2.2 shows microscopic image for plant cellulose and BC (www.res.titech.ac.jp). The cellulose obtained from plants (i.e. wheat straw) contains many impurities, including hemicellulose and lignin. These are important in the production of paper and wood based products. Whereas BC produced by microorganisms are pure and very valuable with excellent properties i.e. transparency, tensile strength, ductility, oxygen permeability, biocompatibility, water-binding capability, adaptability to the living body, high degree of crystallinity, swelling capacity, degree of polymerization and biodegradability.

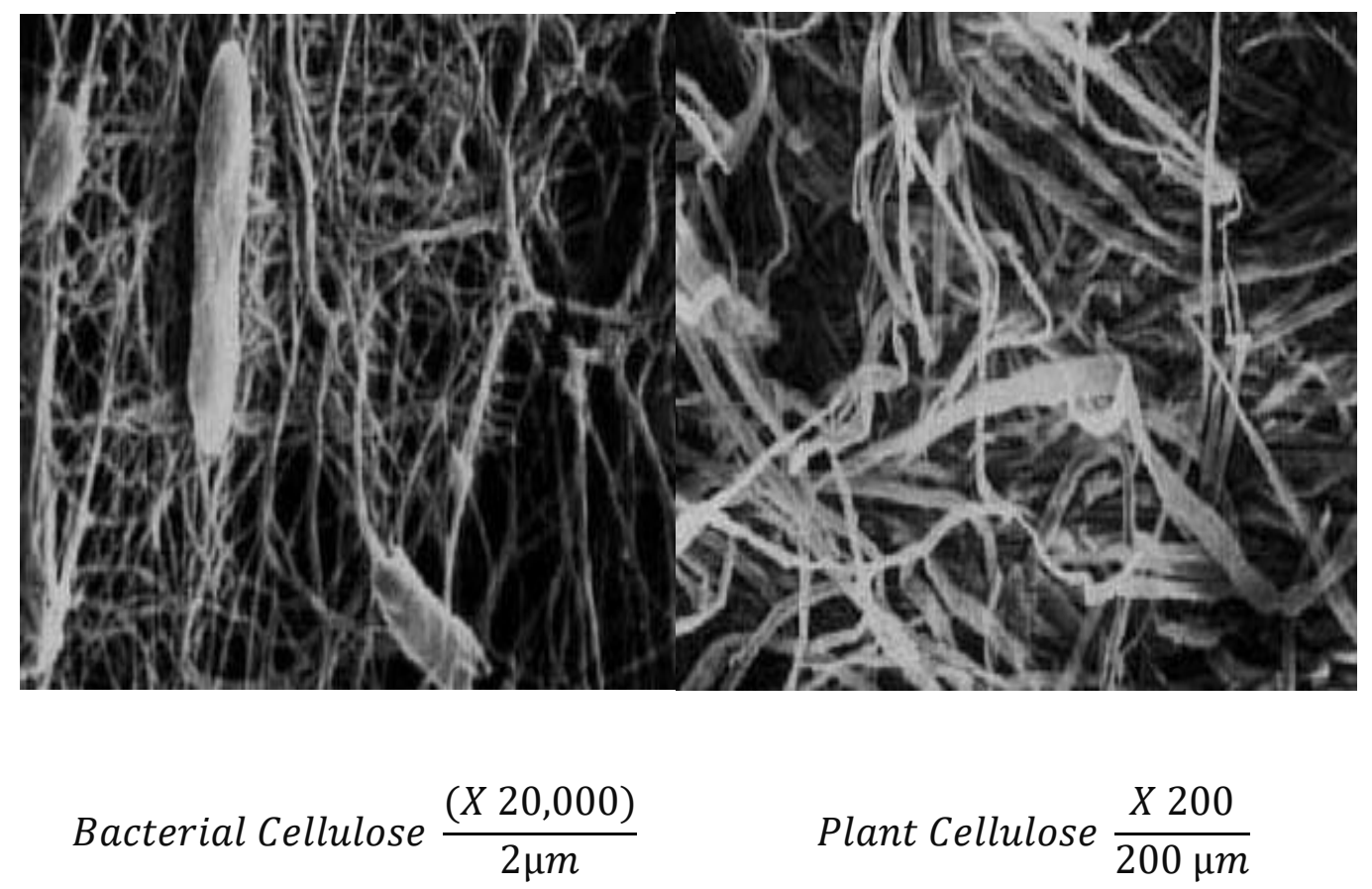

Figure 2.2. BC and plant cellulose (www.res.titech.ac.jp). 
The $\mathrm{BC}$ is gaining lots of interest due to its structure and its advanced properties than Plant Cellulose. The young's modulus of BC is almost equivalent to aluminum, hence it is expected to be a new biodegradable polymer (www.res.titech.ac.jp).

\subsubsection{Bio-compatibility of BC}

$\mathrm{BC}$ is made up of pure cellulose nano-fibrils synthesized from A. xylinum, which allows it to have high mechanical strength along with the ability to be shaped in 3D structures. Cellulose-based materials have been shown to induce negligible foreign body and inflammatory responses, deeming them as biocompatible. The in vivo biocompatibility has not been evaluated systematically, so it is necessary to evaluate the in vivo biocompatibility when developing tissue engineered constructs with a $\mathrm{BC}$ scaffold. Biocompatibility is an important factor in the outcome of a scaffold for tissue-engineered constructs.

According to Helenius et al., (2006), bio-compatible BC was inserted subcutaneously in rats for 1, 4 and 12 weeks and all the rats evaluated in aspects of chronic inflammation, foreign body responses, cell ingrowth and angiogenesis using histology, immunohistochemistry, and electron microscopy. It was found that there were no macroscopic signs of inflammation around the implanted $\mathrm{BC}$ or in the incision at any time, and no giant cells were present. Overall, there were no histological signs of inflammation either (an abnormally large number of small cells in the connective tissue). Fibroblasts infiltrated the $\mathrm{BC}$ which has already been well integrated into the host tissue and there weren't any chronic inflammatory reactions. This helps to prove the biocompatibility of $\mathrm{BC}$ and shows that it has potential to be used as a scaffold in tissue engineering (Helenius, 2006). 


\subsection{Algae Bio-refinery}

\subsubsection{Background on Algae}

Algae are plant-like autotrophic organisms that range from unicellular to multicellular forms. It utilizes sunlight to reduce $\mathrm{CO}_{2}$ to biodiesels (main product), foods, fertilizers and other useful products i.e. energy, proteins, animal feed, nutraceuticals, etc. Microalgae have various advantages over other agricultural raw material. Most significant is, it can be grown anywhere and in every season because algae have a variety of species that have different properties and adaptations. It can grow in open ponds, sea water, fresh water, deserts, arid lands, etc. For growth of algae, some parameters such as $\mathrm{pH}$, light, salinity, temperature and quality of ingredients are important.
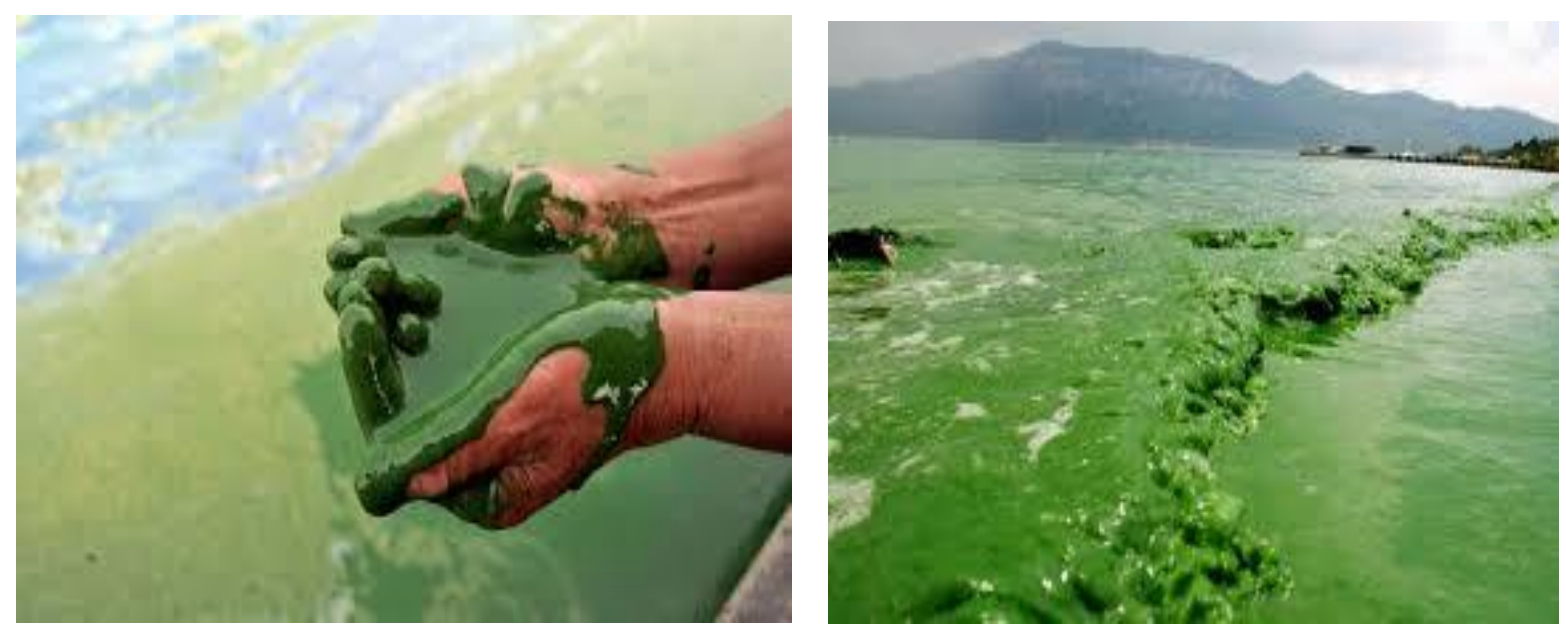

Figure 2.3. Algae in seawater (Dunlop, 2016).

\subsubsection{Algae Strains and Properties}

There are millions of algae strains hence, there are no specific criteria for their classification so can see a variety of classification. They can be found anywhere wherever they can get sunlight for their photosynthesis. For ease, algae can be classified into two major groups - macro algae and microalgae as shown in Figure 2.4. 


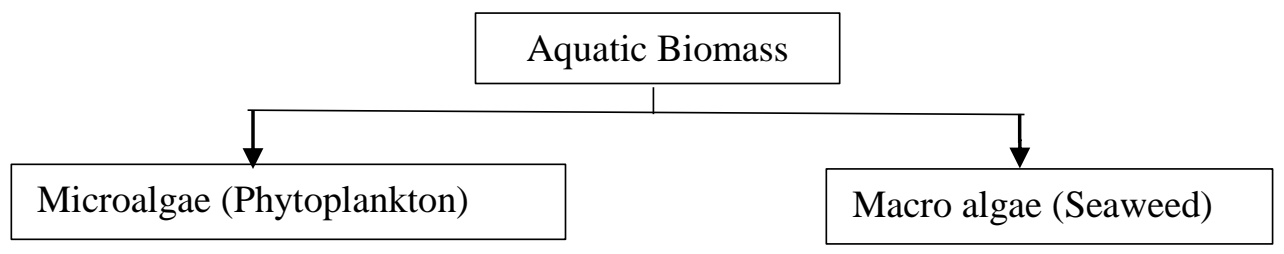

Figure 2.4. Classification of algae.

Macro algae include brown, green and red algae. Nowadays, brown type algae have been used in industries for energy production (alternative source for to fossil fuels), and production of green biodiesel algae can also be used (Burton T., 2009).

Microalgae is defined as unicellular photosynthetic cells and it contains 30000 microalgae species in the world. It is also known as phytoplankton in the coasts lakes, oceans which include diatoms, dynoflagellates, green and brownish flagellate, and blue-green algae (El Gamal, 2010). Microalgae are rich in protein, lipid and sugar and have tolerance for extreme conditions. Along with lipids, proteins, and carbohydrates, microalgae species produce unique products like carotenoids, antioxidants, fatty acids, enzymes, polymers, peptides, toxins and sterols. Table 2.2 below illustrates the major components present in microalgae cells.

Table 2.2. Different components of microalgae (www.biorefinery.nl).

\begin{tabular}{|c|c|c|c|c|}
\hline \multicolumn{5}{|c|}{ ALGAE } \\
\hline \multirow[t]{2}{*}{ Proteins } & \multirow[t]{2}{*}{ Carbohydrates } & \multicolumn{2}{|c|}{ Lipids } & \multirow{2}{*}{$\begin{array}{l}\text { Valuable } \\
\text { Products }\end{array}$} \\
\hline & & Storage Lipids & Membrane Lipids & \\
\hline $\begin{array}{l}\text { High content up to } \\
50 \% \text { of dry weight } \\
\text { in growing } \\
\text { cultures } \\
\text { All } 20 \text { amino } \\
\text { acids }\end{array}$ & $\begin{array}{ll}\checkmark & \text { storage products ó- } \\
& \text { (1-4)-glucans B-(1- } \\
\text { 3)-glucans, } \\
\text { fructans, sugars, } \\
\text { glycerol } \\
\checkmark & \text { low cellulose } \\
& \text { content }\end{array}$ & $\begin{array}{l}\checkmark \text { mainly TAGs } \\
\checkmark \text { up to } 50 \% \text { of DW } \\
\checkmark \text { with solvents } \\
\text { extractable from } \\
\text { wet biomass } \\
\checkmark \text { recovery by } \\
\text { pressing out the dry } \\
\text { and ruptured }\end{array}$ & $\begin{array}{l}\checkmark \text { different lipid classes } \\
\checkmark \text { up to } 40 \% \text { of total } \\
\checkmark \text { lipids are PUFA } \\
\checkmark \text { solubilized by solvent } \\
\quad \text { extraction of wet biomass, } \\
\text { then transesterification }\end{array}$ & $\begin{array}{l}\text { pigments } \\
\text { antioxidants } \\
\text { fatty acids } \\
\text { vitamins } \\
\quad \text { anti- } \\
\text { fungal,-- } \\
\text { microbial }\end{array}$ \\
\hline
\end{tabular}




\subsubsection{Advantage of using Algal Biomass}

\subsubsection{High Productivity}

As mentioned earlier, algae have high growth rates. Algae are the fastest growing plants in the world. They don't require herbicides and fungicides either, providing a cleaner growing environment and fewer emissions. (Brennan and Owende, 2010). They have high levels of oil production, as evident in the Table 2.3 below.

Table 2.3. Productivity of Selected crops (Singh and Gu, 2008)

\begin{tabular}{|c|c|}
\hline CROP & $\begin{array}{c}\text { Oil Yield } \\
\text { (L/hectare) }\end{array}$ \\
\hline Corn & 172 \\
\hline Soybean & 446 \\
\hline Canola & 1190 \\
\hline Rapeseed & 1190 \\
\hline Jatroph & 1892 \\
\hline Oil Palm & 5950 \\
\hline Microalgae $(30 \%$ oil $)$ & 58700 \\
\hline
\end{tabular}

\subsubsection{Feedstock and Land Usage}

One of the main drawbacks of first-generation fuels is the use of food crops for energy production. Using corn and other food products as a feedstock takes away from the amount of food available 
for consumption. Algae does not require the use of fertile land which could otherwise be growing food crops, and therefore, has no impact on the food supply or food costs. In fact, depending on the cultivation methods, algae could be grown on land which does not serve any other purpose, such as brownfields, thereby increasing the carbon density of the land upon which it is grown.

\subsubsection{Water Usage}

Another great advantage of algae is that it doesn't require huge amounts of fresh water to grow. (Pittman et. al., 2011) In fact, it can be grown in sea water and also waste water. Algae can be specially grown in wastewater to remove pollutants like nitrogen and phosphorus which are hard to remove. (Christenson \& Sims, 2011). This characteristic not only satisfies the nutritional needs of the algae but cleans the water as well.

There are some of industries which create large quantities of $\mathrm{CO}_{2}$ as a byproduct of operation. Efforts have been made to integrate the algae biofuel creation process into these industries to stop the $\mathrm{CO} 2$ emissions at the source. "The microalgae Botryococcus braunii 765 is one strain which has shown that it can to thrive in flue $\mathrm{CO} 2$ gas concentrations ranging from $2 \%-20 \%$ " (Ge et. al., 2011). These characteristics makes it feasible for use at industrial plants. For example, Pond Biofuels has established an operation which utilizes the $\mathrm{CO}_{2}$ created as waste during the concrete manufacturing process as feedstock for algal growth (Pond Biofuels, 2011). As for power plants fueled by coal, Brune et. al.'s (2009) paper discusses that conjoined algal biofuel production could lead to a net greenhouse gas avoidance of $26.3 \%$.

Even though algae have these advantages, the main barrier to commercialization of algal biofuel remains the cost of cultivation. However, algae produces a variety of different products and perhaps a good approach is to use the algae left over from fuel generation for co-products. (Raja 
et al., 2008). The biomass left over after the oil has been extracted could also be used for applications such as livestock feed, fertilizer, or electricity production via direct burning or digester gas methane combustion (Brune et. al., 2009). Also after extraction of lipids, the biomass can be used to produce butanol as another source of biofuels. The algae strain is used for biodiesel production because algae are enriched in lipid productivity so that it produces more oil content (Liling jinag, 2011) (Chan Yoo, 2010). Algae is also used to synthesize valuable products from by-products i.e. biogas (Alberto Vergara-Fernandez, 2008), bio-butanol (J. P. Nakas, 1983), omega 3 oil (El-Hhassan Belarbi, 2000), livestock feed (Victoria Besada, 2009), cosmetic (Pauline Spolaoe, 2006). The cell wall of algae consists of polysaccharides that can be hydrolyzed to produce sugar. Therefore, algae can be used as a carbon source in the fermentation process.

\subsubsection{Cultivation System for Algae}

Although not specific to biofuel production from algae, it is important to understand the basics of algae cultivation systems. Systems which use artificial light demand, per definition, more energy in lighting than what is gained as algal energy feedstock, hence only systems using natural light are considered in this document. Seaweed has historically been harvested from natural populations or collected after washing up on shore. To a much lesser extent, a few microalgae have also been harvested from natural lakes by indigenous populations. Given that these practices are unlikely to sustain strong growth, only the cultivation of algae in man-made systems will be considered in this report.

A production system is geared towards a high yield per hectare because it reduces the relative costs for land, construction materials and some operation costs. Realistic estimates of productivity are in the order of magnitude of $40-80$ tons of dry matter per year per hectare, depending on the 
technology used and the location of production (Wijffels et al., 2010). This is still substantially higher than almost all agricultural crops. Surpassing yields of 80 tons per year per hectare will likely require genetically improved strains or other technologies able to counteract photo saturation and photo inhibition (Tredici 2010).

Moreover, algae are a green source. The reason for this is that carbon dioxide emitted from combustion processes can be used as a source of carbon for algal growth ( $1 \mathrm{~kg}$ of the algal biomass requiring about $1.8 \mathrm{~kg}$ of $\mathrm{CO}_{2}$ ). Algal biomass can be utilized for proteins (feed and food), carbohydrates (bioenergy and biofuels) lipids and valuable compounds.

Artificial cultivation systems are of three types:

- Open system

- Closed system

- Sea based

\subsubsection{Open System}

Cultivation of algae in open ponds has been extensively studied. Open ponds can be categorized into natural waters (lakes, lagoons, ponds) and artificial ponds or containers. The most commonly used systems include big shallow ponds, tanks, circular ponds and raceway ponds. One of the major advantages of open ponds is that they are easier to construct and operate than most closed systems. However, major limitations in open ponds include poor light utilization by the cells, evaporative losses, diffusion of $\mathrm{CO}_{2}$ to the atmosphere, and requirement of large areas of land. Furthermore, contamination by predators and other fast growing heterotrophs have restricted the commercial production of algae in open culture systems to only those organisms that can grow 
under extreme conditions. Also, due to inefficient stirring mechanisms in open cultivation systems, their mass transfer rates are very poor resulting in low biomass productivity. (Johnson, 2009). The ponds in which the algae are cultivated are usually called the "raceway ponds". In these ponds, the algae, water \& nutrients circulate around a racetrack. With paddlewheels providing the flow, algae are kept suspended in the water and are circulated back to the surface on a regular frequency. The ponds are usually kept shallow because the algae need to be exposed to sunlight, and sunlight can only penetrate the pond water to a limited depth. The ponds are operated in a continuous manner, with $\mathrm{CO}_{2}$ and nutrients being constantly fed to the ponds while algae-containing water is removed at the other end.

The biggest advantage of these open ponds is their simplicity, resulting in low production costs and low operating costs. While this is indeed the simplest of all the growing techniques, it has some drawbacks owing to the fact that the environment in and around the pond is not completely under control. Bad weather can stunt algae growth. Contamination from strains of bacteria or other outside organisms often results in undesirable species taking over the desired algae growing in the pond. The water in which the algae grow also has to be kept at a certain temperature, which can be difficult to maintain. Another drawback is the uneven light intensity and distribution within the pond. (Shakeel A. Khan, 2009) (Kumar, 2015) (De Bhowmick, 2014).

\subsubsection{Closed System}

Many of the issues with an open cultivation system can be resolved by using a closed system. In a closed system, the configuration usually consists of transparent containers/tubes through which the culture medium flows and since they are transparent light can be provided to the algae, to 
provide ideal growing conditions. Also, $\mathrm{CO}_{2}$ can be supplied from various sources like cement factories etc.

Photo bioreactor is defined as a reactor which is utilized for the inside growth of prototroph or photo-biological reactions to occur. In the contrast to open ponds, photo-bioreactors have better control (Chisti, 2007). They also have controlled environments that entitle higher yield. Photobioreactors have various reactor geometry i.e. tubular reactors can be vertical or horizontal, and they can also be inclined. Usually flat type photo-bioreactors are preferred because of their low energy consumption, high mass transfer capacity, reduce the use of high oxygen concentration, high photosynthetic efficiency compared to other bioreactors. Flat plate bioreactors have illuminated surfaces and are made out of transparent materials, so it utilizes solid light with a maximum degree. Photo-bioreactors can run in a batch or continuous process. For industrial approach continuous bioreactors are preferred because it provides more control and maintained growth rate in the long terms. (Doucha et al., 2005)

\subsubsection{Sea Based System}

Microalgae cultivation has been discussed in the above two headings. However, algae can be grown in seawater, which is seaweed. Due to the availability of large tracks of seawater, cultivation of seaweed for various bi-product productions could be very valuable. Seaweed should be produced in floating cultivation systems spanning hundreds of hectares. Most seaweeds require a substrate to hook to; which in practice means that the cultivation system must contain a network of ropes. The amount of construction material could be drastically reduced when free-floating seaweed (like some Sargasso species) is cultivated, as just a structure to contain the colony would then be needed. Sea-based systems are less well developed than land-based systems, although 
currently R\&D initiatives have been undertaken. The system for seaweed cultivation around the world like in China, Chile (a major exporter of seaweed), etc. has not changed much, hence there is scope for research and development there, and options for modernization have been identified (Tseng 2004).

\subsubsection{Algae Based Bio-energy Products}

There are numerous fuel options that can be produced from algae. Figure 2.5 gives a brief overview along with the production technique.

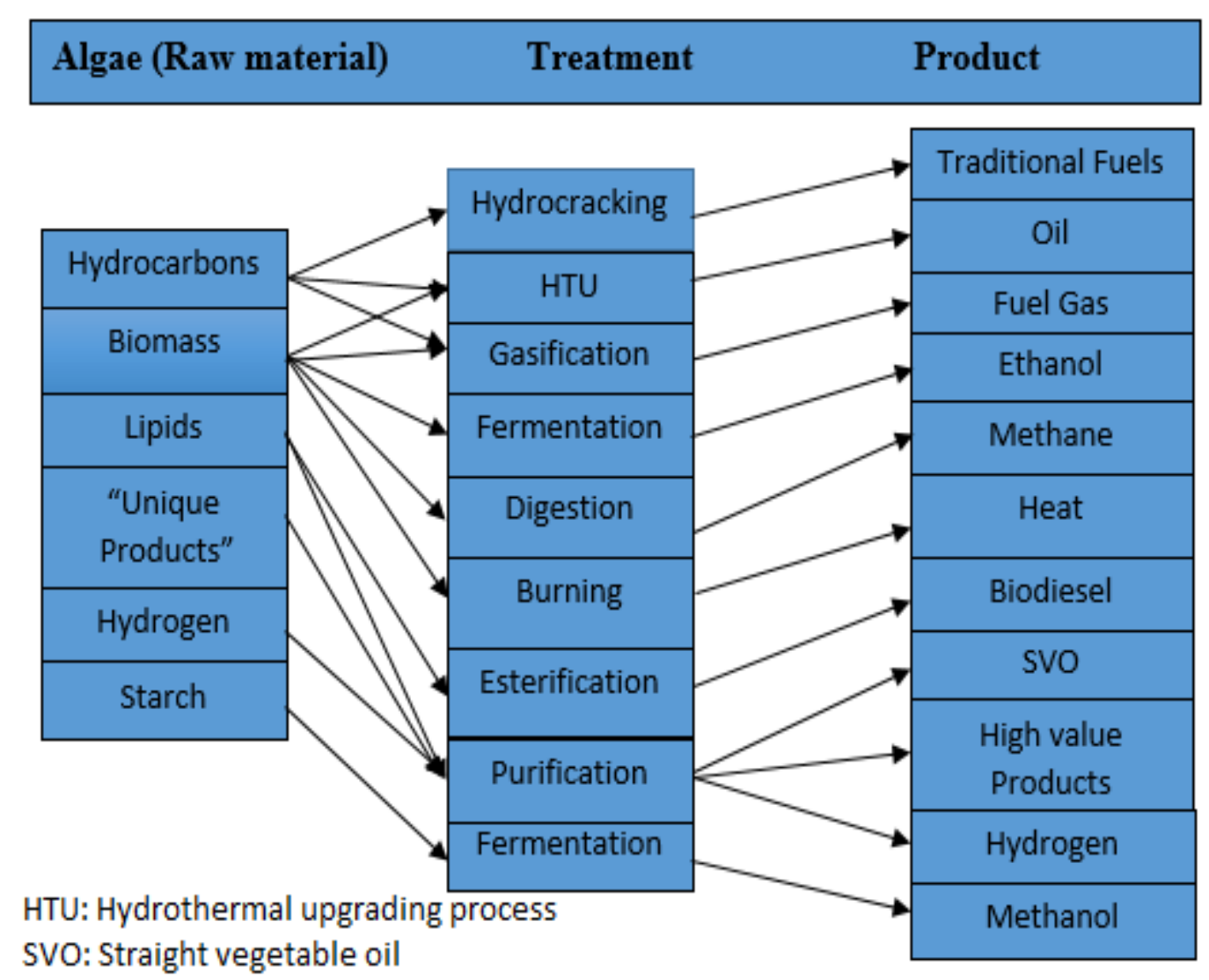

Figure 2.5. Overview of different products obtained from algae using different methods (Bhatnagar, 2011). 
The most popular of these is the biodiesel produced from esterification of lipids. Algae as a source of biodiesel has gained a lot of popularity as algae can contain potentially over $80 \%$ total lipids, (while rapeseed plants, for instance, contain about 6\% lipids). Under normal growth conditions, the lipid concentration is lower $(<40 \%)$ and high oil content is always associated with very low yields. The various lipids production can be stimulated under stress conditions, e.g. insufficient nitrogen availability. Stress conditions do enhance the lipid production but also decrease the biomass content, which can be used for other purposes.

\subsubsection{Hydrocarbons}

Botryococcus species of algae does not produce lipids as other species do making them unsuitable for biodiesel production, but produce long chain hydrocarbons. These can be processes and refined in the same manner as conventional petroleum. (Banerjee et. al., 2002). The disadvantage of this species is the extremely slow growth rate.

\subsubsection{Ethanol}

Ethanol can be produced from starch-containing feedstock as well as the cellulosic and hemicellulosic components of algae, present mainly in the cell wall. Algae contain low levels of cellulose and hemicellulose as compared to other feedstocks. However, they also contain very low amounts of lignin. Also, algae are easier to breakdown than other cellulosic feedstocks, reducing the energy required for the process. (Bush \& Hall, 2006). 


\subsubsection{Butanol}

Cellulosic biomass and starch present in algae can also be converted to butanol using the AcetoneButanol-Ethanol pathway. Recent study in this field has shown this to be a promising product produced from algae growing mostly in waste water. (Ellis et al., 2012).

\subsubsection{Biogas}

Anaerobic digestion converts organic material into biogas that contains about $60 \%-70 \%$ biomethane while the rest is mainly $\mathrm{CO}_{2}$, which can be fed back to the algae. The main advantage is that this process can use wet biomass, reducing the need for drying. Another advantage is that the nutrients contained in the digested biomass can be recovered from the liquid and solid phase. (Samson \& Leduy, 1982). However, the high cost of feedstock makes this not commercially viable, but this can be mitigated using algae from wastewater.

\subsubsection{Hydrogen}

Some green algae can be manipulated to photosynthetically generate $\mathrm{H}_{2}$ gas. This is done by a two stage photosynthesis process in a closed sulfur-deprived environment. The addition of ferrous hydrogenase caused an-aerobiosis in the growth medium, a condition that automatically stimulated $\mathrm{H}_{2}$ production by the algae, Chlymadomonas reinhardtii. However this is extremely expensive and not enough yield is shown to be considered for commercial. (Melis \& Happe, 2002)

\subsection{Synthesis and Characterization}

Algae consist of 16-30\% cellulose, 11-15\% hemicellulose. Lignocellulose is usually pre-treated to break up the recalcitrant structure of lignocellulose and improve the accessibility of hydrolytic 
enzymes to their substrates as shown (Figure 2.6). In studies, the mechanical particle size was reduced to increase the accessible surface area of biomass and was usually followed by physiochemical pretreatments. Some common pretreatments are shown in Table 2.4.
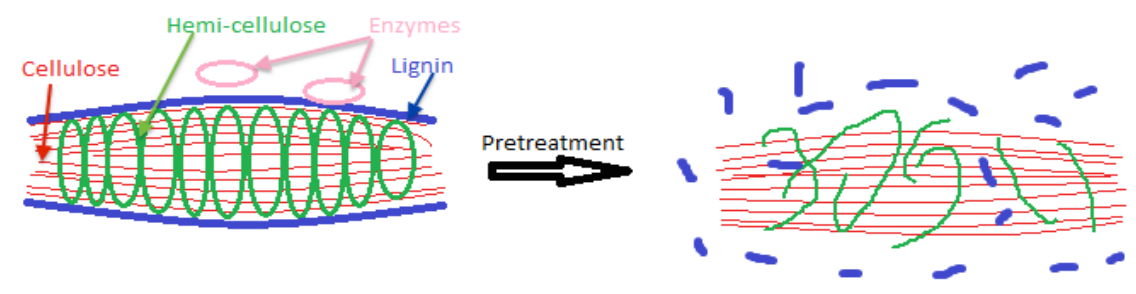

Figure 2.6. The main goal of pretreatment is to increase the accessibility of cellulose to cellulolytic enzymes in subsequent enzymatic hydrolysis stage.

Table 2.4. Common pretreatment methods of lignocellulose.

\begin{tabular}{|l|l|l|l|l|}
\hline \multicolumn{1}{|c|}{ MECHANICAL } & \multicolumn{3}{|c|}{ THERMOCHEMICAL } \\
\hline Milling & Acidic & Alkaline & Oxidative & Fractionation \\
\hline -Knife & $\begin{array}{l}\text {-Steam } \\
\text { Explosion }\end{array}$ & -Lime & -Alkaline & -Organosolv \\
\hline -Hammer & -Liquid Hot & -Ammonium & -Wet & $\mathrm{H}_{2}$ \\
Water & Percolation & Oxidation & -Ionic Liquid \\
\hline -Ball & -Dilute Acid & -Ammonia Fiber & -Ozonolysis & -Phosphoric \\
& Expansion & Acid \\
\hline
\end{tabular}


Enzymatic hydrolysis of cellulose micro-fibrils releases glucose which involved the synergistic action of three enzymes: endo-glucanase, exo-glucanase, and $\beta$-glucosidase. Endo and exoglucanases are commonly referred to as "cellulases" (Teeri, 1997). Endo-glucanases attack amorphous regions of cellulose releasing short cello-oligomers, creating new chain ends for exoglucanases. Exo-glucanases are adsorbed onto cellulose micro-fibrils at the sites where free chain ends are available and proceeded along the chain releasing cellobiose. Exo-glucanases mostly exist in two forms, CBHI and CBHII. CBH I proceeds from reducing end of the chain and CBH II from the non-reducing end (Teeri, 1997). The process of glucose releases from cellulose is depicted in Figure 2.7.

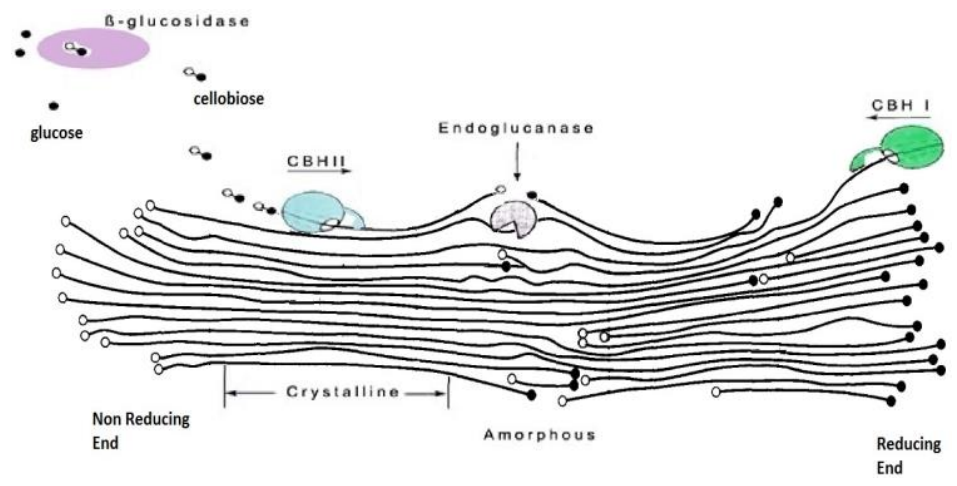

Figure 2.7. Depiction of enzymatic hydrolysis of cellulose by respective enzymes (modified from (Teeri, 1997))

Somayeh et al., (2011) studied the response of numerous growth times and culture medium morphology and characteristics of BC. Three different growth culture mediums were used, and their compositions are shown in Table 2.5. Somayeh et al., (2011) utilized the G. xylinum microorganism and studied the culture media for 7, 14 and 21 days. BC was prepared in the same way given in Nguyen et al., 2008 (Nguyen, 2008). Produced BC was characterized by several test 
like SEM, FT-IR, and XRD, etc. Results showed that after 14 days there was no significant growth in $\mathrm{BC}$ production. Moreover, $\mathrm{BC}$ produced from medium B for 7 days had the most superior properties (Sheykhnazari, 2011).

Table 2.5. Chemical compositions of used mediums (Sheykhnazari, 2011).

\begin{tabular}{|c|c|}
\hline Medium & Compositions \\
\hline A & $\begin{array}{c}20 \mathrm{~g} / \mathrm{L} \text { glucose, } 5 \mathrm{~g} / \mathrm{L} \text { peptone, } 5 \mathrm{~g} / \mathrm{L} \text { yeast extract, } 2.75 \mathrm{~g} / \mathrm{L} \mathrm{NaHPO} 4,1.15 \mathrm{~g} / \mathrm{L} \text { citric } \\
\text { acid. } \mathrm{H} 2 \mathrm{O}\end{array}$ \\
\hline B & $\begin{array}{c}20 \mathrm{~g} / \mathrm{L} \text { manitol, } 5 \mathrm{~g} / \mathrm{L} \text { Peptone, } 5 \mathrm{~g} / \mathrm{L} \text { yeast extract, } 2.75 \mathrm{~g} / \mathrm{L} \mathrm{NaHPO} 4,1.15 \mathrm{~g} / \mathrm{L} \text { citric } \\
\text { acid. } \mathrm{H} 2 \mathrm{O}\end{array}$ \\
\hline C & $\begin{array}{c}15 \mathrm{~g} / \mathrm{L} \text { glucose, } 2.5 \mathrm{~g} / \mathrm{L} \text { poly peptone, } 2.5 \mathrm{~g} / \mathrm{L} \text { yeast extract, } 0.5 \mathrm{~g} / \mathrm{L} \mathrm{MgSO} 4.7 \mathrm{H} 2 \mathrm{O}, \\
500 \mathrm{~cm} 3 \mathrm{dH} 2 \mathrm{O}\end{array}$ \\
\hline
\end{tabular}

D. Mikkelsen et al., (2009) studied the effect of six different carbon sources on the production of BC by G. xylinum (ATCC 53524) (Mikkelsen, 2009). The bacterial strain was cultivated in Hestrin and Schramm (HS) medium or the modified media by simply replacing glucose with glycerol, mannitol, fructose, sucrose or galactose. The amount of cellulose on different carbon sources was recorded at 12 hours intervals over the 96 hours experimental period (Mikkelsen, 2009). After 12 hours, immeasurably small amounts of cellulose were produced with cellulose yields increasing to measurable levels from 24 hours onwards. After 96 hours of fermentation, the highest level of cellulose production was obtained by using sucrose (3.83 $\left.\mathrm{g}^{-1}\right)$. Glycerol, mannitol, glucose and fructose all gave good cellulose yields of 3.75, 3.37, 3.10 and $2.81 \mathrm{~g}^{-1}$ respectively. 
According to Kurosomi et al., (2009) BC can be synthesized from various fruit juices using $A$. xylinum NBRC 13693 (used as an acetic acid) (Kurosumi, 2009). Various fruit juices were studied i.e. orange, apple, pineapple, grape and Japanese pear for the production of BC. Three mediums were prepared for production of BC. Medium I, consisted of fruit juice adjusted $\mathrm{pH} 6$ and nitrogen sources in HS medium. Medium II, consisted of only fruit juice. Medium III, consisted of sugar reagents and a nitrogen source in HS medium. Bacterium was grown in all 3 media at $30^{\circ} \mathrm{C}$, and sugar (glucose, sucrose, and fructose) concentration was analyzed in various fruits.

The results showed that after 14 days of incubation, $\mathrm{BC}$ production was maximum from the medium that consisted of orange juice shown in Figure 2.8. It was also observed that amount of sugar was highest (10.3\%) in grape fruit while least (6.2\%) in Japanese pear.

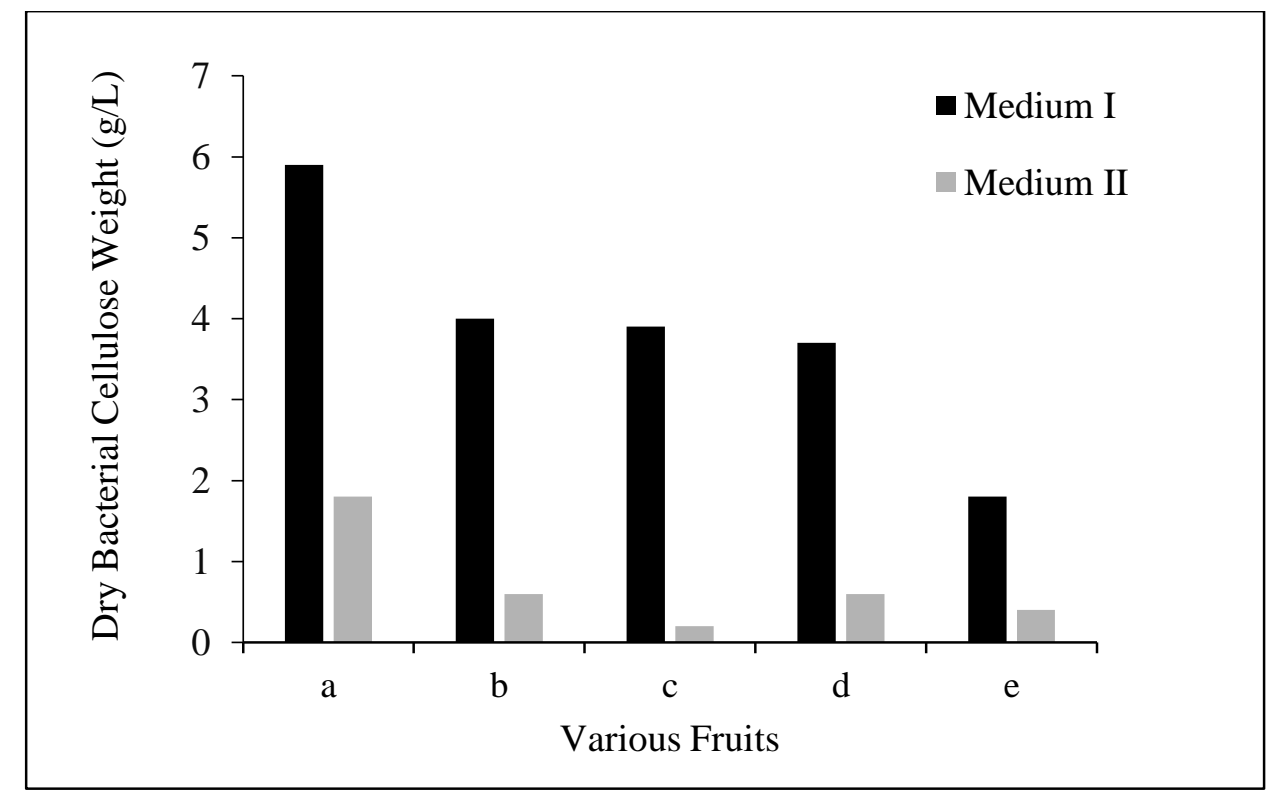

Figure 2.8. BC product from various fruit juices on Medium I and II. (a) Orange (b) Pineapple (c) Apple (d) Japanese pear (e) Grape. (1) Fruit juice adjusted pH 6 + nitrogen source in HS medium. (2) Fruit juice adjusted pH 6 (Kurosumi, 2009). 
Dahman et al., (2010) believed that individual sugars present in WS, CF, and DDGS (Distiller's Dried Grains with soluble) have been examined but mixed sugars have never been examined. Investigation has proved that sugar mixtures can introduce new roots to produce BC (Dahman Y. J., 2010). G. xylinum was utilized and activated according to ATCC mediums. Media composition was as follows: $20 \mathrm{ml} / \mathrm{L}$ of CSL (nitrogen source) total sugars (carbon source: single or mixtures), etc. Table 2.6 shows the composition of different sugar mixtures examined in present studies. The bacterium was cultivated on petri dishes having sterile YGC 459 agar medium. After that, it was incubated for 7 days at $29^{\circ} \mathrm{C}$.

Table 2.6. Compositions of the different feedstock of sugar mixtures that were used in BC production by G. xylinum (Dahman Y. J., 2010).

\begin{tabular}{|l|l|l|l|l|l|l|}
\hline Feedstock & $\begin{array}{c}\text { Glucose } \\
(\mathbf{g} / \mathbf{L})\end{array}$ & $\begin{array}{c}\text { Xylose } \\
(\mathbf{g} / \mathbf{L})\end{array}$ & $\begin{array}{c}\text { Arabinose } \\
(\mathbf{g} / \mathbf{L})\end{array}$ & $\begin{array}{c}\text { Galactose } \\
(\mathbf{g} / \mathbf{L})\end{array}$ & $\begin{array}{c}\text { Mannose } \\
(\mathbf{g} / \mathbf{L})\end{array}$ & \multicolumn{1}{|c|}{ Reference } \\
\hline Mix_1-WS & 19.2 & 13.3 & 3.3 & 2.3 & 1.75 & (Qureshi, 2008) \\
\hline Mix_2-DDGS & 17.95 & 12.7 & 7.8 & 0.9 & 0.6 & (Ezeji, 2008) \\
\hline Mix_3-CF & 21.35 & 10.1 & 6.45 & 2.05 & 0 & (Grohmann, \\
\hline
\end{tabular}

The results show the total $\mathrm{BC}$ production and final $\mathrm{pH}$ for different feedstock's using G. xylinum for (a) single sugar and (b) mixed sugars and observed that highest BC production was obtained in fructose medium, and lowest was obtained in xylose medium. Whereas for sugar mixtures, highest BC production was achieved with Mix_1-WS medium. Which is still considered as 
relatively higher production compared with production in different single sugars (Dahman Y. J., 2010).

Samyar Zabihi et al., (2010) employed that Ethanol, a clean and renewable energy source that can be produced through fermentation from renewable biomass (Zabihi, 2010). WS is an abundant byproduct from wheat production. Cellulose, the major fraction of lignocellulosic biomass, can be hydrolyzed to reducing sugar by cellulase enzymes. Due to hydrolysis, this can be influenced by porosity of lignocellulosic biomass, cellulose fiber crystallinity, and lignin and hemicellulose content. Therefore, According to (Karimi, 2006) pretreatment must be done to remove lignin and hemicellulose, reduce cellulose crystallinity, and increase the porosity of the materials (Karimi, 2006). According to (Sun and Cheng, 2002), steam explosion (includes physical and chemical) pretreatment was the most commonly used method for pretreatment of lignocellulosic materials, than sodium hydroxide (Playne, 1984), alkaline hydrogen peroxide (Saha, 2006)and other pretreatment such as microwave irradiation (Zhu, 2006), milling (Tassinari, 1982), dilute sulphuric acid hydrolysis (Yan, 2009), and anhydrous ammonia pretreatment (Taylor, 2003).

Samyar Zabihi et al., (2010) evaluated the lignin, hemicellulose, and cellulose fractions by using method given in Sun et al., (1995). The equipment consisted of a steam generator and high-pressure pretreatment vessel. After that WS were pretreated by steam, steam/acetic acid, and steam/ethanol to find an additive to increase the efficiency of sugar production. The additives such as citric acid, ethanol, distilled water, carbon tetrachloride, and acetic acid and observed that acetic acid and ethanol were the most effective additives for the reducing sugar.

\subsection{Inhibitors produced during SHF}

When pretreatment conditions are too severe, furfural and 5-Hydroxymethyl furfural are produced 
from pentose and hexose sugars, respectively. During acid pre-treatment, a complex mixture of bacterial inhibitors such as furfural and hydroxymethyl furfural would be generated; however, the inhibitors could be substrate-specific (Palmqvist, 2000).

However, these concentrations were significantly lower than the inhibitory levels of $1 \mathrm{~g} / \mathrm{L}$, above which furfural activity is known to negatively affect fermentation. The low concentration of furfural can be explained by the lower temperature of $121^{\circ} \mathrm{C}$ at which pre-treatment was performed and due to the use of dilute acid. Studies have shown that the concentration of inhibitors increases with an increase in pre-treatment temperature (Saha, 2005). While the decomposition of cellulose and hemicellulose increase the fermentable sugars for cultivation, the liberated in the degradation of lignin are considered microbial inhibitors of fermentation (Modig T., 2002). 


\section{EXPERIMENTAL PART}

\subsection{Materials}

\subsubsection{Chemicals}

For pretreatment and hydrolysis, the following were used: Sulphuric acid (chemical), in addition to Cellulase (700 IU/g), $\beta$-glycosidase (250 IU/g), and Xylanase (2500 IU/g) (enzymatic hydrolysis). Whereas for fermentation, the following chemicals were used: Agar, Ammonium Sulfate $(\mathrm{NH} 4)_{2} \mathrm{SO}_{4}, \mathrm{~L}-(+)$-Arabinose, D-biotin, Calcium Carbonate $\left(\mathrm{CaCO}_{3}\right)$, Calcium Chloride Dihydrate $\left(\mathrm{CaCl}_{2} .2 \mathrm{H}_{2} \mathrm{O}\right)$, Copper Sulfate Pentahydrate $\left(\mathrm{CuSO}_{4} .5 \mathrm{H}_{2} \mathrm{O}\right)$, Ferrous Sulfate Heptahydrate $\left(\mathrm{FeSO}_{4} .7 \mathrm{H}_{2} \mathrm{O}\right), \quad$ Folic Acid, Fructose, D-(+)-Galactose, Glucose, Hydroxymethylfurfural (HMF), Inositol, Magnesium Sulfate Heptahydrate $\left(\mathrm{MgSO}_{4} .7 \mathrm{H}_{2} \mathrm{O}\right)$, Manganese Sulfate Pentahydrate $\left(\mathrm{MnSO}_{4} .5 \mathrm{H}_{2} \mathrm{O}\right)$, Monopotassium Phosphate $\left(\mathrm{KH}_{2} \mathrm{PO}_{4}\right)$, Nicotinic Acid, D-Pantothenic Acid, Pyridoxine Hydrocloride, Riboflavin, Sodium Molybdenum Oxide Dihydrate $\left(\mathrm{NaMoO}_{4} .2 \mathrm{H}_{2} \mathrm{O}\right)$, Zinc Sulfate Heptahydrate $\left(\mathrm{ZnSO}_{4} .7 \mathrm{H}_{2} \mathrm{O}\right)$, Thiamine Hydrochloride, and D-(+)-Xylose, and Corn Steep Liquor (CSL). All chemicals and enzymes used were purchased from Sigma Aldrich and were used as received.

\subsubsection{Biomass}

Biomasses that were used during hydrolysis and BC production experiments were algae and WS. Dry algae were provided by Ponds Biofuel Inc., which is located in Markham Ontario. Microalgae has never been processed prior to receiving them. Total of 20-50\% of algae (dry weight) are usually utilized for production of bio-diesel using trans-esterification process. In the present study, we 
postulated that the rest of the biomass can be utilized as a feedstock (carbon source) for fermentation process. Therefore, lignocellulosic content per gram of algae is almost $50 \%$ to that per gram of WS. WS was collected from a local farm in Barrie, Ontario. The Gluconacetobacter xylinum (a bacterial strain ATCC 700178) was purchased from American Type Culture Collection (ATCC), Manassas, VA 20108, USA.

\subsection{Methods and Procedures}

\subsubsection{Pretreatment and Hydrolysis of Algae}

In order to study hydrolysis of algae, total of 13 samples were subjected to different pretreatment and hydrolysis conditions. Initially, algae were crushed using ball mill (Retsch GmbH Inc. USA, model \# 12930143D) and then sieved through Canadian standard sieve series (No. 200). Each sample consisted of $2 \mathrm{~g}$ algae that were placed in a beaker and total volume was made up to $25 \mathrm{ml}$ by adding the required pretreatment medium. These samples were then subjected to different pretreatment conditions (i.e. chemical and thermal pretreatment) according to conditions summarized in Table 3.1. As for the chemical pretreatment, the algae were subjected to different ratios of dilute sulphuric acid (i.e. $0,1 \& 2 \%$ by volume) and sodium hydroxide (i.e., 1 and $2 \%$ ). Whereas thermal pretreatment was conducted by heating samples to a temperature of $121^{\circ} \mathrm{C}$ for 30 minutes. Moreover, in enzymatic pretreatment, samples were hydrolyzed using enzymes. For this, some samples were hydrolyzed by two enzymes (i.e. Cellulase and $\beta$-glycosidase), while others were hydrolyzed by three enzymes hydrolysis (i.e. Cellulase, $\beta$-glycosidase, and Xylanase). Total amount of $0.375 \mathrm{~mL}$ was used for each enzyme during the enzymatic hydrolysis. During enzymatic hydrolysis, samples were incubated over 3 days at $45^{\circ} \mathrm{C}$ according to Dahman, et al. (2011). 
According to Table 3.1, the effect of acidic concentration was examined by S1 and S2, while the effect of two enzymes hydrolysis on $0 \%$ acid and $1 \%$ acid pretreated samples was examined by samples S8 and S12, respectively. Similarly, the effect of utilizing three enzymes on $0 \%$ acid and $1 \%$ acid pretreated samples was examined by S9 and S13.

Table 3.1. Pretreatment condition of different algae samples used for hydrolysis of algae and WS.

\begin{tabular}{|c|c|c|c|c|}
\hline \multirow{2}{*}{ Sample } & \multirow{2}{*}{$\begin{array}{l}\text { Chemical } \\
\text { Treatment } \\
\text { Acid }(v / v)^{a}\end{array}$} & \multicolumn{2}{|c|}{ Thermal Treatment } & \multirow{2}{*}{ Notice } \\
\hline & & $\begin{array}{c}\text { Temperature } \\
\left({ }^{\circ} \mathrm{C}\right)\end{array}$ & Time & \\
\hline S1 & $1 \% \mathrm{H}_{2} \mathrm{SO}_{4}$ & - & - & No \\
\hline $\mathbf{S 2}$ & $2 \% \mathrm{H}_{2} \mathrm{SO}_{4}$ & - & - & No \\
\hline S3 & $1 \% \mathrm{H}_{2} \mathrm{SO}_{4}$ & 121 & 30 & No \\
\hline S4 & $2 \% \mathrm{H}_{2} \mathrm{SO}_{4}$ & 121 & 30 & No \\
\hline S5 & Water & 121 & 30 & No \\
\hline S6 & $1 \% \mathrm{NaOH}$ & - & - & No \\
\hline S7 & $2 \% \mathrm{NaOH}$ & - & - & No \\
\hline S8 & Water & - & - & Xylanase and Cellulase \\
\hline S9 & Water & - & - & Xylanase, Cellulase, and $\beta$-glucosidase \\
\hline S10 & Water & 121 & 30 & Xylanase and Cellulase \\
\hline S11 & Water & 121 & 30 & Xylanase, Cellulase, and $\beta$-glucosidase \\
\hline S12 & $1 \% \mathrm{H}_{2} \mathrm{SO}_{4}$ & 121 & 30 & Xylanase and Cellulase \\
\hline S13 & $1 \% \mathrm{H}_{2} \mathrm{SO}_{4}$ & 121 & 30 & Xylanase, Cellulase, and $\beta$-glucosidase \\
\hline
\end{tabular}

${ }^{a}$ Total volume of $25 \mathrm{~mL}$ of 1 or $2 \% \mathrm{v} / \mathrm{v}$ dilutes sulphuric acid or sodium hydroxide. 
For the production of BC nanofibers, four samples were utilized out of Table 3.1, namely samples S3, S4, S12 and S13. These samples demonstrate chemical pretreatment using different percentages of sulfuric acid $(1 \% \& 2 \% \mathrm{v} / \mathrm{v})$ and thermal pretreatment at $121^{\circ} \mathrm{C}$ with a heating time of 30 minutes as shown in Table 3.2. The effect of higher acid concentration was examined through sample A2 in Table 3.2. Moreover, after chemical pretreatment, samples A3 and A4 in Table 3.2 were subjected to enzymatic hydrolysis. Sample A3 was subjected to two enzymes hydrolysis (i.e. Cellulase and $\beta$-glycosidase), while sample A4 was subjected to three enzymes hydrolysis (i.e. Cellulase, $\beta$-glycosidase and Xylanase).

Table 3.2. Pretreatment and hydrolysis conditions of the different algae samples that were utilized in the production fermentation of $\mathrm{BC}$.

\begin{tabular}{|c|c|c|c|c|}
\hline \multirow{2}{*}{ Sample } & \multirow{2}{*}{$\begin{array}{l}\text { Chemical } \\
\text { Treatment } \\
\text { Acid }(v / v)^{a}\end{array}$} & \multicolumn{2}{|c|}{ Thermal Treatment } & \multirow{2}{*}{ Notice } \\
\hline & & $\begin{array}{c}\text { Temperature } \\
\left({ }^{\circ} \mathrm{C}\right)\end{array}$ & $\begin{array}{l}\text { Time } \\
(\mathrm{min})\end{array}$ & \\
\hline A1 & 1 & 121 & 30 & Control \\
\hline A2 & 2 & 121 & 30 & High acid concentration \\
\hline A3 & 1 & 121 & 30 & Enzymatic treatment $^{b}$ \\
\hline A4 & 1 & 121 & 30 & Enzymatic treatment $^{c}$ \\
\hline
\end{tabular}

${ }^{\mathrm{a}}$ Total volume of $25 \mathrm{ml}$ of 1 or $2 \mathrm{v} / \mathrm{v}$ dilutes sulfuric acid.

${ }^{b}$ Treated at $45^{\circ} \mathrm{C}$ for 3 days with $0.375 \mathrm{~mL}$ of enzymes: Cellulase and $\beta$-glycosidase.

${ }^{c}$ Treated at $45^{\circ} \mathrm{C}$ for three days with $0.375 \mathrm{~mL}$ of Cellulase, $\beta$-glycosidase and Xylanase

The hydrolysate solutions were finally recovered from the solid content by centrifugation at 4000 rpm for $30 \mathrm{~min}$ (accuSpin ${ }^{\mathrm{TM}}$ 400, Fisher Scientific). They were further purified by a vacuum 
filtration using $0.45 \mu \mathrm{m}$ pore size Pyrex glass filters. Samples of $2 \mathrm{ml}$ were collected at the end of each hydrolysis experiments for sugars' concentrations analysis. They were further filtered through $0.45 \mu \mathrm{m}$ disposable syringe filters (Gelman Acrodisc CR PTEF, Millipore) prior to their use in the HPLC.

\subsubsection{Bacterial Strain and Cultural Growth Conditions}

\subsubsection{Activation of Bacteria}

The bacterial strain (Gluconacetobacter xylinum bacterium (ATCC 700178)) was activated following the ATCC recommendations. This includes using YGC 459 medium that consisted of the following dissolved in one liter of distilled water: glucose (50 g/L), yeast (5 g/L), $\mathrm{CaCO}_{3}(12.5$ $\mathrm{g} / \mathrm{L})$, agar (15 g/L; only used for solid mediums).

Step 1. Preparation of liquid culture

Initially, YGC 459 medium was prepared, and initial pH was adjusted to 5 using $\mathrm{pH}$ meter (Easy Seven, Mettler Toledo). After that, the medium was autoclaved at $121^{\circ} \mathrm{C}$ for 15 minutes. Laminar flow biosafety hood ((Labgard, class II, type A2, Nuaire) was used to transfer bacteria into the sterile YGC 459 medium once medium is reached to room temperature. The liquid culture was then statically incubated (Symphony $8.5 \mathrm{~A}$, VWR) at $29^{\circ} \mathrm{C}$ for 3 days.

Step 2. Bacterium cultivation on agar plates

Initially, solid YGC 459 agar medium was prepared, and initial $\mathrm{pH}$ was adjusted to 5. The medium was then autoclaved at $121^{\circ} \mathrm{C}$ for 15 minutes. The agar medium was poured into petri dishes under the sterile conditions of laminar flow hood and wait for the medium to solidify. Bacterium cultivation was done by transferring liquid culture aseptically into Petri plates or by streaking petri 
dish (see section 3.2.5.2), containing YGC 459 Agar medium, and incubated at $29^{\circ} \mathrm{C}$ and initial $\mathrm{pH}$ of 5 for 7 days.

Inoculum solution was prepared by aseptically flooding the 7 days old culture plates with $20 \mathrm{~mL}$ sterile distilled water and gently suspending the culture with a cell spreader. Then the resulting solution was transferred to sterile inoculum tubes and mixed thoroughly using a VWR Analogue Vortex Mixer.

\subsubsection{Production of BC Nanofibers}

Production of BC nanofibers was pursued in $500 \mathrm{~mL}$ shaking flasks. Each flask contained $100 \mathrm{~mL}$ of fermentation medium. The fermentation medium was composed of algae hydrolysate solution as the carbon source and CSL i.e., as the nitrogen source, in addition to required nutrients (i.e., 1 $\mathrm{g} / \mathrm{L}$ of $\mathrm{KH}_{2} \mathrm{PO}_{4}, 0.25 \mathrm{~g} / \mathrm{L}$ of MgSO $4.7 \mathrm{H} 2 \mathrm{O}, 3.3 \mathrm{~g} / \mathrm{L}$ of $\left(\mathrm{NH}_{4}\right)_{2} \mathrm{SO}_{4}, 3.6 \mathrm{mg} / \mathrm{L}$ of $\mathrm{FeSO}_{4} .7 \mathrm{H}_{2} \mathrm{O}, 14.7$ $\mathrm{mg} / \mathrm{L}$ of $\mathrm{CaCl}_{2} .2 \mathrm{H}_{2} \mathrm{O}, 2.42 \mathrm{mg} / \mathrm{L}$ of $\mathrm{NaMoO}_{4} .2 \mathrm{H}_{2} \mathrm{O}, 1.73 \mathrm{mg} / \mathrm{L}$ of $\mathrm{ZnSO}_{4} .7 \mathrm{H}_{2} \mathrm{O}, 1.39 \mathrm{mg} / \mathrm{L}$ of $\mathrm{MnSO}_{4} .5 \mathrm{H}_{2} \mathrm{O}, 0.05 \mathrm{mg} / \mathrm{L}$ of $\mathrm{CuSO}_{4} .5 \mathrm{H}_{2} \mathrm{O}, 2 \mathrm{mg} / \mathrm{L}$ of Inositol, $0.4 \mathrm{mg} / \mathrm{L}$ of Nicotinic Acid, 0.4 $\mathrm{mg} / \mathrm{L}$ of Pyridoxine Hydrochloride, $0.2 \mathrm{mg} / \mathrm{L}$ of D-Pantothenic Acid $0.2 \mathrm{mg} / \mathrm{L}$ of Riboflavin, 0.2 $\mathrm{g} / \mathrm{L}$ of Folic Acid, $0.2 \mu \mathrm{g} / \mathrm{L}$ of D-biotin and $0.4 \mathrm{~g} / \mathrm{L}$ of Thiamine Hydrochloride). All glass wares were sterilized in autoclave (Sanyo MLS 3780) at $121^{\circ} \mathrm{C}$ for 10 minutes prior to being used. Hydrolysate solutions and their additives were sterilized separately from CSL, each at $121^{\circ} \mathrm{C}$ for 15 min with initial pH 5.0 to prevent high-temperature reaction of sugars and amino acids at which produce black nitrogen-containing compounds that impede microorganism's growth. CSL was aseptically added to the hydrolysate additives mixture, and sterile distilled water was added to compensate for evaporated water during autoclave. 
When the solutions reached room temperature, each flask was aseptically inoculated using $2 \mathrm{~mL}$ of the inoculum, and the top of the flask covered with a sponge that allow oxygen transfer then incubated at $29^{\circ} \mathrm{C}$ for 7 days with shaking speed of $250 \mathrm{rpm}$ (MaxQ 2000). At the end of the 7 days, the $\mathrm{pH}$ of each flask was checked, and solutions were treated with excess $2 \mathrm{~N} \mathrm{NaOH}$ at $100^{\circ} \mathrm{C}$ for $5 \mathrm{~min}$ for cell lysis. In all fermentation experiments, samples of $2 \mathrm{~mL}$ were first taken after inoculation and periodically after that till the end of 7 days. These samples were collected in a biosafety hood that is direct before used cleaned with ethanol and subjected to UV sterilization for 15 min. All other tools such as pipettes, syringes, and burner and centrifuge tubes were cleaned in the same 8 scheme. All collected samples were stored at $-80^{\circ} \mathrm{C}$ until analyze.

\subsubsection{Recovery and Calculation of BC Yields}

After 7 days of incubation, the reaction medium was treated with excess $2 \mathrm{~N} \mathrm{NaOH}$ at $100^{\circ} \mathrm{C}$ for 5 min to kill the bacterial cells. Then, the medium was centrifuged at $4000 \mathrm{rpm}$ for $15 \mathrm{~min}$. The extracted $\mathrm{BC}$ was repeatedly washed with distilled water and centrifuged four times. The volume of extracted $\mathrm{BC}$ was then raised to $25 \mathrm{~mL}$ by adding distilled water, and the solution homogenized

in a grinder (Kenmore) for $15 \mathrm{sec}$. Subsequently, $1 \mathrm{~mL}$ of the sample was transferred to a previously weighed crucible and placed in an oven at $80^{\circ} \mathrm{C}$ for one day to dry to a permanent weight, the crucible containing dried sample was then returned to room temperature and weighed.

\subsubsection{Lignocellulosic Composition Calculation}

Since the algal biomass used in the study is a mix of micro-algae harvested from ponds, the sugar profile for the algal biomass as a result of pre-treatment and saccharification is essential in 
determining the cellulose and hemicellulose concentrations present in the biomass. In the present study cellulose and hemicellulose contents of algal biomass were quantified.

Four samples of air dried, ground $(75 \mu \mathrm{m})$ algal biomass ( 2 grams each) were boiled with $10 \mathrm{~mL}$ of $72 \% \mathrm{w} / \mathrm{w} \mathrm{H}_{2} \mathrm{SO}_{4}$ solution for 4.5 hours in order to hydrolyse the cellulose and hemicellulose. The suspension remaining after the above treatment was filtered through a crucible and the solid residue dried at $105{ }^{\circ} \mathrm{C}$ for 24 hours and weighed $(W 1)$. The residue was then transferred to a preweighed dry porcelain crucible and heated at $600{ }^{\circ} \mathrm{C}$ for 5 hours. After cooling down, it was weighed (W2) and ash content (\%) was determined. Acid insoluble lignin was then calculated by the difference $(W 1-W 2)$. The filtrate from the $\mathrm{H}_{2} \mathrm{SO}_{4}$ treatment that contained the sugars released from cellulose and hemicellulose was thoroughly stirred and homogenized. Glucose $(C 1)$ and reducing sugar $(C 2)$ concentrations in the filtrate were determined from HPLC data (Ververis, 2007). Following these measurements, the cellulose content in the starting material was calculated using the following equation (Ververis, 2007):

$$
\text { Cellulose content }\left(\% \frac{w}{w}\right)=(0.9 / 0.96) C 1(V / M) \alpha 100
$$

Where 0.9 is the coefficient that results from the molecular weight ratio of the polymer and the monomer hexose. The saccharification yield was taken as $0.96, C 1$ as the glucose concentration $(\mathrm{g} / \mathrm{L}), V$ the total volume of sugar solution $(\mathrm{L}), M$ the dry weight of the algal biomass sample $(\mathrm{g})$ and $\alpha$ the dilution of the sample (if any).

The hemicellulose content was calculated from the following equation (Ververis, 2007): 


$$
\text { Hemicellulose content }\left(\% \frac{w}{w}\right)=(0.88 / 0.93)(C 2-C 1)(V / M) \alpha 100
$$

where 0.88 is the coefficient that results from the molecular weight ratio of the polymer and the monomer pentose, 0.93 is the saccharification yield of xylane to xylose, $C 2$ is the determined from reducing sugars concentration $(\mathrm{g} / \mathrm{L})$ from the HPLC results, $C 1$ the glucose concentration $(\mathrm{g} / \mathrm{L})$ from above, $V$ the total volume of sugar solution (L), $M$ the dry weight of the algal biomass sample (g) and $\alpha$ the dilution of the sample (if any).

\subsection{Aseptic Technique}

\subsubsection{Laminar Flow Biosafety Hood}

A laminar flow biosafety hood is a carefully enclosed bench designed to prevent contamination of semiconductor wafers, biological samples, or any sensitive particle materials. Air is drawn through an HEPA filter and blown in a very smooth, laminar flow towards the user. It contains a have a UV-C germicidal lamp to sterilize the interior and contents when not in use. (It is important to switch this light off during use, to limit exposure to skin and eyes as stray ultraviolet light emissions can cause cancer and cataracts.

Aseptic culture handling was done in a laminar flow biosafety hood (Labgard, class II, type A2, Nuaire). Every time the bench was used, the air flow blower was turned on 5-10 min before starting any work. Then the entire surface was cleaned with $70 \%$ ethanol spray and tissue, and then followed by 10-15 minute UV lamb disinfection. All the used tools such as Petri plates, Para films, 
burner, inoculation loop, spatula, cell spreader, needles, pipettes, and tips were kept under UV for disinfection. Before work, hands were washed thoroughly with anti-bacterial soap and warm water, and then disposable medical gloves were used. All metallic tools used inside the hood (needles, loop, spatula and cell spreader) were flamed until red-heated and cooled before use. While working under aseptic conditions, the protective glass of the hood was left open to the minimum to allow enough working space.

\subsubsection{Streaking}

Inoculation loop was flamed until it is red hot and then allowed to cool. Remove a small amount of bacterial growth (either a loopful from a broth culture or a single colony from a plate) with the sterile inoculating loop. Immediately streak the inoculating loop very gently over a quarter of plate using a back forth motion. The loop was flamed again and allowed to cool. Going back to the edge of area 1, just streaked and extended the streaks to the second quarter. The loop was flamed again and allowed to cool. Going back to the edge of area 2, just streaked and extended the streaks to the third quarter. The loop was flamed again and allowed to cool. Going back to the edge of area 3, just streaked and extended the streaks into the Centre of the fourth quarter. Area of initial inoculation and first streaks yields heavy growth. Area of second streaks yields less dense growth than area 1. Area of third streaks yields weak growth than area 2. Area of fourth streaks from area 3 yields single colonies. 


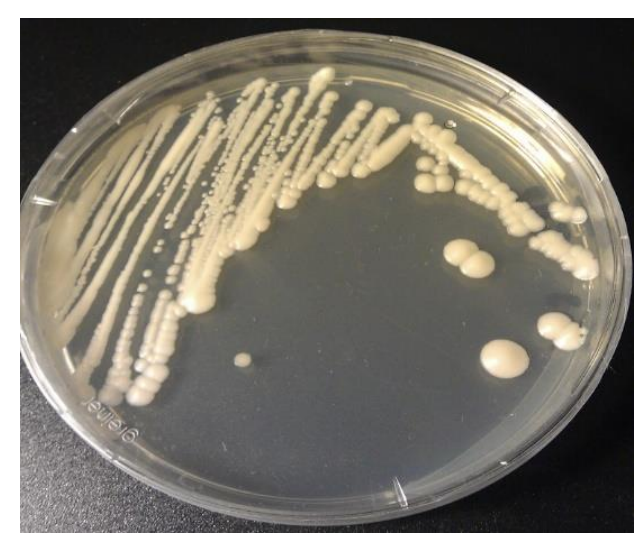

Figure 3.1. Petri dish showing growth of bacteria.

\subsection{Analytical Methods}

\subsubsection{High-Performance Liquid Chromatography (HPLC)}

During the fermentation process, a sample of $2 \mathrm{~mL}$ was periodically taken for analyzing sugar concentrations. Sugar concentrations were analyzed using pre-calibrated High-Performance Liquid Chromatography (HPLC) (Perkin Elmer) (Nabors, 2004). This instrument is equipped with an Ion Exchange column, a pump Series 200 (Perkin Elmer), Auto-sampler Series 200 (Perkin Elmer) and a Refractive Index Detector (HP1047A, Hewlett Packard).

Samples of $100 \mu \mathrm{L}$ were diluted 20 -fold with deionized water and filtered $(0.45 \mu \mathrm{m}$-Gelman Acrodisc CR PTEF, Millipore) (Nabors, 2004). Total of $10 \mu \mathrm{L}$ from each diluted sample was injected into the column and circulated for $30 \mathrm{~min}$ at a flow rate of $0.6 \mathrm{~mL} / \mathrm{min}$ using filtered $(0.2$ $\mu \mathrm{m}$ nylon Millipore) and degassed mobile phase of $5 \mathrm{mM} \mathrm{H}_{2} \mathrm{SO} 4$. Two HPLC columns were used separately, Shodex KC811 for measuring sugars concentration and Shodex SP0810 for measuring inhibitors concentration (Nabors, 2004). The samples were centrifuged at $15000 \mathrm{rpm}$ for $15 \mathrm{~min}$ and double filtered through $0.2 \mu \mathrm{m}$ PTFE- filters (Whatman, USA). The column temperature was maintained at $60^{\circ} \mathrm{C}$ using the column heater $\mathrm{CH}-30$ controlled by an Eppendorf TC 50. Sugar 
concentrations were quantified from calibration curves that were constructed from standard sugar of known concentration.

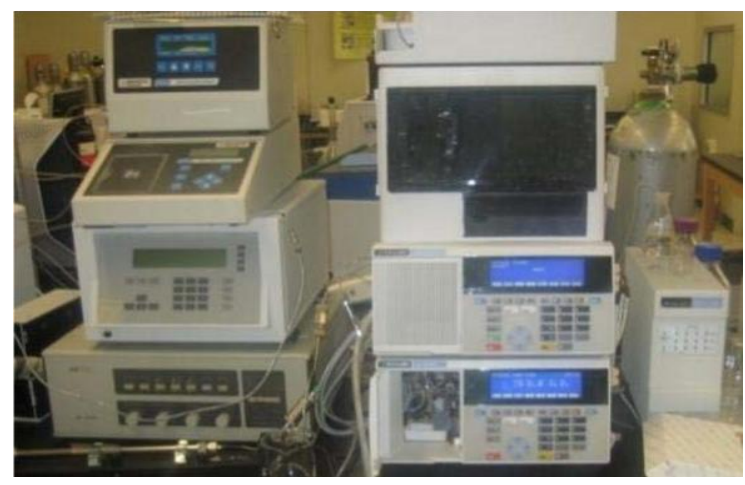

Figure 3.2. HPLC (model \# 600 by Perklin Elmer) equipped with refractive index (Model \# HP1047 A, Hewlett Packard). 


\section{RESULTS AND DISCUSSIONS}

\subsection{Lignocellulosic Composition of Algae and WS}

Agriculture biomass is mainly composed of three bio based chemicals called cellulose (35-48 \%dry wt), hemicellulose (22-48\%) and lignin (15-27\%) (Scurlock et al., 2004; Sun and Cheng, 2005). Together, they are called lignocellulose, a composite material of rigid cellulose fibers embedded in a cross-linked matrix of lignin and hemicellulose that bind the fibers. Lignocellulose material is by necessity resistant to physical, chemical, and biological attack, but it is of interest to bio-refining because the cellulose and hemicellulose can be broken down through a hydrolysis process to produce fermentable products and simple sugars.

Similarly, the algal biomass also contains cellulose, hemicellulose and lignin. The exact composition of the algal strains used in this study is being identified. The values for algae were calculated from sugar values derived from the algal hydrolysis study and calculated according to the method stated in section 3.2.5. The lignocellulosic composition of both WS and algae are given in Table 4.1.

Table 4.1. Lignocellulose composition of WS and Algae.

\begin{tabular}{|l|c|c|l|}
\hline Feed Stock & Cellulose (\%w/w) & Hemicellulose (\%w/w) & Reference \\
\hline \multirow{3}{*}{ Wheat Straw } & 30 & 50 & $($ Cheng, 2002) \\
& 38 & 32.8 & (Talebnia, 2010) \\
\cline { 2 - 4 } & 16.6 & 11.8 & Present study \\
\hline Algae & & & \\
\hline
\end{tabular}


From above table, it is observed that the amount of cellulose and hemicellulose in algae is almost half of that of WS. Thus, algae have less potential to generate sugars which later can be converted to $\mathrm{BC}$ nanofibers, biofuel, polymers and other valuable products. However, an advantage is that algae are easier to break down than WS and requires less energy. Also the absence of an inhibitor is attractive, which is due to lack of furfural releasing lignin in algal biomass (Ververis, 2007). Also, the sugars being extracted from the biomass is in addition to the lipids that can be extracted from them, which are also used as biofuel. Thus, the energy content of algae is quite high.

\subsection{Hydrolysis of Algae}

Figure 4.1 lists the amount of individual sugars (i.e. glucose, xylose, galactose, mannose, and arabinose) whereas Figure 4.2 lists the amount of total sugar concentrations that were produced during the hydrolysis of algae under different conditions detailed in Table 3.1. According to Figure 4.1, glucose production was the highest among all algae samples under different hydrolysis conditions when compared to other individual sugars. Amounts of individual and total sugars produced in $\mathrm{g} / \mathrm{L}$ are presented in Table 4.2. According to results in this table, individual sugars production was in the range of 8 to 12.48 for glucose, 5.6 to 6.72 for xylose, 1.6 to 1.84 for galactose, 3.2 to 4.08 for mannose, and 1.76 to 2.96 for arabinose. Further examination of the

results in Figure 4.1 shows that the highest glucose production of $12.48 \mathrm{~g} / \mathrm{L}$ was achieved by sample S8. This sample was subjected to enzymatic pretreatment using enzymes i.e. Cellulose and $\beta$-glycosidase. Utilization of enzymes is common to achieve maximum biomass hydrolysis (Duarte L. C., 2009). During the enzymatic hydrolysis, the hemicellulose and cellulose components break down to reducing sugars (Dien B. S., 2008). 


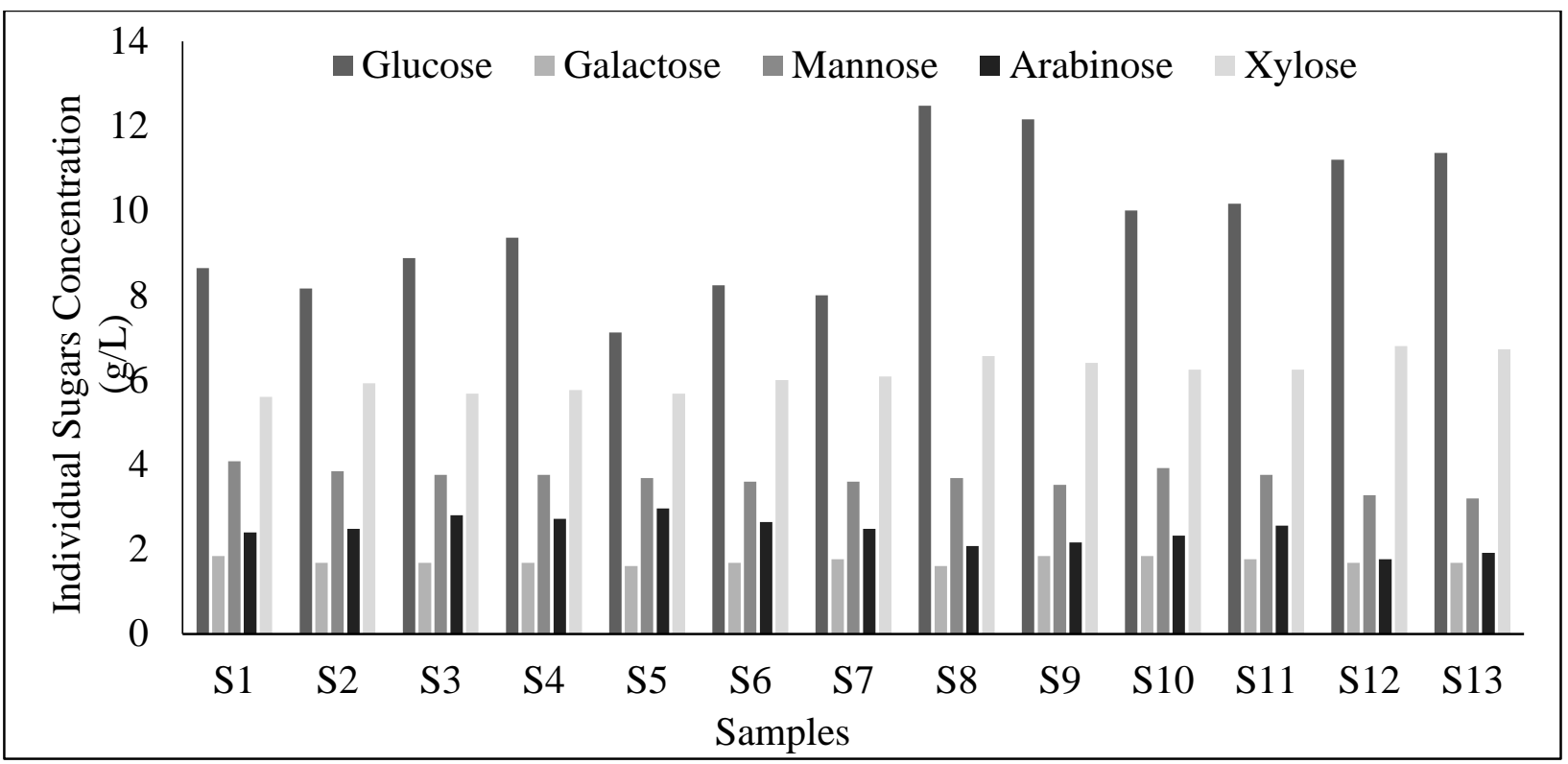

Figure 4.1. Individual sugars concentration produced by different algal hydrolysis samples under different pretreatments.

Actually, the partial hydrolysis of hemicellulose can enable a reduction both on energy requirements and especially on the formation of many relevant sugar degradation compounds, particularly, 5-hydroxymethylfurfural (HMF) and furfural (Duarte L. C., 2009).

Table 4.2 lists the individual and total sugar concentration produced from hydrolysis of 13 different algae samples subjected to different pretreatment methods i.e. chemical pretreatment, thermal pretreatment and enzymatic pretreatment. Table 4.2 depicts that glucose sugar production was increased in the presence of the xylanase enzyme, sample S11 and S13 when compared to S10 and S12 (three enzymes were utilized versus two enzymes, respectively). However, sample S8 has slightly higher amount of glucose and total sugar (12.48 and $26.4 \mathrm{~g} / \mathrm{L}$, respectively) which were produced with utilization of two enzymes than sample S9 (12.16 and $26.08 \mathrm{~g} / \mathrm{L}$, respectively) with three enzymes. Sample S9 produced higher amount of glucose and total sugar, this could be because of competitive inhibition of cellulose (Thirmal and Dahman, 2012). However, in samples 
S11 and S13, xylose production was reduced in the presence of xylanase. It is common that xylanase was used to break down xylan from hemicellulose into xylose.

Table 4.2. Individual and Total Sugars concentration from Algae hydrolysis.

\begin{tabular}{|c|c|c|c|c|c|c|}
\hline Sample & $\begin{array}{c}\text { Glucose } \\
(\mathrm{g} / \mathrm{L})\end{array}$ & $\begin{array}{c}\text { Xylose } \\
(\mathrm{g} / \mathrm{L})\end{array}$ & $\begin{array}{c}\text { Galactose } \\
(\mathrm{g} / \mathrm{L})\end{array}$ & $\begin{array}{c}\text { Mannose } \\
(\mathrm{g} / \mathrm{L})\end{array}$ & $\begin{array}{c}\text { Arabinose } \\
(\mathrm{g} / \mathrm{L})\end{array}$ & $\begin{array}{c}\text { Total } \\
(\mathrm{g} / \mathbf{L})\end{array}$ \\
\hline $\mathbf{S 1}$ & 8.64 & 5.6 & 1.84 & 4.08 & 2.4 & 22.56 \\
\hline S2 & 8.16 & 5.92 & 1.68 & 3.84 & 2.48 & 22.08 \\
\hline S3 & 8.88 & 5.68 & 1.68 & 3.76 & 2.8 & 22.8 \\
\hline S4 & 9.36 & 5.76 & 1.68 & 3.76 & 2.72 & 23.28 \\
\hline S5 & 7.12 & 5.68 & 1.6 & 3.68 & 2.96 & 21.04 \\
\hline S6 & 8.24 & 6 & 1.68 & 3.6 & 2.64 & 22.16 \\
\hline S7 & 8 & 6.08 & 1.76 & 3.6 & 2.48 & 21.92 \\
\hline S8 & 12.48 & 6.56 & 1.6 & 3.68 & 2.08 & 26.4 \\
\hline S9 & 12.16 & 6.4 & 1.84 & 3.52 & 2.16 & 26.08 \\
\hline S10 & 10 & 6.24 & 1.84 & 3.92 & 2.32 & 24.32 \\
\hline S11 & 10.16 & 6.24 & 1.76 & 3.76 & 2.56 & 24.48 \\
\hline S12 & 11.2 & 6.8 & 1.68 & 3.28 & 1.76 & 24.72 \\
\hline S13 & 11.36 & 6.72 & 1.68 & 3.2 & 1.92 & 24.88 \\
\hline
\end{tabular}

Here, results illustrate that xylose was produced without the application of xylanase. Cellulase contributed in increasing production of xylose as demonstrated by sample S8 (Gírio, 2010). This occurred because hemicellulose could be hydrolyzed by cellulase and result in xylose production (Gilbert, 1993). However, glucose concentrations slightly increased in the presence of xylanase, indicating that the xylanase may have interacted with cellulose. This interaction between xylanase and cellulose decreased hydrolysis of hemicellulose into xylose i.e. it can be observed from table 
that in samples S11 and S13, xylose concentration has been decreased in presence of xylanase. According to Figure 4.1, in samples S8, S11 and S13, the concentration of sugars i.e. glucose and arabinose increased in the presence of Xylanase except for sample S8 in which glucose concentration is decreased in presence of xylanase instead of increasing. Whereas, under similar conditions the concentration of xylose and mannose decreases in the presence of Xylanase.

Figure 4.2 lists total sugar concentrations (in $\mathrm{g} / \mathrm{L}$ ) that were produced during the hydrolysis of algae under different conditions in Table 3.1. It was observed from Figure 4.2 that highest total sugar concentration was produced by sample S8 followed by S9 which is 26.40 and $26.08 \mathrm{~g} / \mathrm{L}$, respectively. Moreover, the lowest total sugars produced were by sample S5 which was $21.04 \mathrm{~g} / \mathrm{L}$. Similarly, this is due to the presence of enzymes which achieved nearly complete hydrolysis (Duarte L. C., 2009). During the enzymatic hydrolysis, the hemicellulose and cellulose components break down to reducing sugars (Dien B. S., 2008).

In presence of thermal pretreatment, higher amount of total sugar concentration were produced than the samples that were pretreated in absence of heat. In Figure 4.2, it can be observed that samples S3 and S4 (thermally pretreated) have produced higher amount of total sugars than samples S1, S2, S6 and S7 (in absence of heat). In presence of acidic pretreatment, higher amount of total sugars were obtained when samples were subjected to thermal pretreatment or thermal and enzymatic pretreatment than the samples that were only hydrolyzed by acid. It can be observed that samples that were pretreated with $1 \%$ of acid (i.e. samples S1 and S6) seems more effective than samples which used 2\% acid i.e. samples S2 and S7. This can be attributed to the less rigid structure of algae, which gets partially oxidised on treatment with higher concentrations of sulfuric acid (Nguyen M. T., 2009). 


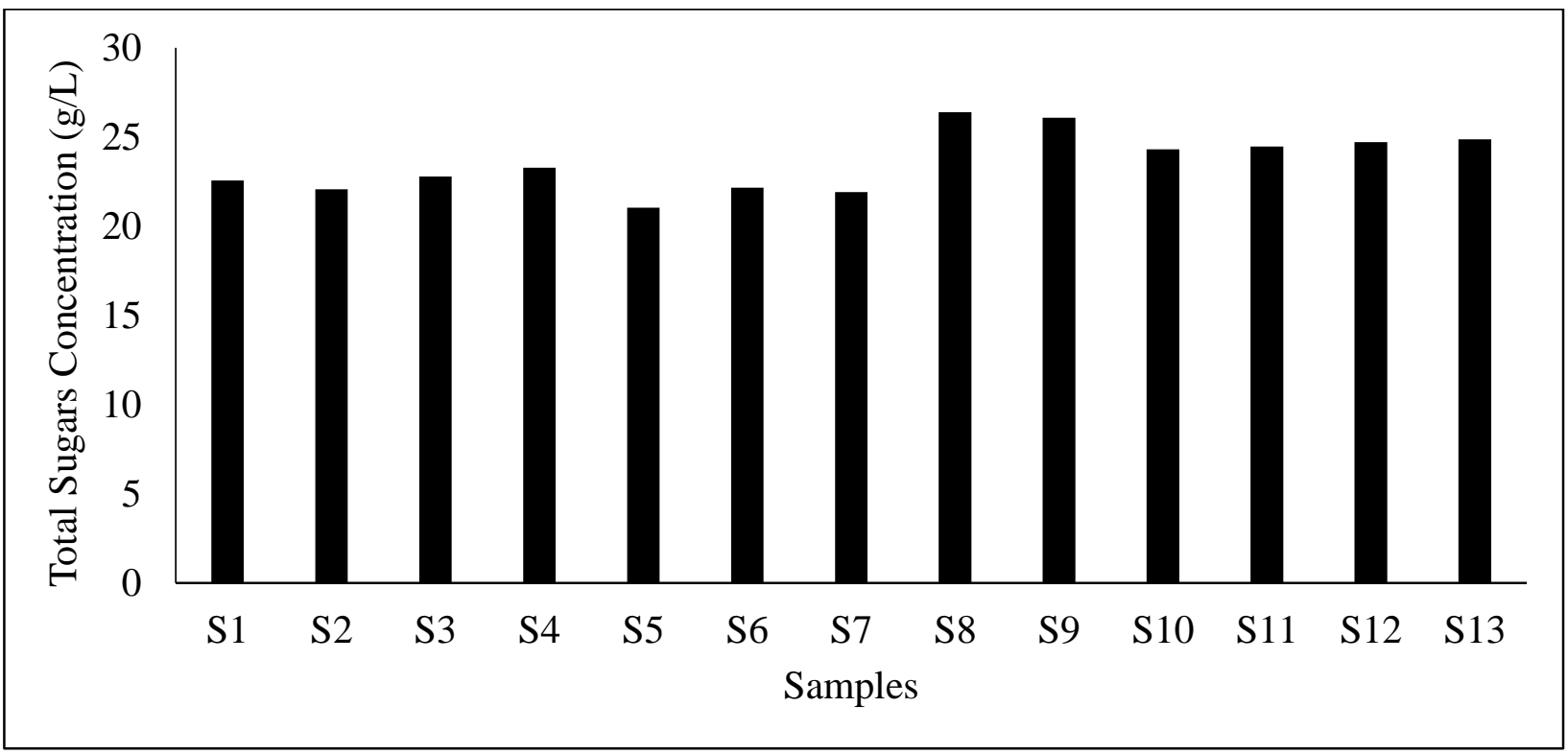

Figure 4.2. Total sugars concentration produced by different algal hydrolysis samples under different pretreatments.

\subsection{Production of BC Nanofibers in SHF}

\subsubsection{BC Production and pH}

Four samples were utilized from Table 3.1 (samples S3, S4, S12 and S13) to produce BC in SHF. These samples demonstrate chemical pretreatment using different percent of sulfuric acid (1\% \& $2 \% \mathrm{v} / \mathrm{v}$ ) and thermal pretreatment at $121^{\circ} \mathrm{C}$ with a heating time of 30 minutes (see Table 3.2).

Figure 4.3 shown below summarizes the final production of $\mathrm{BC}$ nanofibers and the corresponding $\mathrm{pH}$ of culture media at the end of the seven days of fermentation process for all samples in Table 
3.2. According to Figure 4.3, the range of $\mathrm{BC}$ production during the SHF was from 3.12 to 4.86 $\mathrm{g} / \mathrm{L}$ and the range for the final $\mathrm{pH}$ is from 1.5 to 3 .

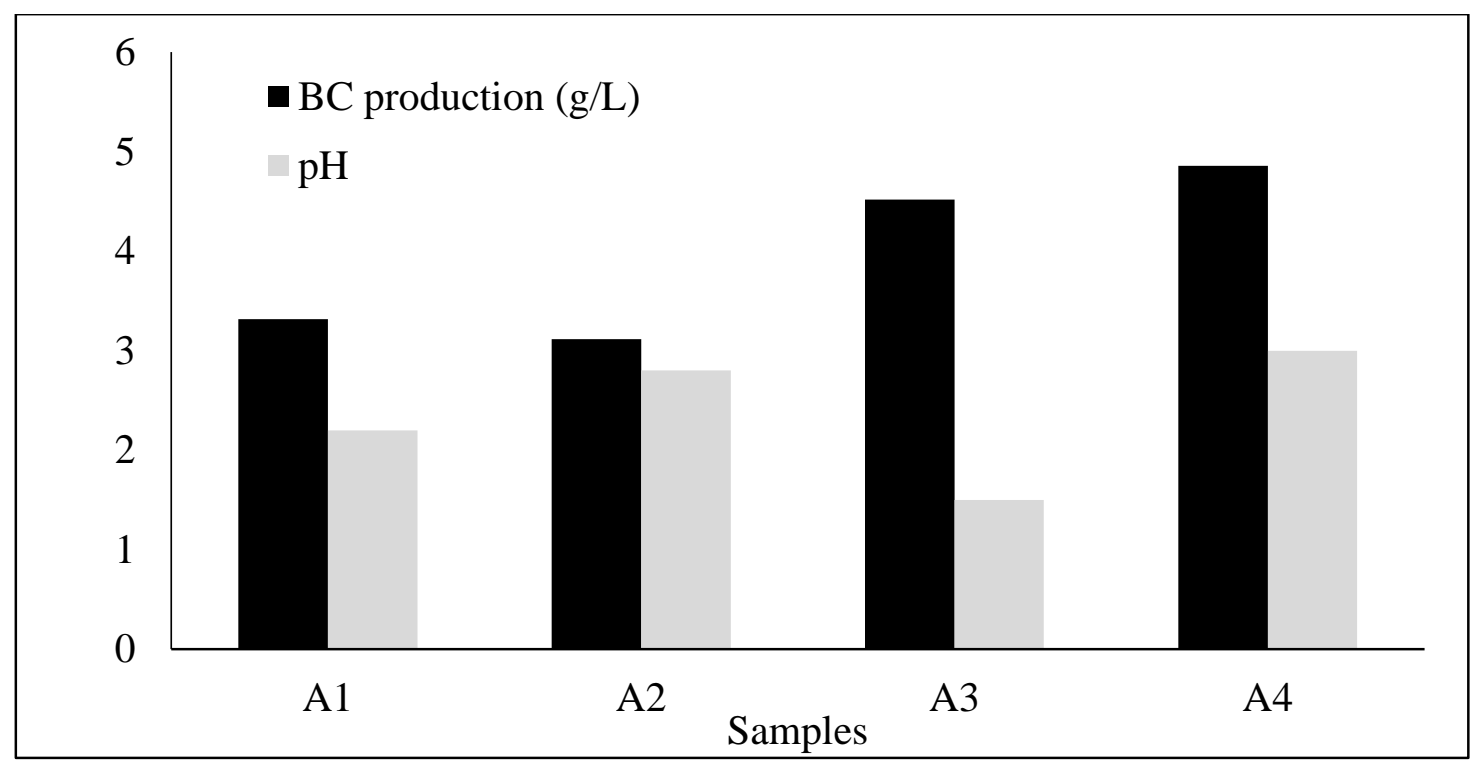

Figure 4.3. Final BC production obtained using the different cultures prepared with conditions in Table 3.2, in addition to the final $\mathrm{pH}$ of the culture media.

Figure 4.3 depicts that the highest BC production was achieved with Sample A4 which was 4.86 $\mathrm{g} / \mathrm{L}$ (the sample was produced with enzymatically hydrolyzed algae, as shown in Table 3.2). However, lowest BC production of $3.12 \mathrm{~g} / \mathrm{L}$ was achieved by A2 (which was hydrolyzed with higher concentration of acid i.e. 2\%). Figure 4.3 further shows that samples that were pretreated with enzymes (i.e. Samples A3 and A4) produced higher amounts of BC than the other samples (i.e. Sample A1 and A2). This is because during enzymatic hydrolysis, the enzymes breaks or degrades the crystalline component of cellulose and hemicellulose which leads to the production of more reducing sugars that can be utilized by desired bacterial strain to produce desired products (Dien B. S., 2008). According to Table 4.3, total sugars produced during hydrolysis of A3 and A4 
were 26.73 and $27.58 \mathrm{~g} / \mathrm{L}$, comparing to 24.29 and $25.01 \mathrm{~g} / \mathrm{L}$ for samples $\mathrm{A} 1$ and A3. The enzymatic pretreatment of Sample A3 (with two enzymes of Cellulase and $\beta$-glucosidase) resulted in slightly lower production (i.e. $4.52 \mathrm{~g} / \mathrm{L}$ ) than Sample A4, which was pre-treated with the three enzymes: Cellulase, $\beta$-glucosidase and Xylanase and produced the highest BC production of 4.8 $\mathrm{g} / \mathrm{L}$. Table 4.3 quantitatively list final production of BC for all samples.

According to results in Table 4.3, Sample A1 (control) and A2 were subjected to different concentrations of acidic pretreatment (1\% v/v and 2\% v/v) and produced BC of $3.32 \mathrm{~g} / \mathrm{L}$ and 3.12 g/L, respectively. Examining Figure 4.3, final fermentation medium had pH range from 1.5 to 3. This final $\mathrm{pH}$ values are generally less than the initial $\mathrm{pH}$ of 5 that was adjusted at the beginning of the fermentation. This can be explained based on the production of gluconic acid and acetic acid as a part of the metabolic pathway of $\mathrm{BC}$ fermentation production using the polysaccharides which lowers the pH of fermentation broths (Velasco-Bedran. H., 2007) (Yang Y. K., 1998). According

to Yang Y. K. (1998) and Velasco-Bedran, H. (2007) G. Xylinus bacterium metabolized part of the polysaccharides to produce gluconic acid or acetic acid that increases the acidity of the fermentation broths and leads to reducing the final pH (Yang Y. K., 1998) (Velasco-Bedran. H., 2007).

\subsubsection{Sugar Concentrations Profiles}

Table 4.3 summarizes the total sugar produced during pretreatment of algae and consumed during fermentation for the production of $\mathrm{BC}$ from different samples. Results for the total and individual sugars produced during the pretreatment of algae demonstrate the amount of sugars available at the beginning of fermentation process for different samples. The results in Table 4.3 depict that the maximum sugar available for fermentation process was produced from Sample A4 (i.e. with the use of three enzymes of Cellulase, $\beta$-glucosidase and Xylanase). Accordingly, higher amounts 
of total sugars were produced by samples A3 and A4 (i.e. enzymatic hydrolysis) as compared to samples A1 and A2 (i.e. non-enzymatic treatment). The concentrations of sugar available from acidic pretreatment of $1 \%$ and $2 \%$ were $24.29 \mathrm{~g} / \mathrm{L}$ and $25.01 \mathrm{~g} / \mathrm{L}$, respectively. It can be observed that more sugars were produced with the high concentration of acid (i.e. $2 \%$ v/v). The yield was obtained in terms of, weigh of BC produced to weight of total sugars consumed. Highest yield was obtained from sample A4 which was 62.51 followed be A3 and then from samples A2 and A1 in which we obtained a yield of $61.35,54.86$ and 51.08 respectively. Table 4.3 shows the average cell concentration and its proliferation rate. Sample A4 has the highest average cell proliferation rate and concentration than sample A3. This is because in sample A3 pH was dropped and inhibited the cell growth.

Table 4.3. Results obtained from the fermentation experiments using Algal hydrolysate as a feedstock to produce BC by G. xylinum.

\begin{tabular}{|c|c|c|c|c|c|c|c|}
\hline \multirow{2}{*}{$\frac{\mathscr{e}}{\bar{E}}$} & \multirow{2}{*}{$\begin{array}{c}\text { BC } \\
\text { Production } \\
(\mathrm{g} / \mathrm{L})\end{array}$} & \multicolumn{2}{|c|}{ Total Sugars (g/L) } & \multirow{2}{*}{$\begin{array}{l}\text { Average cell } \\
\text { concentration } \\
\left(10^{6} \text { cells } / \mathrm{mL}\right)\end{array}$} & \multirow{2}{*}{$\begin{array}{c}\text { Average cell } \\
\text { proliferation } \\
\text { rate } \\
\left(10^{6} \text { cells } / \mathrm{mL} . h\right)\end{array}$} & \multicolumn{2}{|c|}{ Cellulose Yield } \\
\hline & & $\begin{array}{c}\text { Availabl } \\
\text { e }\end{array}$ & $\begin{array}{c}\text { Consume } \\
\text { d }\end{array}$ & & & $\mathbf{Y}_{\mathbf{P} / \mathbf{C}^{\mathbf{a}}}$ & $\mathbf{Y}_{\mathbf{P} / \mathbf{S}^{\mathbf{b}}}$ \\
\hline A1 & 3.32 & 24.29 & 18.29 & 2.09 & 43.25 & 51.08 & 0.18 \\
\hline A2 & 3.12 & 25.01 & 17.34 & 2.47 & 22.15 & 54.86 & 0.179 \\
\hline A3 & 4.52 & 26.73 & 18.06 & 3.90 & 50.24 & 61.35 & 0.25 \\
\hline A4 & 4.86 & 27.58 & 19.25 & 3.84 & 61.25 & 62.51 & 0.254 \\
\hline
\end{tabular}

${ }^{a}$ Weight of BC produced to dry cell weight at the beginning of fermentation.

${ }^{b}$ Weight of BC produced to weight of total sugars consumed. 
Figure 4.4 represents the change of total sugars during the fermentation process for the production of BC. It can be observed from Figure 4.4, that the total sugar consumption in all culture mediums were in the range of 68-76\%. Moreover, maximum sugar was consumed in Sample A1, which was $75.29 \%$ and produced $3.32 \mathrm{~g} / \mathrm{L}$ of BC. Moving further, the samples A3 and A4 consumed 68 69\% of available sugar and produced the highest concentrations of BC. The results in Table 4.3 show that the $\mathrm{pH}$ has negligible effects on the production of sugar during the fermentation process.

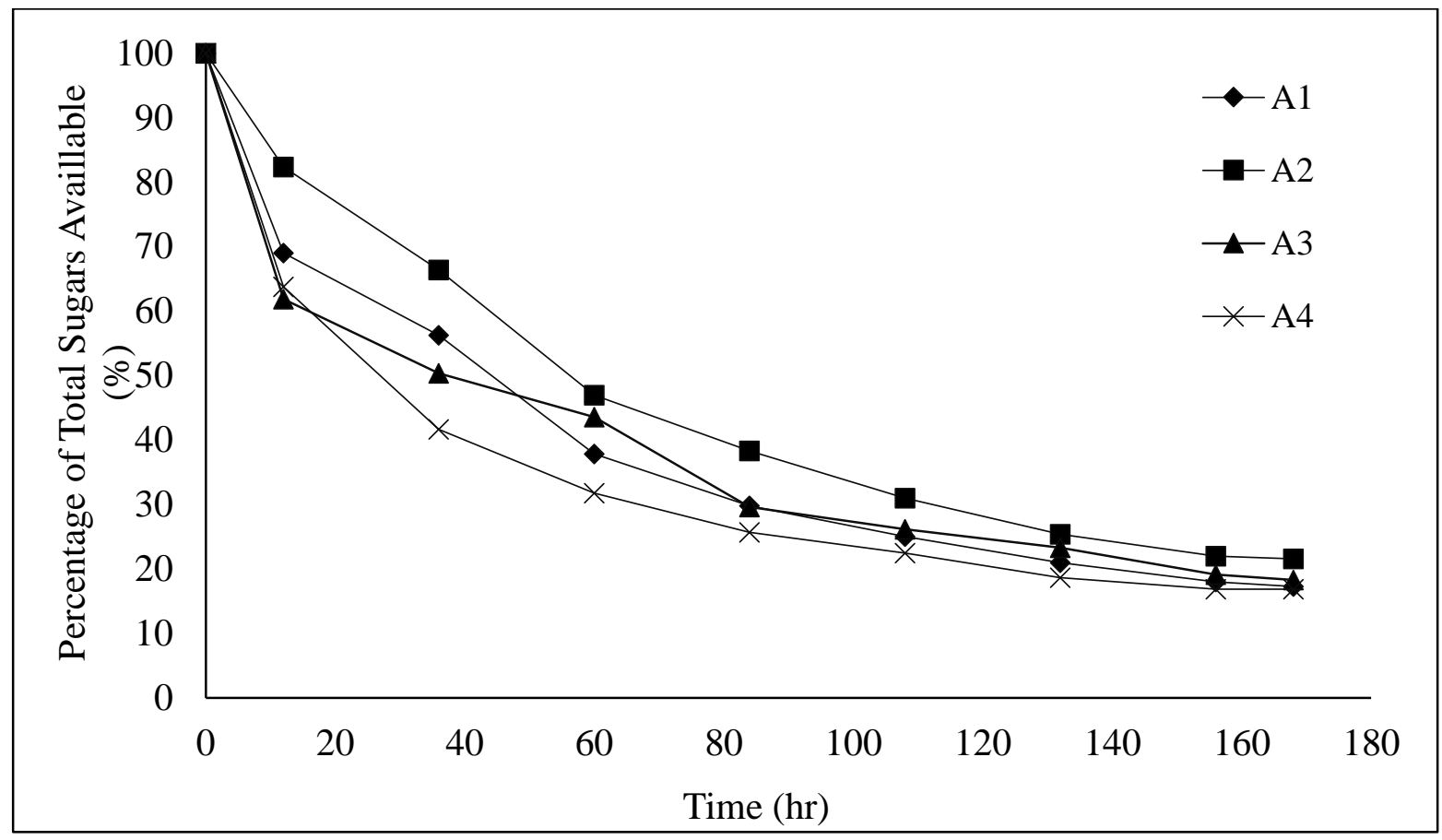

Figure 4.4. Changes in the percentage of total sugars concentration in the fermentation medium during SHF for all samples.

Further examination of Figure 4.4 illustrates that during the fermentation for all culture media, consumptions of sugars were high during the first 65 hours. Then, the consumption rate decreases until 120 hours of fermentation and then reached a minimum consumption rates. The initial 
consumption rates of sugars were high for all samples. In Figure 4.4, it can be seen that almost 79$84 \%$ of sugar was consumed during the fermentation process.

It is also observed that more than $50 \%$ of sugars were consumed in the first 60 hours of fermentation except for samples A3 and A4 in which approximately 50\% of sugar was consumed in the first 30 hours. After 130 hours, the consumption of sugar was almost negligible. Sugar consumption rate was constantly decreased with time. It can be observed that almost $20-23 \%$ of sugar remained unconsumed. The higher amount of sugar was consumed in samples A3 and A4, and this significantly explains why these samples produce higher BC nanofibers production. Hence, can be said consumption of sugar in a sample is proportional to the production of $\mathrm{BC}$ nanofibers.

Table 4.4. Concentration of individual sugars before and after production fermentation of BC through utilizing algae hydrolysate in the feedstock.

\begin{tabular}{|c|c|c|c|c|c|c|c|c|c|c|}
\hline \multirow{2}{*}{$\frac{\tilde{e}}{\bar{\Xi}}$} & \multicolumn{2}{|c|}{ Glucose } & \multicolumn{2}{|c|}{ Galactose } & \multicolumn{2}{|c|}{ Mannose } & \multicolumn{2}{|c|}{ Xylose } & \multicolumn{2}{|c|}{ Arabinose } \\
\hline & 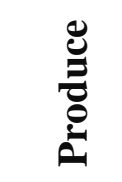 & 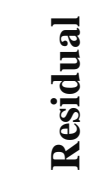 & 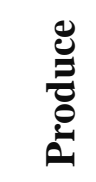 & 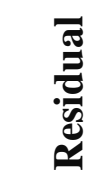 & 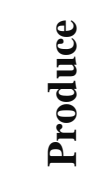 & 窇 & 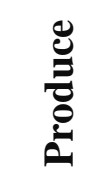 & 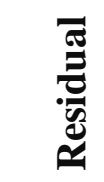 & تِ & 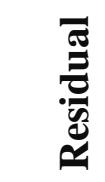 \\
\hline A1 & 9.49 & 1.64 & 1.61 & 0.40 & 5.45 & 0.91 & 5.32 & 1.82 & 2.42 & 1.23 \\
\hline A2 & 10.38 & 2.24 & 1.59 & 0.57 & 4.58 & 1.19 & 5.95 & 2.40 & 2.51 & 1.27 \\
\hline $\mathbf{A 3}$ & 12.03 & 2.20 & 1.80 & 0.62 & 3.32 & 1.41 & 6.98 & 2.71 & 2.60 & 1.35 \\
\hline A4 & 13.23 & 2.23 & 1.78 & 0.64 & 3.36 & 1.60 & 6.60 & 2.73 & 2.61 & 1.51 \\
\hline
\end{tabular}


Table 4.4 shows the individual sugars produced during hydrolysis and residual sugars or unconsumed sugars after the fermentation process. Individual sugars produced during hydrolysis were mainly composed of glucose and xylose that constitutes the maximum percentage of total sugar than the rest of the sugars, which contains only 16-20\% of total sugars (see Table 4.2). The higher percentage of glucose and xylose is because of the higher content of cellulose and hemicellulose in algae. The higher concentration of glucose in samples A3 and A4 is because of enzymes present in the samples breaks the hemicellulose and converts it to cellulose.

According to results in Table 4.4, approximately an average of $17.29 \%$ of glucose was unconsumed at the end of the fermentation process, whereas it was $32-34 \%$ of total content of galactose, mannose, and arabinose remained unconsumed. Moreover, it was average of 38.68\% for xylose sugar that was not consumed. The higher concentration of glucose and xylose concentration in samples A3 and A4 is due to the presence of enzymes Xylanase, Cellulase and $\beta$ glucosidase in the pretreatment of algae. The enzymes helps in complete hydrolysis and they beak the crystalline component of cellulose and hemicellulose present in algae.

\subsubsection{Changes in Bacterium Cell Concentrations}

Bacterial growth and the corresponding cell concentrations are directly associated to the production of $\mathrm{BC}$ and quantity of total sugars consumed during fermentation. As shown in Table 4.3 the sugar consumed was in the range of 17.34 to $19.25 \mathrm{~g} / \mathrm{L}$ and led to BC production in the range 3.12 to $4.86 \mathrm{~g} / \mathrm{L}$. According to Table 4.3, minimum sugar was consumed by sample A2 and maximum by sample A3, which resulted in producing 3.12 and $4.86 \mathrm{~g} / \mathrm{L}$ of BC, respectively. Figure 4.5 shows the change in bacterial cell concentrations during the fermentation process for

all samples in Table 4.3. Examining Figure 4.5 reveals that the different growth phases (Lag phase, 
log-exponential phase, stationary phase, and death phase) can be observed. Figure 4.5 shows that the lag phase was observed between 0 to 40 hours except for sample A4 which has a lag phase of 0-12 hours. After 40 hours, the number of cells increases exponentially for all samples. However, in sample A4, the number of cells increased at earlier time compared to all other samples without a delay phase is reasoned to high sugar concentration in the sample as it was pretreated with enzyme Xylanase that degrades the crystalline component of cellulose and hemicellulose. Around the time at 65 hours, all samples went under stationary phase.

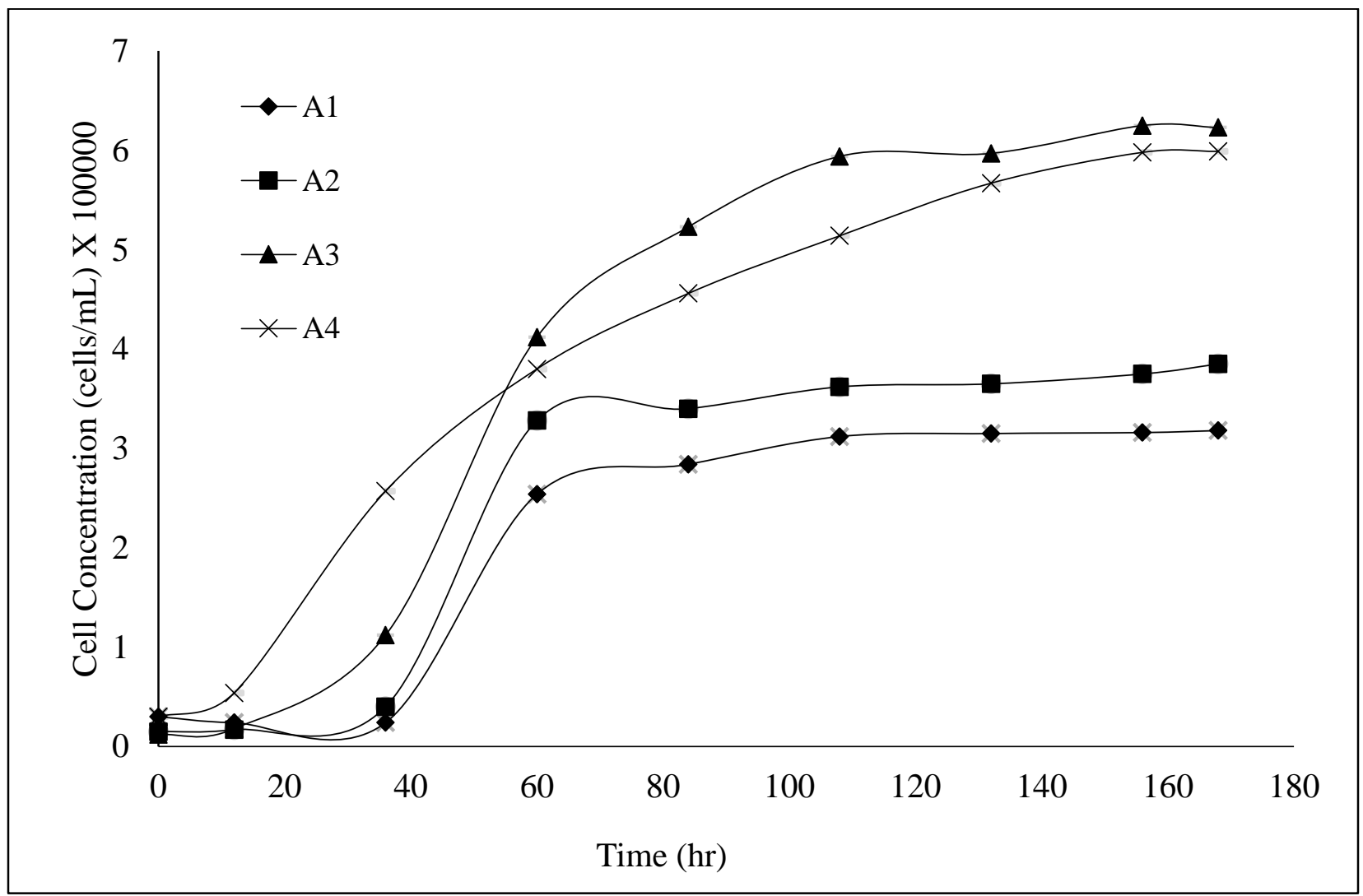

Figure 4.5. Change in G. Xylinum bacterial cell concentrations during the SHF method. 


\subsection{Comparison between Algae and WS}

\subsubsection{Production of Individual and Total sugars from Algae and WS Hydrolysis}

The composition of total sugars at the beginning of fermentation of algae and WS are presented in Table 4.5. The results depict that sugar content in all sample contained a maximum percentage of glucose compared to the rest of individual sugars (i.e. xylose, galactose, mannose, and arabinose). Lignocellulosic composition of WS and algae in Table 4.1 is composed of cellulose and hemicellulose, which are the key source of glucose and xylose during pretreatment (Iguchi M, 2000) (Zabihi S, 2010). Examining Table 4.5, glucose concentration produced by algae was decreased by almost $46 \%$ as compared to WS whereas algae produce $55 \%$ of xylose as compared to that of WS. This is due to the higher lingo-cellulosic composition in WS as compared to algae. Cellulose, the most profuse element present in plant biomass; it can be seen in nature exclusively in the cell walls of plants. As per the study conducted, it was evident that the cellulose present in WS far exceeds the cellulose present in the algae; also, the hemicellulose present in WS exceeds the hemicellulose present in algae (Pearson, 1995). Furthermore, lignin is absent in algae. Thus, it may be inferred that in terms of lingo-cellulosic composition, WS is a better option compared to algae.

A comparison has been made regarding total sugar in Figure 4.6. However, if we talk about rest of reducing sugars like galactose, mannose, and arabinose, they are produced in very less percentage as compared to glucose and xylose. Because cellulose and hemicellulose are the key sources for the production of glucose and xylose as compared to rest of individual sugars. Cellulose, the most profuse element present in plant biomass; it can be seen in nature exclusively 
in the cell walls of plants (Brodo, 2001). Thus, the acid hydrolysis of algal biomass proved that protein and sugar concentrations usually are enhanced with enhanced acid concentration.

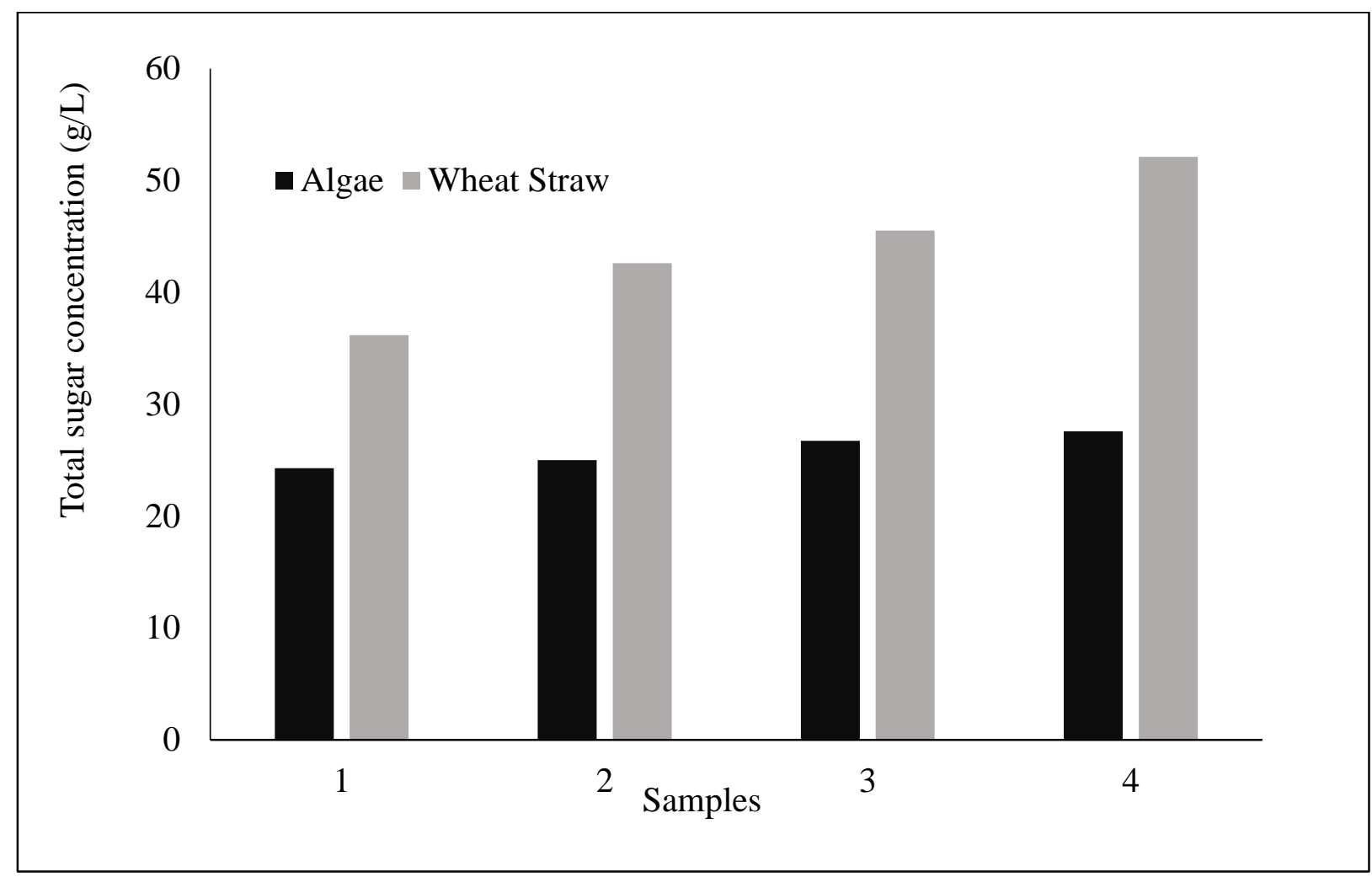

Figure 4.6. Total sugars concentration from algae and WS hydrolysis.

Table 4.5 shows the concentration of individual sugars produced during hydrolysis of WS and algae. These concentrations represent the sugars that were available at the beginning of the fermentation process. Moreover, during the fermentation process, these sugars were utilized by the bacterial strain to produce BC nanofibers. The high concentration of sugar in sample A4 and W4 than rest of samples is due to the presence of enzymes. However, we can see in Table 3.2 that sample A3 and W3 also uses enzymes Cellulase and $\beta$-glycosidase but still has less sugar 
production. This is because, in sample A4 and W4, three enzymes were utilized during the enzymatic hydrolysis (i.e. Cellulase, $\beta$-glycosidase, and Xylanase).

Table 4.5. Concentration of Individual sugars produced during hydrolysis of algae and WS.

\begin{tabular}{|c|c|c|c|c|c|c|c|c|c|c|}
\hline \multirow{2}{*}{ 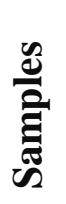 } & \multicolumn{2}{|c|}{ Glucose } & \multicolumn{2}{|c|}{ Galactose } & \multicolumn{2}{|c|}{ Mannose } & \multicolumn{2}{|c|}{ Xylose } & \multicolumn{2}{|c|}{ Arabinose } \\
\hline & $\mathbf{A}^{*}$ & $\mathbf{W}^{* * *}$ & A & $\mathbf{W}$ & A & $\mathbf{W}$ & $\mathbf{A}$ & $\mathbf{W}$ & $\mathbf{A}$ & $\mathbf{W}$ \\
\hline 1 & 9.49 & 19.43 & 1.61 & 2.02 & 5.45 & 1.53 & 5.32 & 9.79 & 2.42 & 3.41 \\
\hline 2 & 10.38 & 22.74 & 1.59 & 2.21 & 4.58 & 2.00 & 5.95 & 11.89 & 2.51 & 3.76 \\
\hline 3 & 12.03 & 28.75 & 1.80 & 2.04 & 3.32 & 1.53 & 6.98 & 9.79 & 2.60 & 3.42 \\
\hline 4 & 13.23 & 27.85 & 1.78 & 2.99 & 3.36 & 2.25 & 6.60 & 15.06 & 2.61 & 3.97 \\
\hline
\end{tabular}

* Hydrolysate from algae.

** Hydrolysate from WS.

It is known that the presence of xylanase allows further hydrolysis of algae and WS, during which it break or degrade the crystalline component of cellulose and hemicellulose. This leads to production of more reducing sugars that can be utilized by bacterial strain during fermentation (Dien B. S., 2008). It can be observed that sample A4 and W4 produces more sugar than the rest of the sample except for xylose in which sample A3 produces more xylose than A4. This is because of interaction of xylanase with which decreased the hydrolysis of xylose to hemicellulose. 


\subsubsection{Production of $\mathrm{BC}$ Nanofibers}

Figure 4.7 shown below summarizes the comparison between the production of $\mathrm{BC}$ nanofibers from algae and WS for the different samples with different hydrolysate solutions (hydrolysis conditions are summarized in Table 3.2). It can be seen that both algae and WS followed a similar trend as sample 4 produces the highest concentration of BC in algae as well as in WS similarly sample 2 produces the lowest in both. All data for WS is according to Wahib et al. (2013) who used a similar method for production of BC nanofibers (Al-Abdallah, 2013).

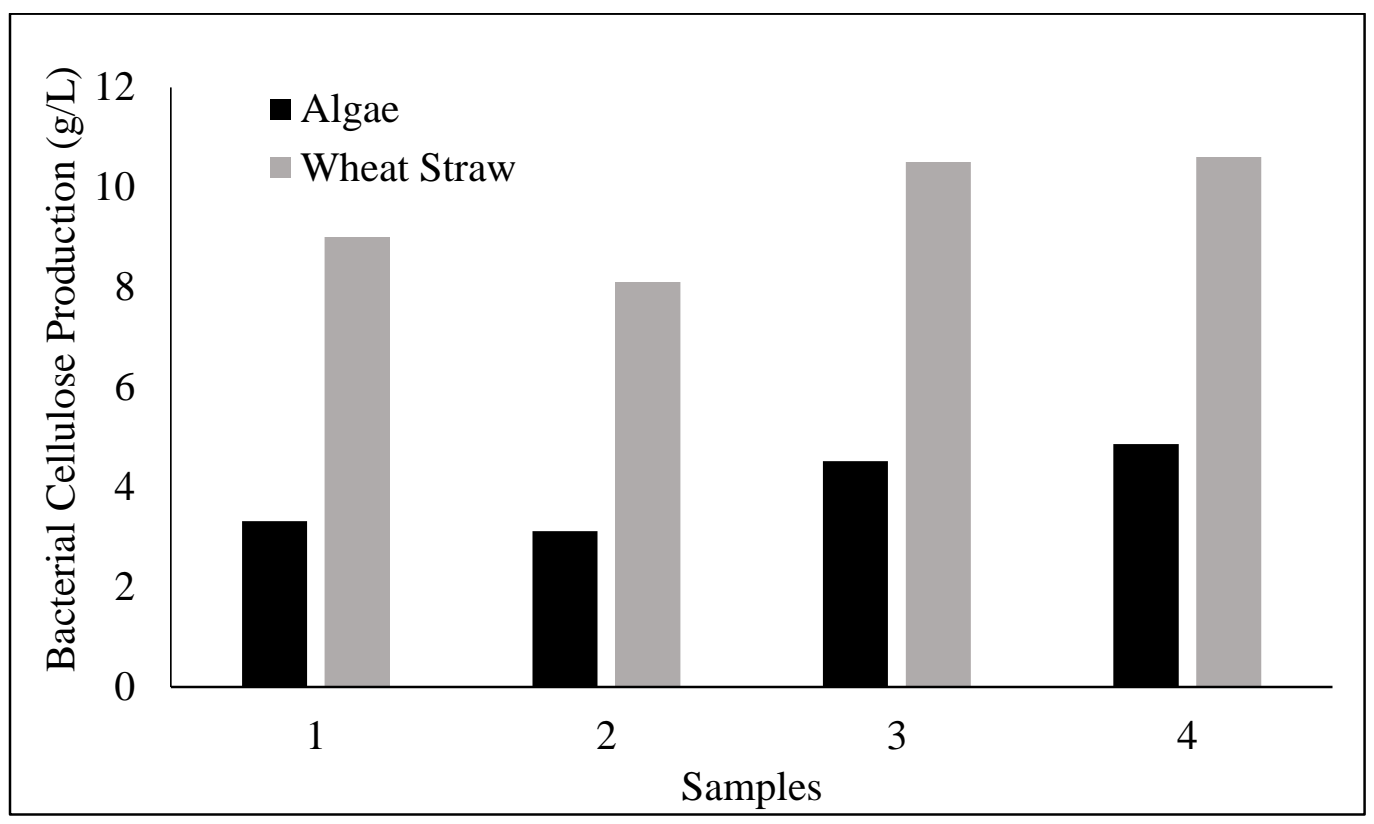

Figure 4.7. Final BC production from algae and WS.

The highest $\mathrm{BC}$ production of $10.6 \mathrm{~g} / \mathrm{L}$ among all samples was reached by sample W4 with WS whereas at similar condition algae only produces $4.86 \mathrm{~g} / \mathrm{L}$, which is almost half of that is produced by WS. According to this Figure, higher BC production was achieved by WS compared to the corresponding algae. This is due to the presence of the high lignocellulosic composition of WS (Talebnia, 2010). It depicts that, the samples ( $3 \& 4)$ with enzymatic treatment in both cases, 
produce more $\mathrm{BC}$ nanofibers as compared to samples 1 and 2. This is because, during enzymatic hydrolysis, the enzymes break and degrade the crystalline component of cellulose and hemicellulose, which leads to the producing more reducing sugars that can be utilized by desired bacterial strain to produce desired products (Dien B. S., 2008). Hence, it can be observed from results obtained that more the sugar concentration, more the production of $\mathrm{BC}$ nanofibers. Figure 4.8 shows the consumption of sugars by bacterial strain G. xylinum during the 7 days fermentation process for both algae (Figure 4.8(a)) and WS (Figure 4.8 (b)).
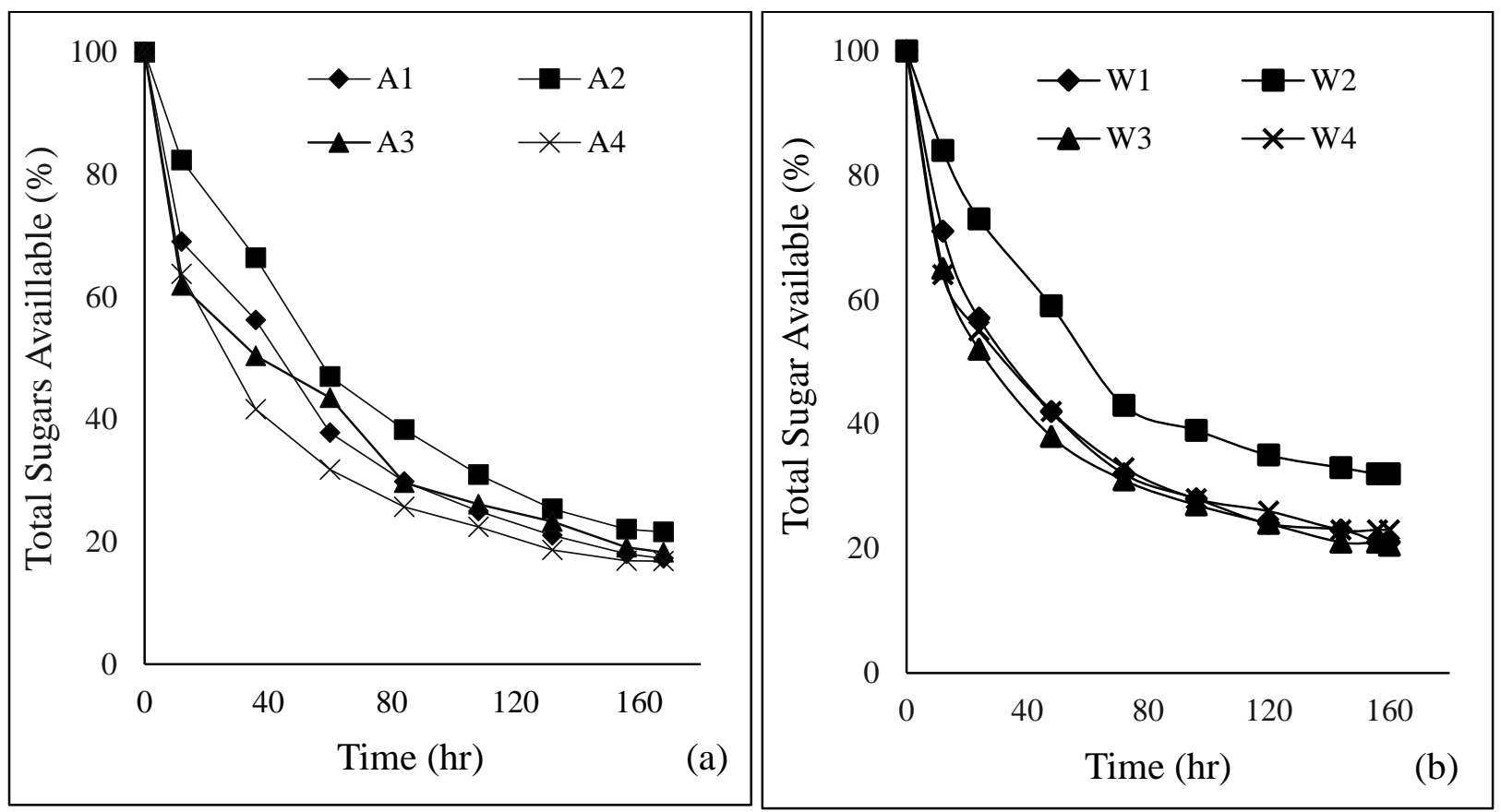

Figure 4.8. Changes in the percentage of total sugars concentrations in the fermentation medium during SHF (a) for algae (b) for WS.

According to this Figure, during the fermentation for algae, the consumption of sugar was highest during the first 80 hours of fermentation. Then, the consumption rate decreases until 120 hours of fermentation and then, reached a minimum consumption rates. In general, initial consumption rates 
of sugars were high for all samples. Moreover, for WS, sugars were consumed at higher rates during the first 60 hours of fermentation, while consumption was decreased after 100 hours of fermentation. Following that, it reached a minimum level.

The sugar produced during hydrolysis (i.e. algae and WS hydrolysis) was mainly composed of glucose and xylose, which constitute the maximum percentage of total sugar than the rest of the sugars that constitute only $20-25 \%$ of total sugars. The higher percentage of glucose and xylose presence is due to the higher content of cellulose and hemicellulose. The higher concentration of glucose in samples A3, W3, A4, and W4, is because of enzymes present in the samples break the hemicellulose and converts it to cellulose. In Figure 4.8, it can be seen that almost 79-84\% of sugar were consumed during the fermentation process of algae whereas for WS it is 76-78\% except for sample W2 that utilized only $68 \%$ of the available sugar.

It is also observed that during fermentation of algae average of $59 \%$ of sugars were consumed in the first 60 hours of fermentation except for samples A3 and A4 in which average of $50 \%$ of sugar was consumed in 30 hours. Whereas, for WS the same amount of sugar was consumed in 50 hours of fermentation. After 130 hours, the consumption of sugar was almost negligible for both algae and WS. Sugar consumption rate was constantly decreased with time. It can be observed that almost 20-23\%of sugar remained unconsumed and remained in all samples. A higher amount of sugar was consumed in samples A3, W3, A4, and W4 and this significantly explains why these samples produce higher $\mathrm{BC}$ nanofibers production. Hence, can be said consumption of sugar in a sample is proportional to the production of BC nanofibers. Figure 4.9 illustrates the Change in $G$. xylinum cell counts during the fermentation process for different samples (a) algae and (b)WS. 


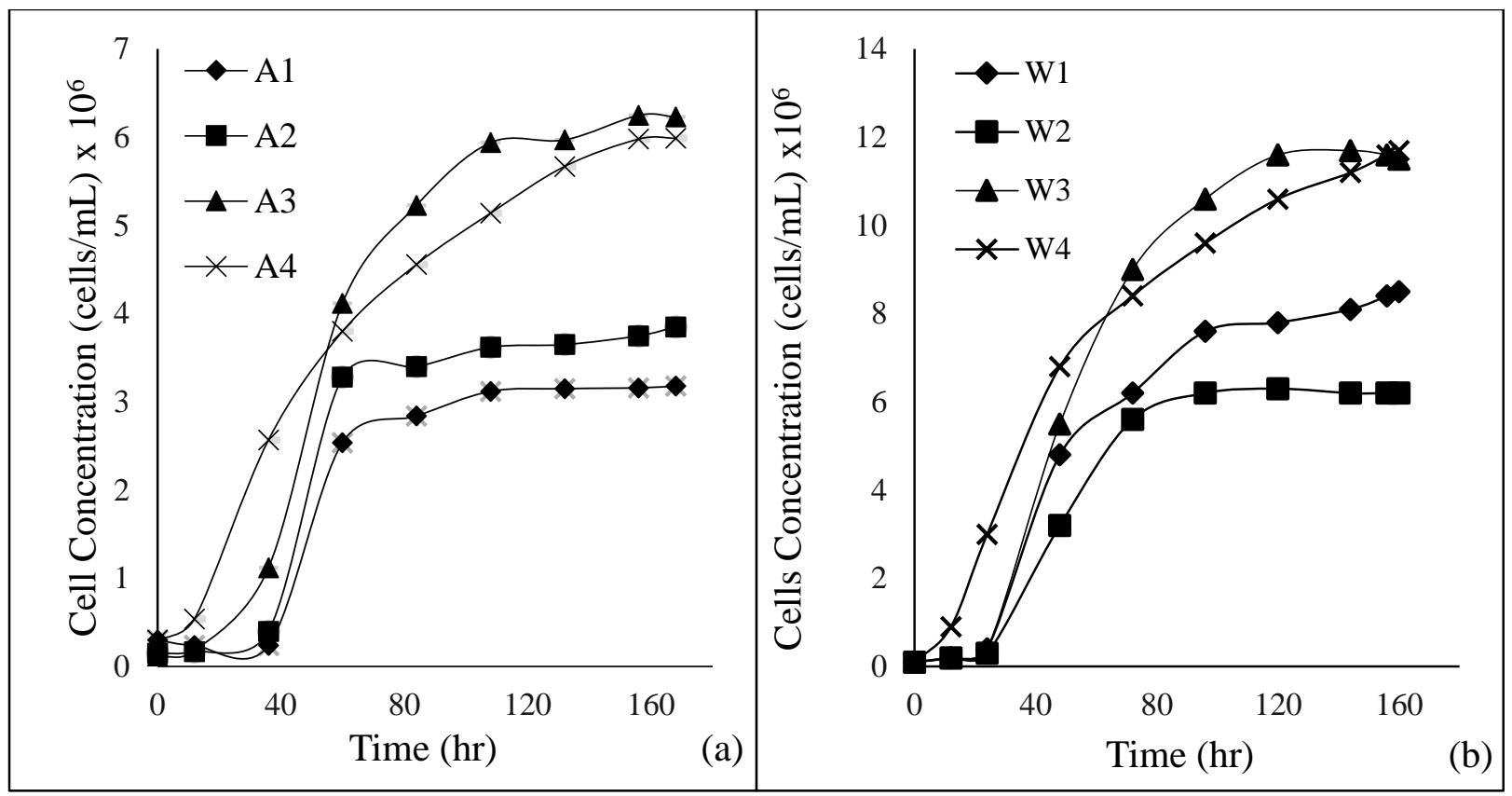

Figure 4.9. Change in $G$. xylinum cell counts during the fermentation process for different samples (a) Algae and (b) WS.

The growth or cell concentration is related to the production of $\mathrm{BC}$ and quantity of consumed reduced sugar. As we know, in bacterial cell growth mechanism there are different phases they undergoes i.e. Lag phase, log-exponential phase, stationary phase, and death phase. Figure 4.9, follows the same trend for algae and WS. However, the concentration of bacteria was decreased as compared to WS. This is due to that the medium produced acid which killed the bacterial concentration present in the medium. Figure 4.9 (a) algae show the lag phase in between 0 to 40 hours except for sample A4 that have lag phase of 0-12 hours. Whereas Figure 4.9 (b) i.e. WS shows the lag phase of 40 hours. In the case of algae, after 40 hours the number of cells increases exponentially. In sample F4, the number of cells increases right from time 0 . Around time at 65 hours all samples went under stationary phase. The sample A4 and W4 have shorter lag phase 
because of high concentration of xylose that is present due to the presence of xylanase enzyme (Kurosumi, 2009)

Moreover, it is marine algae biomass that is drawing attention as a biofuel on account of the fast bio-refineries expansion that has resulted in a shortage on present energy crops planned for the bioethanol and biodiesel sector. Apart from being a potential bioethanol biomass, algae can also be used as a feedstock for several other biofuels chiefly comprising of biodiesel and fuel for aviation apart from other usages, which include bio-crude oils, bio-plastics and recovered livestock co-products. Additionally, algae feedstock with its thin cellulose layer includes a huge carbohydrate composition that allows it to yield over 60 times more alcohol in contrast to soybeans per given acre of land (Linnaeus, 2003).

\subsection{Inhibitors during SHF process}

Two fermentation inhibitors were monitored during WS and algae pretreatment since they have been reported to inhibit BC production in G. Xylinus metabolism, furfural and 5-hydroxymethylfurfural (5 - HMF) (G., 2000). The negligible concentrations of 5-HMF measured are in consistence with previous studies on WS hydrolysis (Duarte L. C., 2009). Furfural is produced by dehydration of hemicelluloses when subjected to intensive heating in the presence of sulfuric acid (Singh A., 1984). This explains the increase of furfural concentration as acid concentration or

boiling temperature and time were increased during WS pretreatment. However, an advantage is that algae are easier to break down than wheat straw thus requiring less energy. Also the absence of an inhibitor is attractive, which is due to lack of furfural releasing lignin in algal biomass (F., Velasco-Bedran H. and Lopez-Isunza, 2007). 


\subsection{BC yield from Algae and WS}

Table 4.6 summarizes the BC nanofibers yield from algae and agricultural residue WS. In this table, yield is calculated by four different ways based on dry cell weight, dry biomass weight, and total sugars consumed during fermentation, in addition to the lignocellulosic content of algae and WS before hydrolysis.

Table 4.6. BC yield from algae and WS

\begin{tabular}{|c|c|c|c|c|c|c|c|c|}
\hline \multirow{2}{*}{ 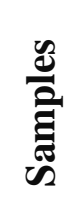 } & \multicolumn{2}{|c|}{ Yield $\left(\mathbf{Y}_{\mathrm{BC} / \mathrm{CW}}\right)^{*}$} & \multicolumn{2}{|c|}{ Yield $\left(\mathbf{Y}_{\mathrm{BC} / \mathrm{WB}}\right)^{* *}$} & \multicolumn{2}{|c|}{ Yield $\left(\mathbf{Y}_{\mathrm{BC} / \mathrm{SC}}\right) * * *$} & \multicolumn{2}{|c|}{ Yield $\left(\mathbf{Y}_{\mathrm{BC} / \mathrm{LC}}\right)^{* * * * *}$} \\
\hline & WS & Algae & WS & Algae & WS & Algae & WS & Algae \\
\hline 1 & 58.86 & 51.08 & 0.1659 & 0.45 & 0.31 & 0.18 & 11.6831 & 12.7119 \\
\hline 2 & 64.22 & 54.86 & 0.1559 & 0.405 & 0.28 & 0.179 & 10.9789 & 11.4407 \\
\hline 3 & 57.73 & 61.35 & 0.226 & 0.525 & 0.29 & 0.25 & 15.9155 & 14.8305 \\
\hline 4 & 67.17 & 62.25 & 0.243 & 0.53 & 0.27 & 0.254 & 17.1127 & 14.9718 \\
\hline
\end{tabular}

* Weight of BC produced to dry cell weight at the beginning of fermentation.

** Weight of BC produced to weight of dry biomass.

*** Weight of BC produced to weight of total sugars consumed.

**** Weight of BC produced to gram of lignocellulosic content at the beginning.

Highest yield was obtained based on dry cell weight and subsequent the lignocellulosic composition. Yield is determined based on $2 \mathrm{~g}$ of algae per $25 \mathrm{ml}$ of solution compared to $20 \mathrm{~g}$ of WS per $250 \mathrm{ml}$ of solution. Examining Table 4.6 shows that highest yield was achieved based on dry cell weight was in the range of 51.08 to 62.25 for algae and 58.86 to 67.17 for WS. Moreover, lowest yield that was calculated based on total sugars consumed was in the range of 0.405 to 0.53 
for algae and 0.27 to 0.31 for WS. The yield was approximately two folds for WS when comparing results obtained for samples 1 and 2 . This demonstrates that total sugars contents from algae hydrolysis is half of that for the WS hydrolysis. Moreover, similar yields were obtained when calculating that based on the lignocellulosic content of the non-processed biomass (i.e., algae and WS). According to Table 4.1 above, total lignocelluloses content is 0.47 per 1 gram of algae. 


\section{ERROR ANALYSIS}

In the present study, few experiments conducted were repeated to examine reproducibility of results through calculating the Percent Relative Standard Deviation (\%RSD). Tables E1, E2, and E3 show raw data for individual and total sugars' concentrations in addition to BC production. These table present calculated values for mean, standard deviation and Percent Relative Standard Deviation $(\%$ RSD. For calculation of standard deviation and \%RSD, following equations were used

For Standard Deviation,

$$
\text { Standard Deviation }=\sqrt{\frac{\sum(x-\bar{x})^{2}}{(n-1)}}
$$

Where,

$$
\begin{gathered}
x=\text { data point }, \\
\bar{x}=\text { sample mean value } \\
n=\text { sample size }
\end{gathered}
$$

For Percent Relative Standard Deviation,

$$
R S D(\%)=\frac{\text { Standard Deviation }}{\bar{x}} \times 100
$$

According to Tables E1, E2, and E3, range of \%RSD was 4.9 to $5.6 \%$, with an average of $5.238 \%$ for the production of BC nanofibers. Moreover, the range of \% RSD was 5.4 to 6.7, with an average of 5.086 for total sugars concentrations that were produced during the hydrolysis. 
Table E1. Error analysis for production of BC nanofibers.

\begin{tabular}{|c|c|c|c|c|c|c|c|c|c|}
\hline \multirow{2}{*}{ 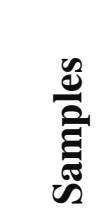 } & \multicolumn{3}{|c|}{ Trial 1} & \multicolumn{3}{|c|}{ Trial 2} & \multirow{2}{*}{$\begin{array}{r}\text { Mean } \\
(\mathrm{g} / \mathrm{L})\end{array}$} & \multirow{2}{*}{ STDEV } & \multirow{2}{*}{$\%$ RSD } \\
\hline & $\mathbf{W}^{\mathrm{e}}$ & $W^{f}$ & $\mathbf{W}^{\mathrm{g}}$ & $\mathbf{W}^{\mathrm{e}}$ & $\mathrm{W}^{\mathrm{f}}$ & $\mathbf{W}^{\mathrm{g}}$ & & & \\
\hline A3 & 8.0879 & 8.3139 & 4.52 & 8.0842 & 8.3287 & 4.89 & 4.705 & 0.2616 & 5.561 \\
\hline A4 & 8.2956 & 8.5386 & 4.86 & 8.3545 & 8.615 & 5.21 & 5.035 & 02475 & 4.915 \\
\hline
\end{tabular}

${ }^{\mathrm{e}}$ Weight of empty weighing plate

${ }^{f}$ Weight of plate with $B C$

${ }^{g}$ Weight of $B C$ in $g / L$

Table E2. Concentration of individual sugars before fermentation of BC.

\begin{tabular}{|c|c|c|c|c|c|c|c|c|c|c|}
\hline \multirow{2}{*}{$\frac{\mathscr{U}}{\tilde{n}}$} & \multicolumn{2}{|c|}{ Glucose } & \multicolumn{2}{|c|}{ Galactose } & \multicolumn{2}{|c|}{ Mannose } & \multicolumn{2}{|c|}{ Xylose } & \multicolumn{2}{|c|}{ Arabinose } \\
\hline & $\overline{\bar{J}}$ & $\frac{N}{\stackrel{N}{\underline{E}}}$ & & 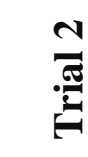 & 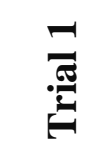 & $\frac{N}{E}$ & $\overline{\bar{E}}$ & $\frac{N}{\stackrel{N}{\mathscr{J}}}$ & $\overline{\bar{E}}$ & 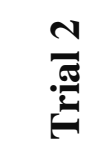 \\
\hline A3 & 12.03 & 11.45 & 1.80 & 1.64 & 3.32 & 3.41 & 6.98 & 6.05 & 2.60 & 2.13 \\
\hline A4 & 13.23 & 14.49 & 1.78 & 1.96 & 3.36 & 3.21 & 6.60 & 7.32 & 2.61 & 2.83 \\
\hline
\end{tabular}


Table E3. Error analysis for concentration of total sugars available before fermentation of BC.

\begin{tabular}{|c|c|c|c|c|c|}
\hline \multirow{2}{*}{ 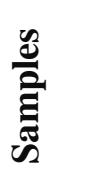 } & \multicolumn{2}{|c|}{ Total sugar } & \multirow{2}{*}{ Mean } & \multirow{2}{*}{ STDEV } & \multirow{2}{*}{$\%$ RSD } \\
\hline & Trial 1 & Trial 2 & & & \\
\hline A3 & 26.73 & 24.32 & 25.525 & 1.7041 & 6.6763 \\
\hline A4 & 27.58 & 29.81 & 28.695 & 1.5768 & 5.4952 \\
\hline
\end{tabular}




\section{CONCLUSION AND RECOMMENDATIONS}

\subsection{Conclusions}

In the present study, the exact composition of algae strain used in research is being identified using sugar values derived from algal hydrolysis study. From composition analyses results, it is observed that lignocellulosic content per gram of algae to per gram of WS is $\sim 50 \%$ per algae wt. Different samples were studied based on different pretreatment condition for hydrolysis of algae. During hydrolysis different individual sugars (i.e., glucose, xylose, mannose, arabinose, and galactose) and total sugars were abnalyzed. From results, it is observed that glucose production was the highest in all samples and similar results were seen from WS. Further examination of results shows that highest glucose production of $12.48 \mathrm{~g} / \mathrm{L}$ from sample $\mathrm{S} 8$ which utilized enzymes. In presence of thermal pretreatment, higher amount of total sugar concentration were produced than the samples which were pretreated in absence of heat. From results, it can be observed that samples S3 and S4 (thermally pretreated) have produced higher amount of total sugars (i.e., $22.8 \mathrm{~g} / \mathrm{L}$ and 23.28 g/L respectively) than samples S1, S2, S6 and S7 (in absence of heat) (i.e. $22.56 \mathrm{~g} / \mathrm{L}, 22.08$ $\mathrm{g} / \mathrm{L}, 22.16 \mathrm{~g} / \mathrm{L}$, and $21.92 \mathrm{~g} / \mathrm{L}$ respectively).

Since algae is composed of lignocellulosic materials and produces sugar. Therefore, algae is used as a carbon source in the fermentation process for the production of $\mathrm{BC}$ nanofibers. The results revealed that the most efficient sample for the production of $\mathrm{BC}$ is using $1 \%$ dilute sulphuric acid at $121^{\circ} \mathrm{C}$ for 30 minutes (using enzymes), which produced $4.86 \mathrm{~g} / \mathrm{L}$ of BC. Results shows that bacteria (G. xylinum) utilized sugar for production of nanofibers and samples which were hydrolyzed using enzymes produced the highest amount of BC nanofibers. 


\section{Recommendations}

As we know, for the production of $\mathrm{BC}$ nanofibers $\mathrm{pH}$ is the controlling factor hence reactors can be used for the fermentation process to enhance the production. Moreover, in my research I used SHF method, so in future BC can be produced using the simultaneous saccharification fermentation (SSF) method and can find a way how to separate algae from BC nanofibers. In future, one can work on SSF method and can see how it effect the production of BC nanofibers and results can be compared with SHF. This research in future may open doors for various researches in coming generation. 


\section{APPENDICES}

\section{Appendix A: Chemicals Used}

Table A1. List of chemicals used and their chemical formulas.

\begin{tabular}{|c|c|c|c|}
\hline \multicolumn{2}{|r|}{ Name } & Chemical Formula & Catalogue Number \\
\hline $\mathrm{i}$ & Agar & $\mathrm{C}_{14} \mathrm{H}_{24} \mathrm{O}$ & 5038 \\
\hline ii & Ammonium Sulfate & $\left(\mathrm{NH}_{4}\right)_{2} \mathrm{SO}_{4}$ & A4418 \\
\hline iii & L (+) Arabinose & $\mathrm{C}_{5} \mathrm{H}_{10} \mathrm{O}_{5}$ & A3256 \\
\hline iv & D-biotin & $\mathrm{C}_{10} \mathrm{H}_{16} \mathrm{~N}_{2} \mathrm{O}_{3} \mathrm{~S}$ & 47868 \\
\hline $\mathrm{v}$ & Calcium Carbonate & $\mathrm{CaCO}_{3}$ & $\mathrm{C} 4830$ \\
\hline vi & Calcium Chloride Dihydrate & $\mathrm{CaCl}_{2} .2 \mathrm{H}_{2} \mathrm{O}$ & C3306 \\
\hline vii & Copper Sulfate Pentahydrate & $\mathrm{CuSO}_{4} .5 \mathrm{H}_{2} \mathrm{O}$ & $\mathrm{C} 8027$ \\
\hline viii & Ferrous Sulfate Heptahydrate & $\mathrm{FeSO}_{4} .7 \mathrm{H}_{2} \mathrm{O}$ & 215422 \\
\hline ix & Folic Acid & $\mathrm{C}_{19} \mathrm{H}_{19} \mathrm{~N}_{7} \mathrm{O}_{6}$ & F7876 \\
\hline $\mathrm{X}$ & Fructose & $\mathrm{C}_{6} \mathrm{H}_{12} \mathrm{O}_{6}$ & F0127 \\
\hline $\mathrm{xi}$ & D-(+)-Galactose & $\mathrm{C}_{6} \mathrm{H}_{12} \mathrm{O}_{6}$ & G0750 \\
\hline xii & Glucose & $\mathrm{C}_{6} \mathrm{H}_{12} \mathrm{O}_{6}$ & G8270 \\
\hline xiii & Hydoxymethylfurfural (5-HMF) & $\mathrm{C}_{6} \mathrm{H}_{6} \mathrm{O}_{3}$ & 53407 \\
\hline
\end{tabular}




\begin{tabular}{|c|c|c|c|}
\hline xiv. & Inositol & $\mathrm{C}_{6} \mathrm{H}_{12} \mathrm{O}_{6}$ & I5125 \\
\hline xv. & Magnesium sulfate heptahydrate & $\mathrm{MgSO}_{4} .7 \mathrm{H}_{2} \mathrm{O}$ & 230391 \\
\hline xvi. & Manganese Sulfate Pentahydrate & $\mathrm{MnSO}_{4} .5 \mathrm{H}_{2} \mathrm{O}$ & 229784 \\
\hline xvii. & Monopotassium Phosphate & $\mathrm{KH}_{2} \mathrm{PO}_{4}$ & P0662 \\
\hline kviii. & Nicotinic Acid & $\mathrm{C}_{6} \mathrm{H}_{5} \mathrm{NO}_{2}$ & N4126 \\
\hline xix. & D-Pantothenic Acid & $\mathrm{C}_{9} \mathrm{H}_{17} \mathrm{NO}_{5}$ & $\mathrm{P} 2250$ \\
\hline $\mathrm{xx}$. & Pyridoxine Hydrochloride & $\mathrm{C}_{8} \mathrm{H}_{12} \mathrm{CINO}_{3}$ & P6280 \\
\hline xxi. & Riboflavin & $\mathrm{C}_{17} \mathrm{H}_{20} \mathrm{~N}_{4} \mathrm{O}_{6}$ & R9504 \\
\hline xxii. & $\begin{array}{l}\text { Sodium Molybdenum Oxide } \\
\text { Dihydrate }\end{array}$ & $\mathrm{NaMoO}_{4} \cdot 2 \mathrm{H}_{2} \mathrm{O}$ & AA1221436 \\
\hline xxiii. & Zinc sulfate heptahydrate & $\mathrm{ZnSO}_{4} .7 \mathrm{H}_{2} \mathrm{O}$ & Z0251 \\
\hline xxiv. & Thiamine Hydrochloride & $\mathrm{C}_{12} \mathrm{H}_{18} \mathrm{CI}_{2} \mathrm{~N}_{4} \mathrm{OS}$ & $\mathrm{T} 4625$ \\
\hline $\mathrm{xxv}$ & D-(+)-Xylose & $\mathrm{C}_{6} \mathrm{H}_{12} \mathrm{O}_{6}$ & X3877 \\
\hline xxvi. & Corn Steep Liquor & - & - \\
\hline
\end{tabular}


Appendix B: HPLC Analysis Results

Table B1. Sample A1, area of absorbance.

\begin{tabular}{|c|c|c|c|c|c|}
\hline \multirow{2}{*}{ Time (hr.) } & \multicolumn{5}{|c|}{ Area of Absorbance } \\
\cline { 2 - 6 } & Glucose & Xylose & Arabinose & Mannose & Galactose \\
\hline 0 & 2340000 & 1616000 & 808000 & 1109000 & 275000 \\
\hline 12 & 1606000 & 1066000 & 557000 & 772000 & 203500 \\
\hline 36 & 1314000 & 884000 & 442000 & 636000 & 175000 \\
\hline 60 & 867000 & 681000 & 432000 & 432000 & 158000 \\
\hline 108 & 562000 & 515000 & 424000 & 292000 & 132000 \\
\hline 132 & 467000 & 484000 & 418000 & 246000 & 123200 \\
\hline 156 & 396000 & 459000 & 413500 & 208000 & 115300 \\
\hline 168 & 379000 & 449000 & 409000 & 202000 & 102000 \\
\hline
\end{tabular}


Table B2. Sample A2, area of absorbance.

\begin{tabular}{|c|c|c|c|c|c|}
\hline \multirow{2}{*}{ Time (hr.) } & \multicolumn{5}{|c|}{ Area of Absorbance } \\
\cline { 2 - 6 } & Glucose & Xylose & Arabinose & Mannose & Galactose \\
\hline 0 & 2564000 & 1826000 & 844000 & 936000 & 272000 \\
\hline 12 & 2107000 & 1507000 & 697000 & 774000 & 231500 \\
\hline 36 & 1691000 & 1159000 & 592000 & 627000 & 196000 \\
\hline 60 & 1188000 & 1007000 & 546000 & 451000 & 151000 \\
\hline 84 & 964000 & 884000 & 517000 & 371000 & 132000 \\
\hline 108 & 774000 & 821000 & 477600 & 303000 & 129000 \\
\hline 132 & 627000 & 774000 & 436000 & 263000 & 127500 \\
\hline 156 & 541000 & 681000 & 433000 & 260000 & 127000 \\
\hline 168 & 529000 & 643000 & 424000 & 258000 & 125000 \\
\hline
\end{tabular}


Table B3. Sample A3, area of absorbance.

\begin{tabular}{|c|r|r|r|r|l|}
\hline \multirow{2}{*}{ Time (hr.) } & \multicolumn{5}{|c|}{ Area of Absorbance } \\
\cline { 2 - 6 } & \multicolumn{1}{|c|}{ Glucose } & \multicolumn{1}{c|}{ Xylose } & \multicolumn{1}{c|}{ Arabinose } & Mannose & Galactose \\
\hline 0 & 2977000 & 2043000 & 431000 & 684000 & 302000 \\
\hline 12 & 2011000 & 1336000 & 152000 & 522000 & 223000 \\
\hline 36 & 1483000 & 948000 & 128000 & 468000 & 185000 \\
\hline 60 & 1279000 & 885000 & 105000 & 411000 & 169500 \\
\hline 108 & 761000 & 847000 & 79000 & 367000 & 155200 \\
\hline 132 & 671000 & 781000 & 39000 & 335000 & 142200 \\
\hline 156 & 544000 & 762000 & 25500 & 308000 & 138000 \\
\hline 168 & 519000 & 746000 & 14500 & 303000 & 133000 \\
\hline
\end{tabular}


Table B4. Sample A4, area of absorbance.

\begin{tabular}{|c|c|c|c|c|c|}
\hline \multirow{2}{*}{ Time (hr.) } & \multicolumn{5}{|c|}{ Area of Absorbance } \\
\cline { 2 - 6 } & Glucose & Xylose & Arabinose & Mannose & Galactose \\
\hline 0 & 3277000 & 2172000 & 434000 & 740125.32 & 299000 \\
\hline 12 & 2077000 & 1327000 & 236000 & 503214.56 & 207000 \\
\hline 36 & 1346000 & 994000 & 149000 & 416325.23 & 173000 \\
\hline 60 & 1020000 & 914000 & 136000 & 394258.65 & 167000 \\
\hline 108 & 819000 & 879000 & 115000 & 376589.56 & 162000 \\
\hline 132 & 585000 & 791000 & 85000 & 348751.25 & 144500 \\
\hline 156 & 528000 & 764000 & 72000 & 343514.24 & 138000 \\
\hline 168 & 527000 & 753000 & 67000 & 338456.72 & 136000 \\
\hline
\end{tabular}


Table B5. Retention times for standard solutions used in HPLC.

\begin{tabular}{|c|c|}
\hline Standard solution & Retention time (min) \\
\hline Glucose & 12.92 \\
\hline Xylose & 14.02 \\
\hline Mannose & 9.38 \\
\hline Arabinose & 21.61 \\
\hline Galactose & 15.73 \\
\hline Furfural & 28.72 \\
\hline
\end{tabular}




\section{Appendix C. HPLC Standard Calibration Curves.}

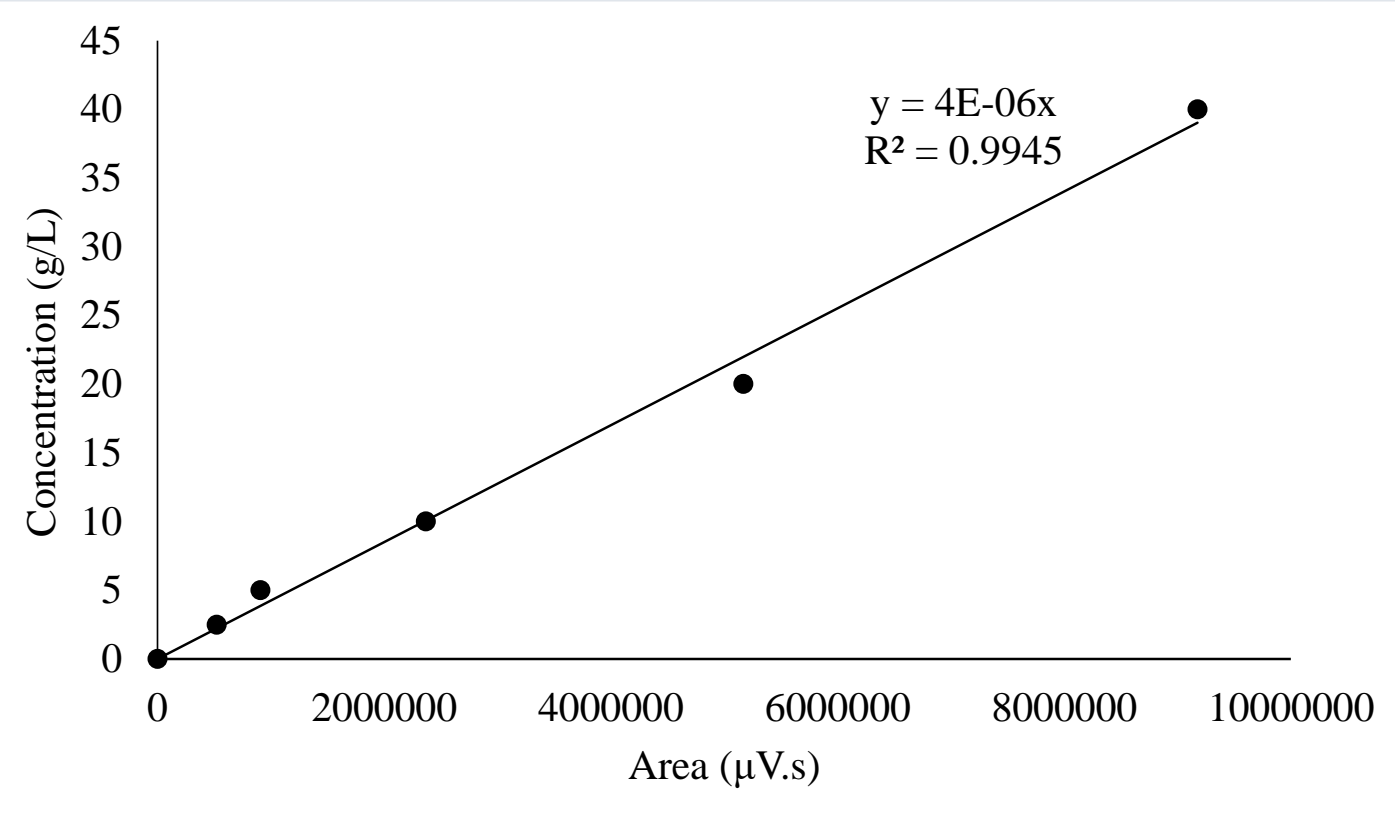

Figure C1. HPLC calibration curve for glucose

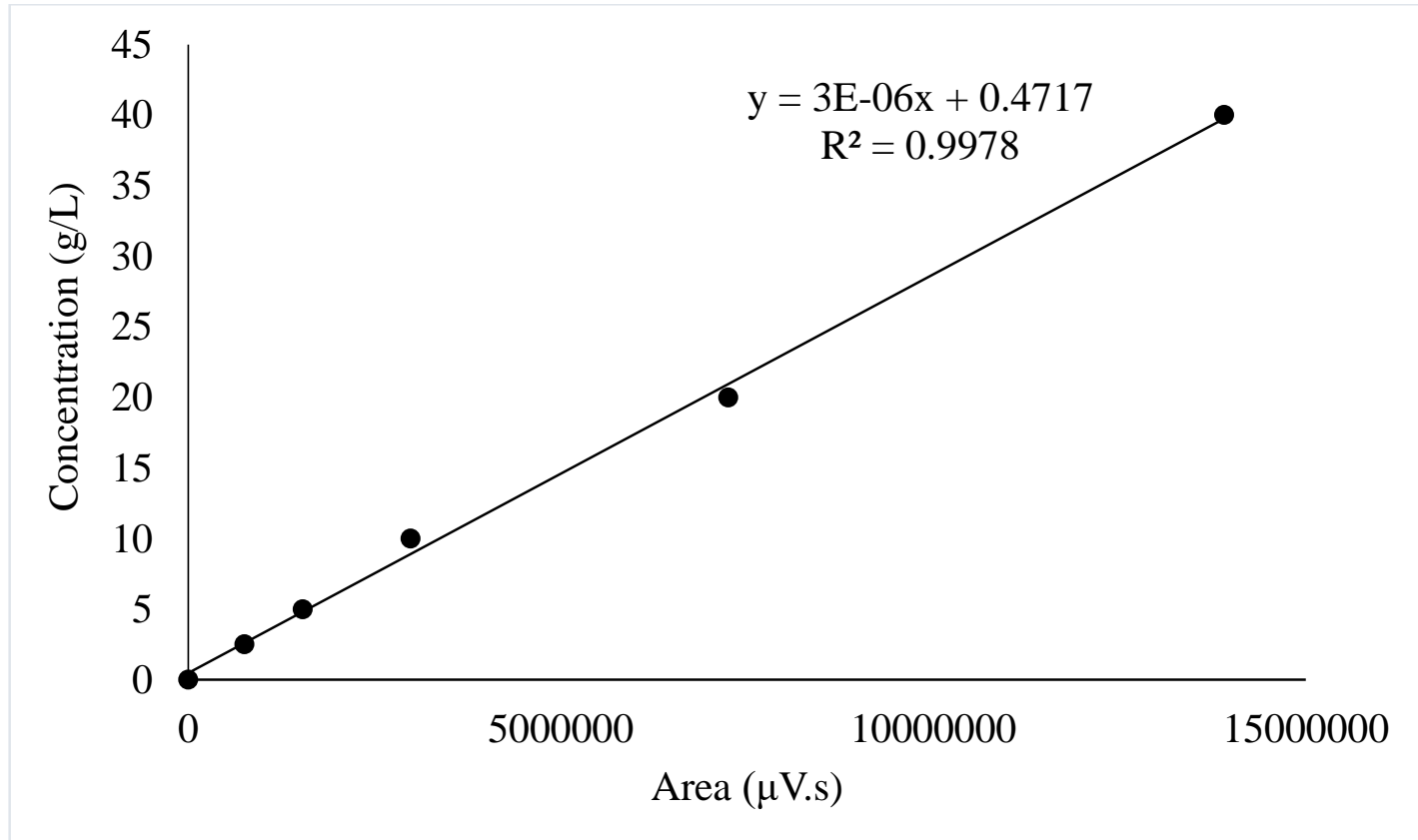

Figure C2. HPLC calibration curve for xylose 


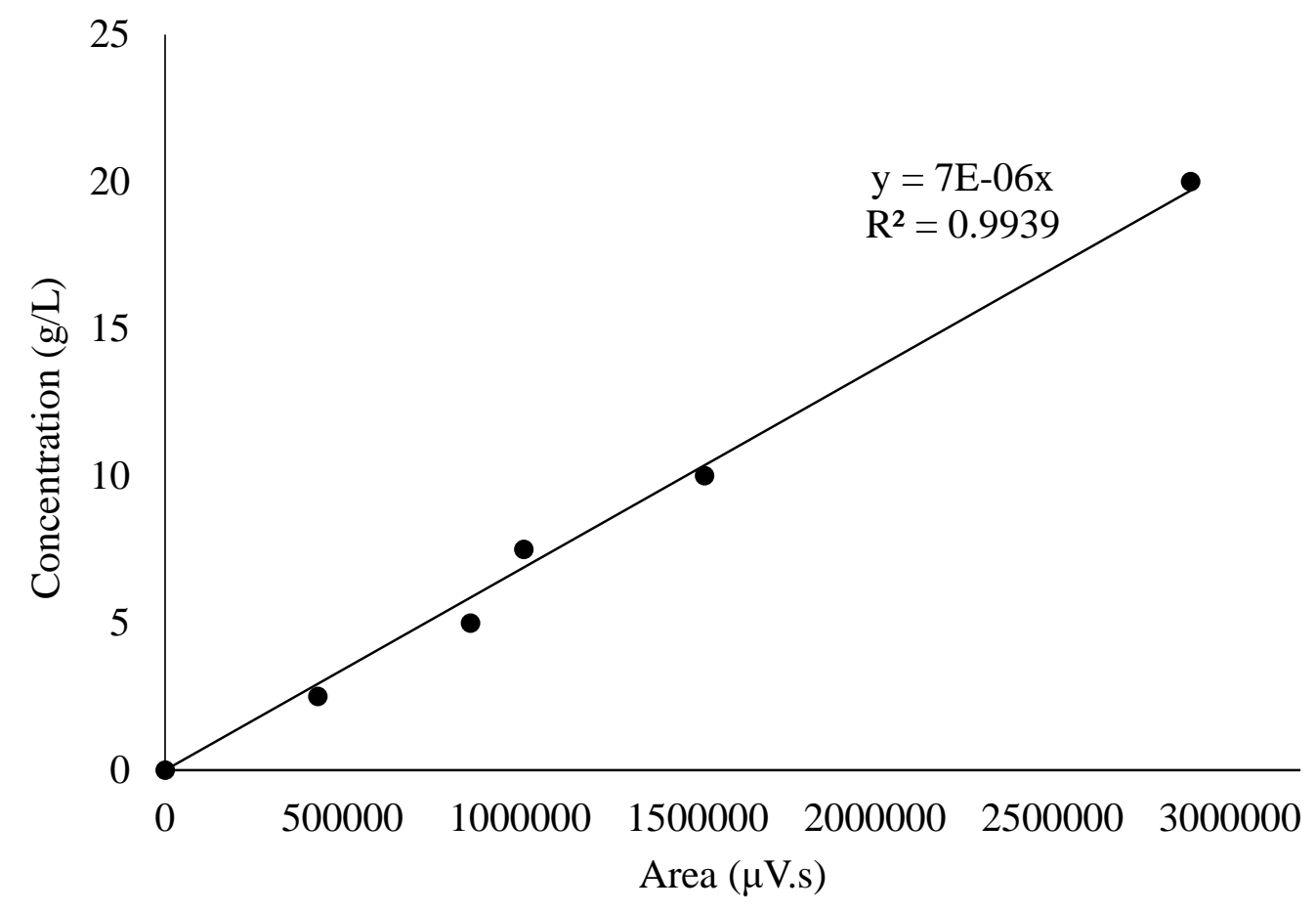

Figure C3. HPLC calibration curve for galactose

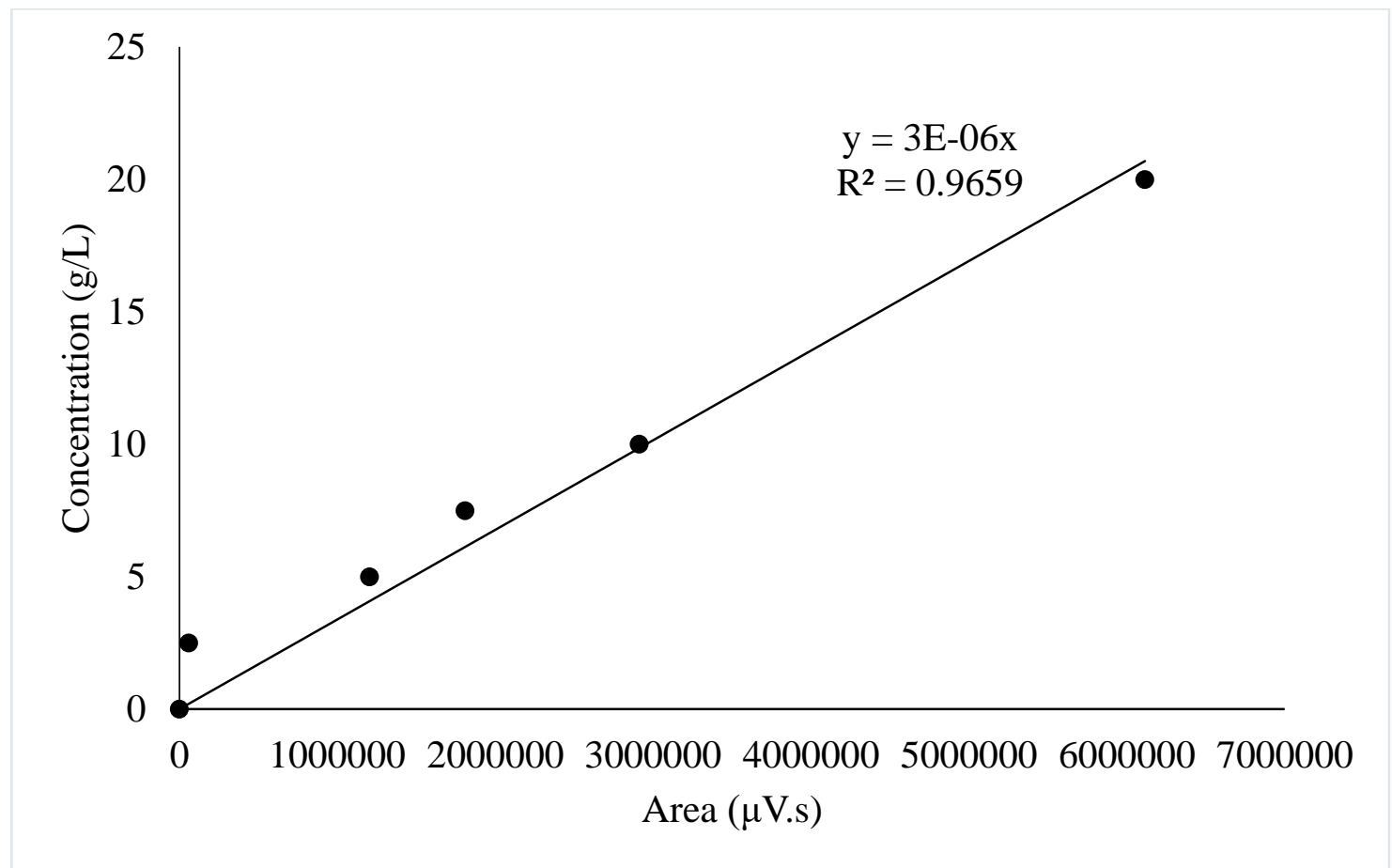

Figure C4. HPLC calibration curve for arabinose 


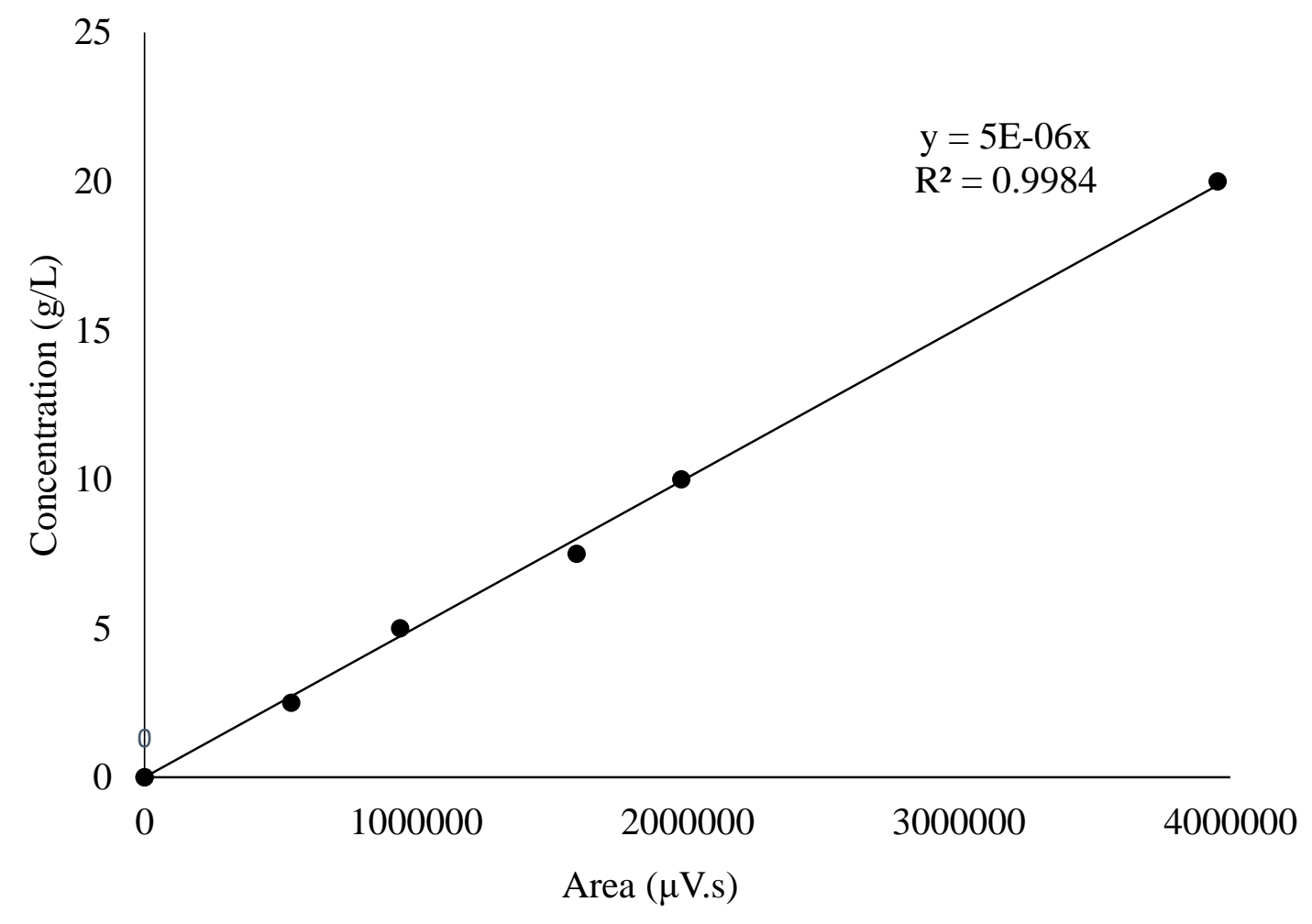

Figure C5. HPLC calibration curve for mannose

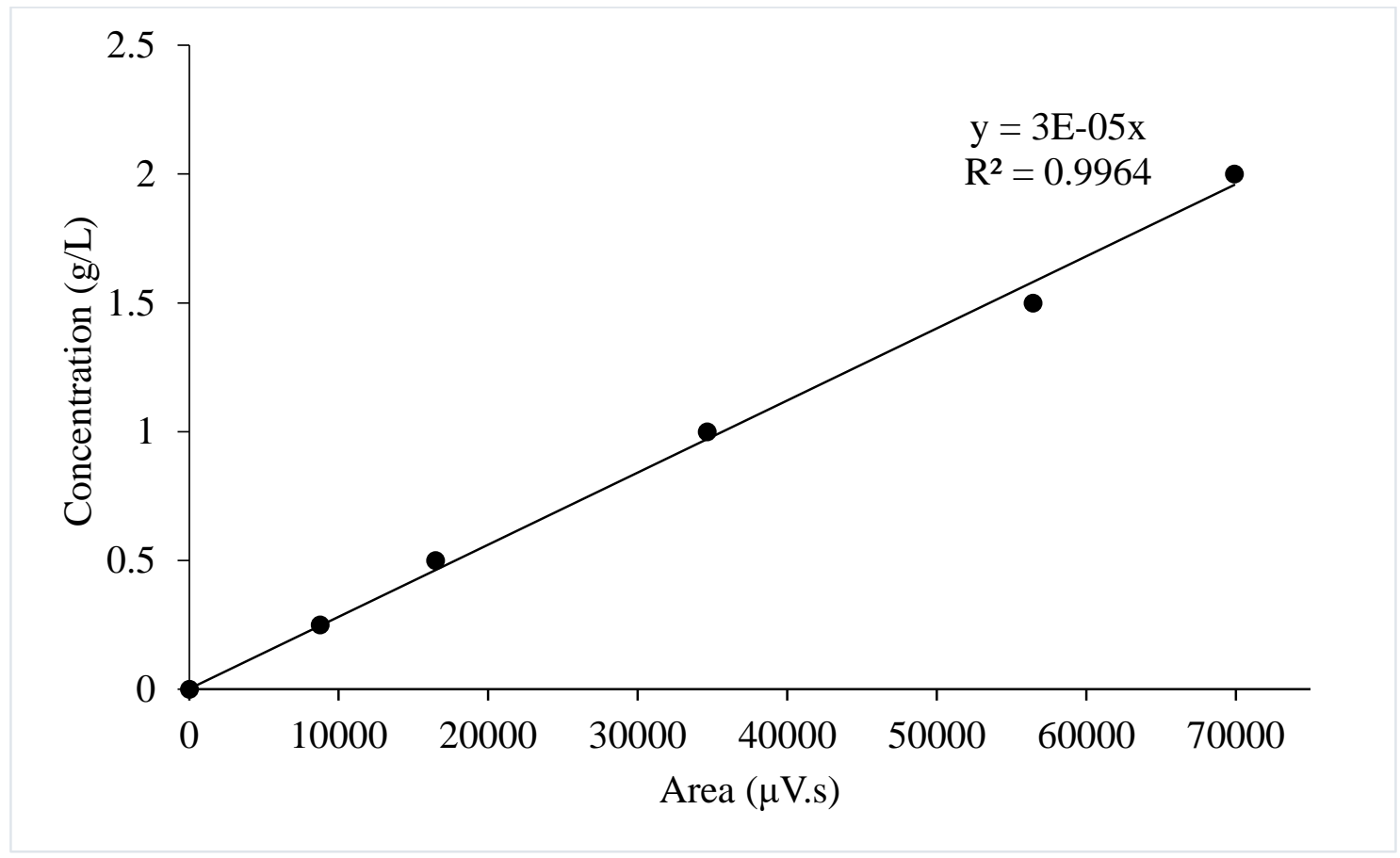

Figure C6. HPLC calibration curve for furfural 
Appendix D. Graphs and Tables related to SHF and hydrolysis.

Table D1. Production of BC nanofibers

\begin{tabular}{|c|c|c|c|c|}
\hline Samples & $\begin{array}{c}\text { Weight of } \\
\text { Empty plate }\end{array}$ & $\begin{array}{c}\text { Weight of } \\
\text { Empty plate }+ \\
\text { BC }\end{array}$ & $\begin{array}{c}\text { Weight of BC } \\
(\mathbf{g} / \mathbf{5 0 m L})\end{array}$ & BC (g/L) \\
\hline $\mathbf{A 1}$ & 8.9731 & 9.139 & 0.1659 & 3.318 \\
\hline $\mathbf{A 2}$ & 8.0842 & 8.2401 & 0.1559 & 3.118 \\
\hline $\mathbf{A 3}$ & 8.0879 & 8.3139 & 0.226 & 4.52 \\
\hline $\mathbf{A 4}$ & 8.2956 & 8.5386 & 0.243 & 4.86 \\
\hline
\end{tabular}

Table D2. Percentage of sugar available during seven days of fermentation.

\begin{tabular}{|c|c|c|c|c|c|c|c|c|c|}
\hline $\begin{array}{c}\text { Time } \\
\text { Samples }\end{array}$ & $\mathbf{0}$ & $\mathbf{1 2}$ & $\mathbf{3 6}$ & $\mathbf{6 0}$ & $\mathbf{8 4}$ & $\mathbf{1 0 8}$ & $\mathbf{1 3 2}$ & $\mathbf{1 5 6}$ & $\mathbf{1 6 8}$ \\
\hline $\mathbf{A 1}$ & 100 & 69 & 56.23 & 37.8292 & 29.821 & 25.016 & 21.011 & 18.008 & 17.281 \\
\hline $\mathbf{A 2}$ & 100 & 82.349 & 66.377 & 46.969 & 38.323 & 30.982 & 25.375 & 22.019 & 21.5799 \\
\hline $\mathbf{A 3}$ & 100 & 61.8786 & 50.374 & 43.541 & 29.642 & 26.1429 & 23.316 & 19.118 & 18.287 \\
\hline $\mathbf{A 4}$ & 100 & 63.7417 & 41.647 & 31.783 & 25.684 & 22.4489 & 18.647 & 16.893 & 16.8556 \\
\hline
\end{tabular}


Graphs and Tables used during Hydrolysis.

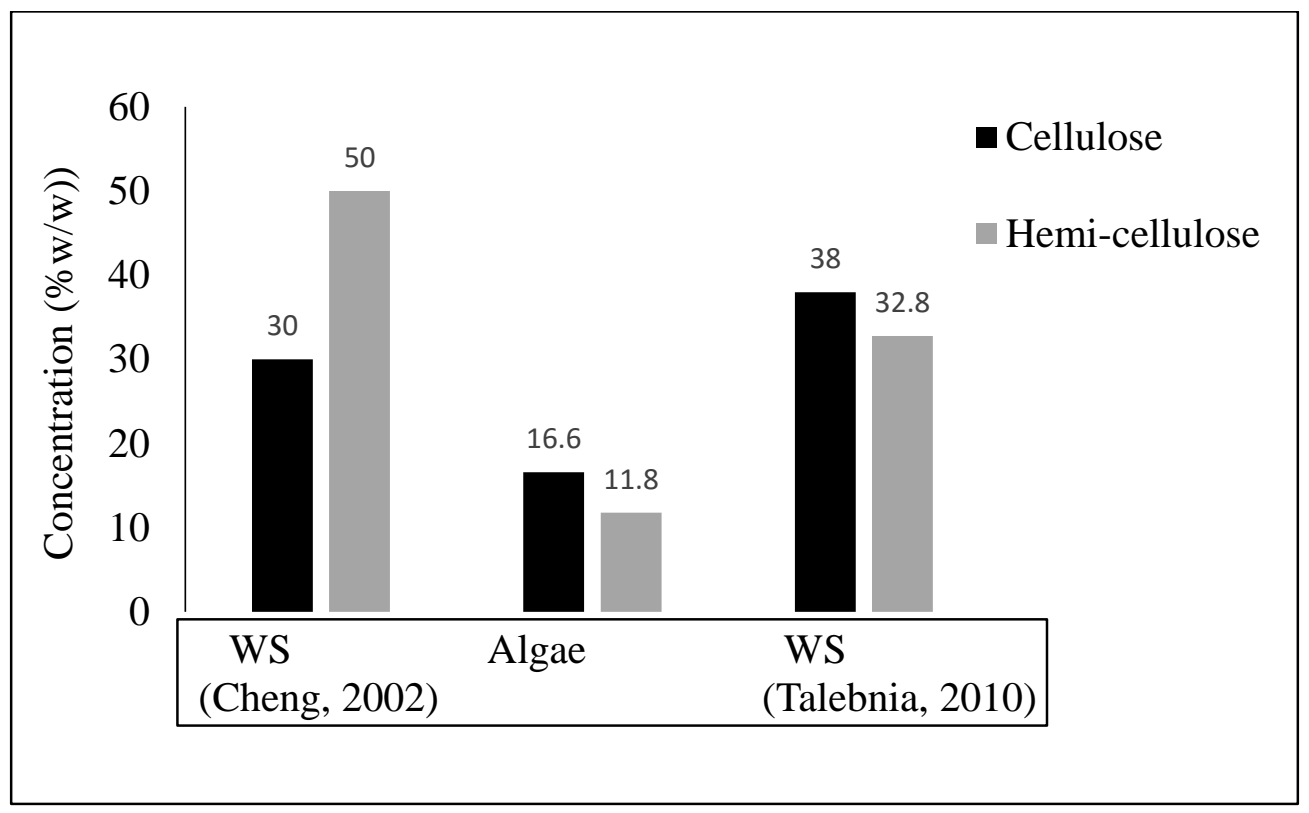

Figure D3. Lignocellulose composition from WS and algae

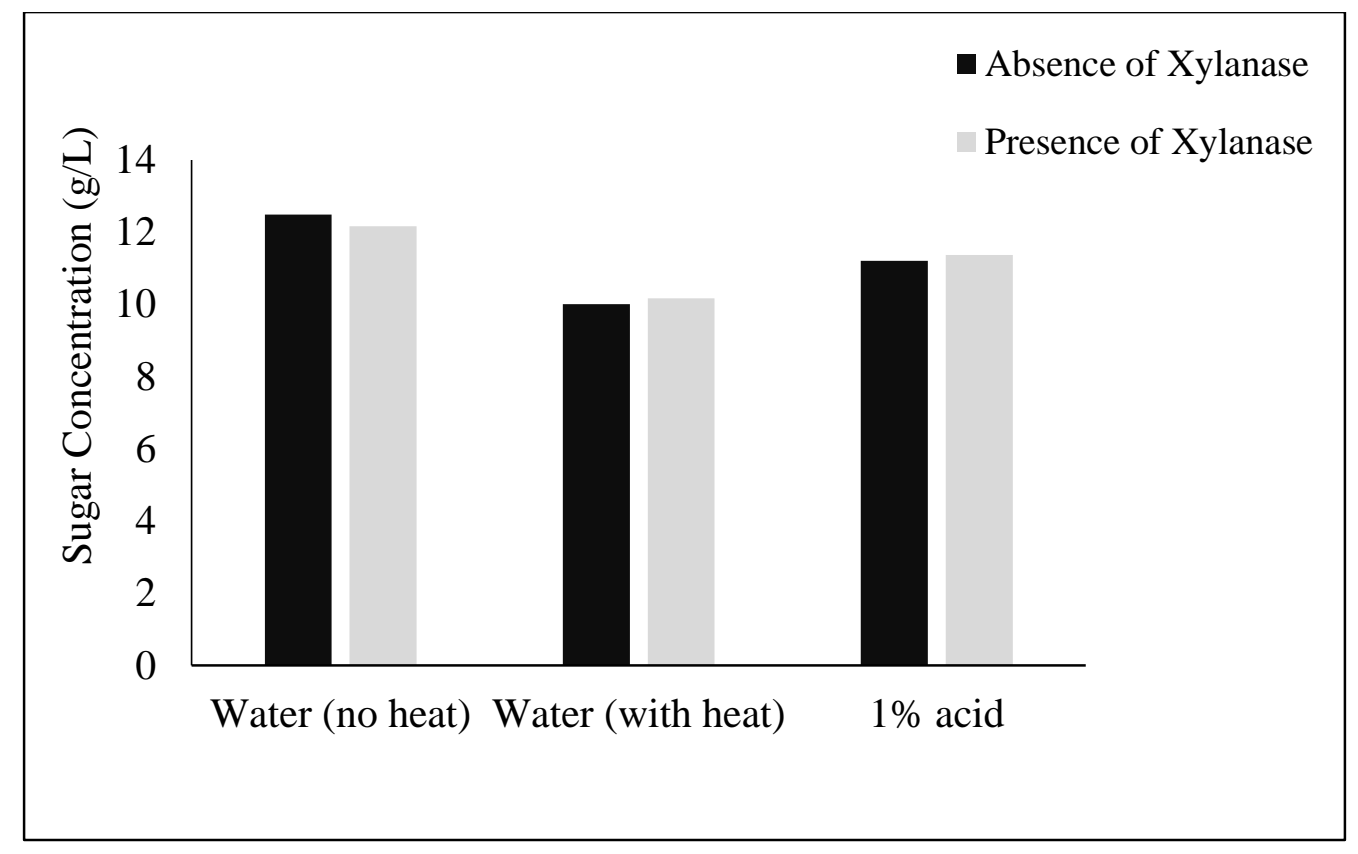

Figure D4. Glucose sugar concentration. 


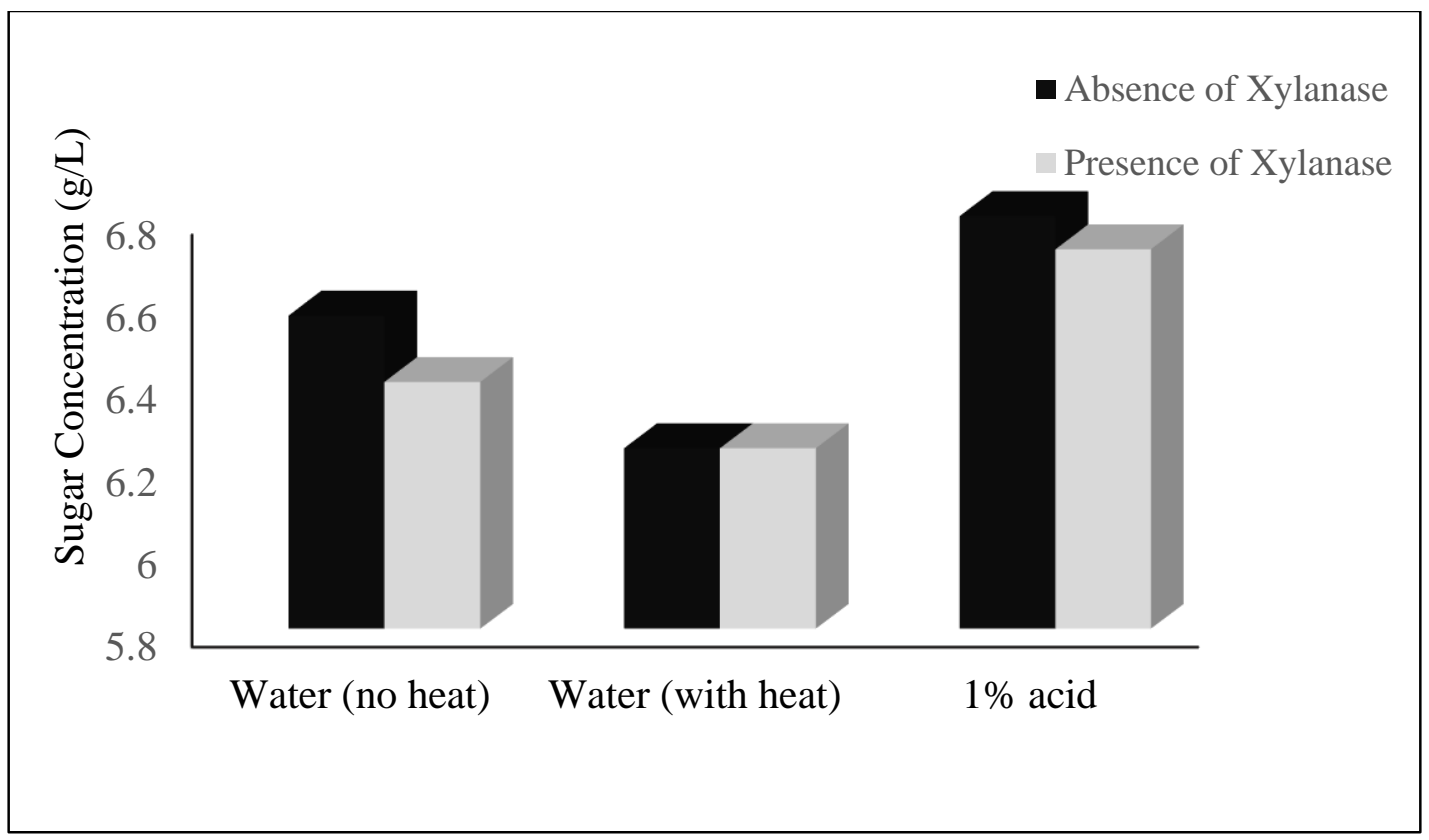

Figure D5. Xylose sugar concentration.

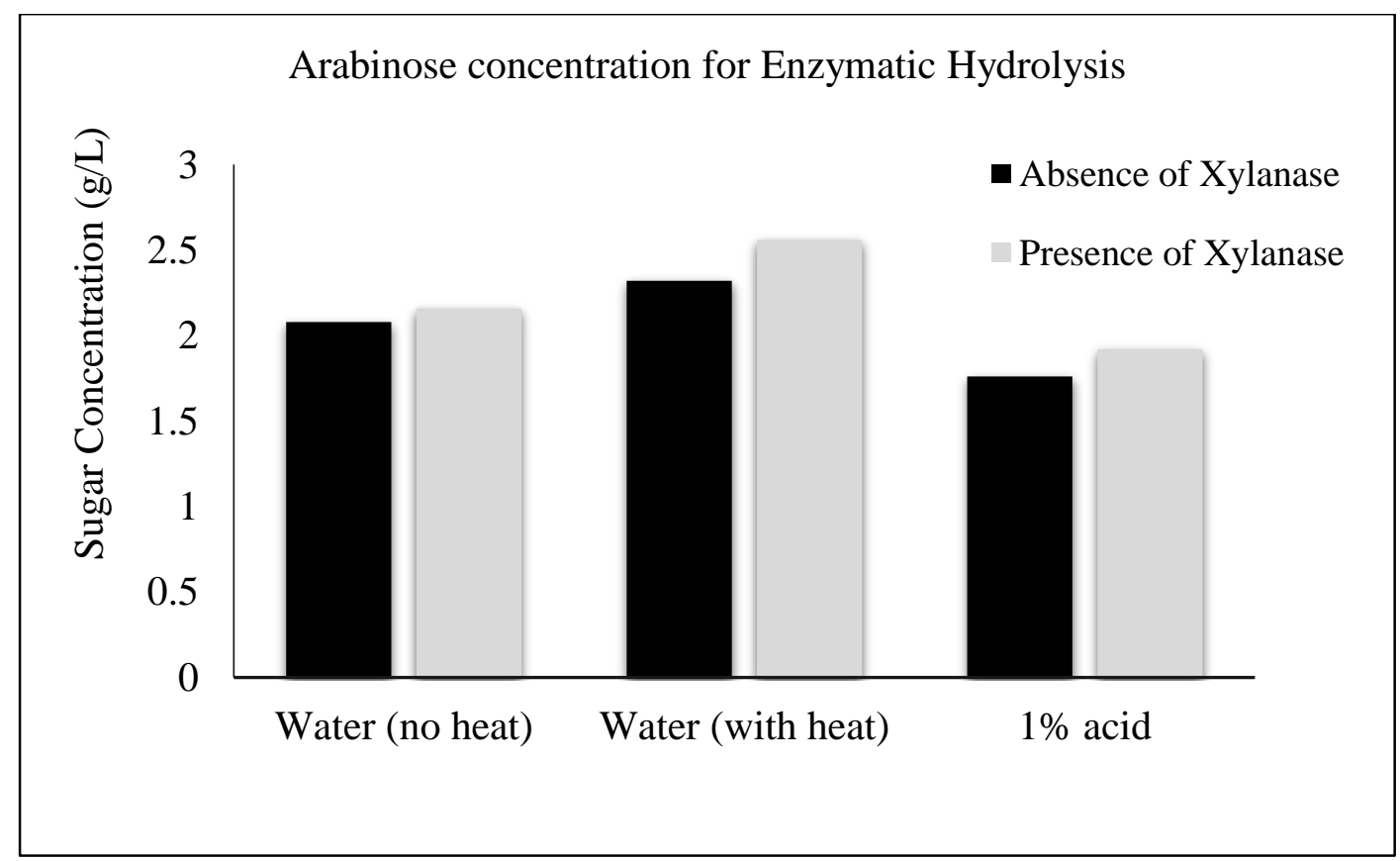

Figure D6. Arabinose sugar concentration. 


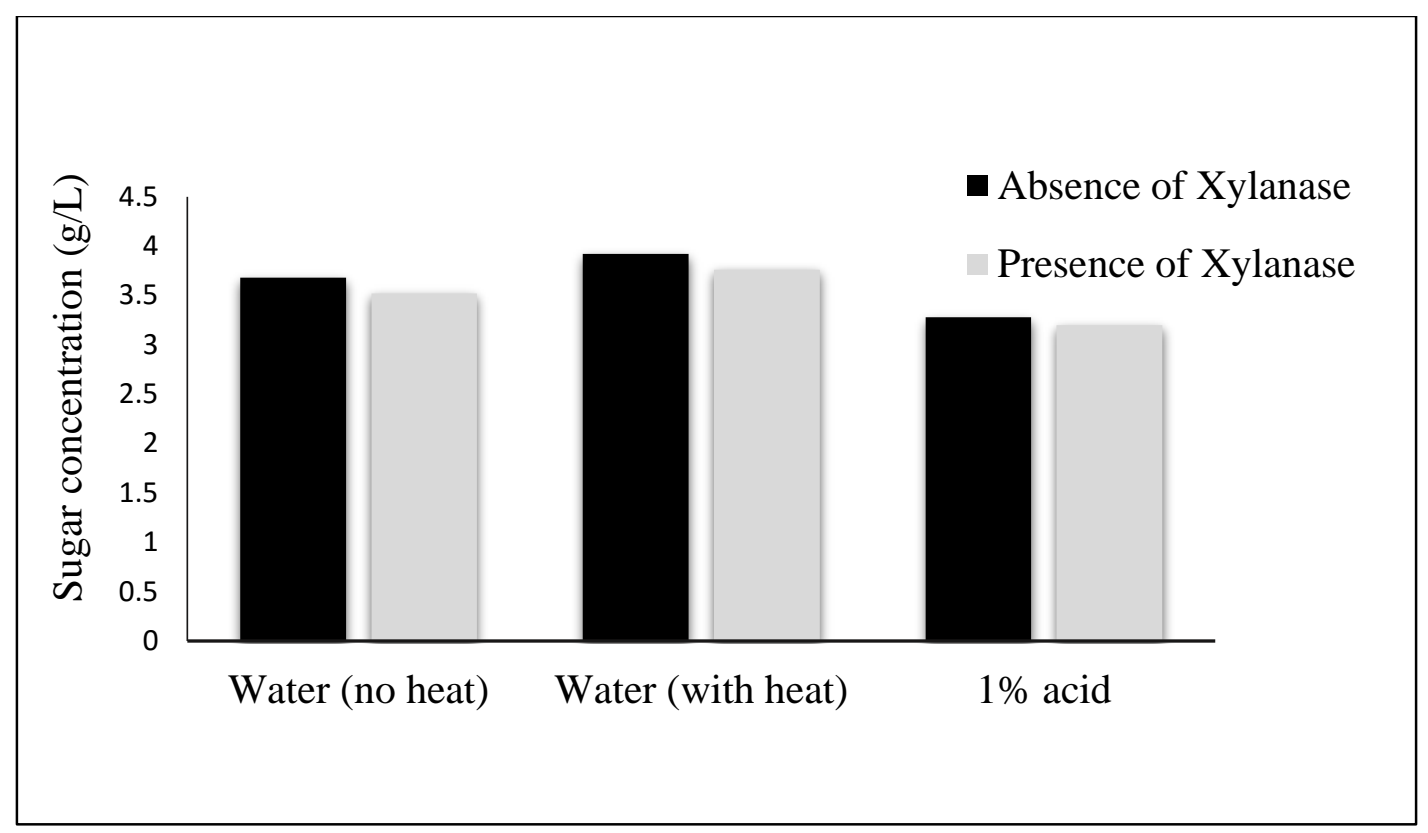

Figure D7. Mannose sugar concentration. 


\section{REFERENCES}

Adejoye, O. D., Adebayo-Tayo, B. C., Ogunjobi, A. A., Olaoye, O. A., \& Fadahunsi, F. I. (2006). Effect of carbon, nitrogen and mineral sources on growth of Pleurotus Florida, a Nigeria edible mushroom. African Journal of Biotechnology, 5(14), 1355-1359.

Alvarez, O. M., Patel, M., Booker, J., \& Markowitz, L. (2004). Effectiveness of a bio-cellulose wound dressing for the treatment of chronic venous leg ulcers: results of a single center randomized study involving 24 patients. Wounds-a Compendium of Clinical Research and Practice, 16(7), 224-233.

Al-Abdallah, W., \& Dahman, Y. (2013). Production of green bio-cellulose nanofibers by Gluconacetobacter xylinus through utilizing the renewable resources of agriculture residues. Bioprocess and bio-systems engineering, 36 (11), 1735-1743.

Bae, S., \& Shoda, M. (2004). Bacterial Cellulose Production by Fed-Batch Fermentation in Molasses Medium. Biotechnology progress, 20(5), 1366-1371.4

Belarbi, E. H., Molina, E., \& Chisti, Y. (2000). A process for high yield and scale able recovery of high purity eicosapentaenoic acid esters from microalgae and fish oil. Enzyme and microbial technology, 26(7), 516-529.

Besada, V., Andrade, J. M., Schultze, F., \& González, J. J. (2009). Heavy metals in edible seaweeds commercialized for human consumption. Journal of Marine Systems, 75(1), 305-313.

Bhatnagar, S. K., Saxena, A., \& Kraan, S. (2011). Algae-Based Biofuels: a review of challenges and opportunities for developing countries. Algae biofuel, 1-40. 
Brodo, I. M., Sharnoff, S. D., \& Sharnoff, S. (2001). Lichens of north America. Yale University Press.

Brown Jr, R. M. (1978). Biosynthesis of natural polymer systems with special reference to cellulose assembly and deposition. In Structure and Biochemistry of Natural Biological Systems: Proceedings of the 3rd Philip Morris Science Symposium, 51-123.

Brown, R. M. (1990). 1: Cell Walls and Surfaces, Reproduction, Photosynthesis; Wiessner, G.; Robinson, D. G.; Starr, R. C., Eds. Springer-Verlag: Berlin. Jr. In Experimental Phycology, 20.

Brown, R. M., Willison, J. H., \& Richardson, C. L. (1976). Cellulose biosynthesis in Acetobacter xylinum: visualization of the site of synthesis and direct measurement of the in vivo process. Proceedings of the National Academy of Sciences, 73(12), 4565-4569.

Brown, A. J. (1886). XLIIL-On an Acetic Ferment which form Cellulose. journal of the chemical society, 49, 432-439.

Brown, R. M. (2004). Cellulose structure and biosynthesis: what is in store for the $21 \mathrm{st}$ century? Journal of Polymer Science Part A: Polymer Chemistry, 42(3), 487-495.

Burton, T., Lyons, H., Lerat, Y., Stanley, M., \& Rasmussen, M. B. (2009). A review of the potential of marine algae as a source of biofuel in Ireland. Dublin: Sustainable Energy IrelandSEI.

Cannon, R. E. (1991). Biogenesis of bacterial cellulose A Critical Review. Microbiology, 17(6), 435-437. 
Castro, C., Zuluaga, R., Putaux, J. L., Caro, G., Mondragon, I., \& Ganan, P. (2011). Structural characterization of bacterial cellulose produced by Gluconacetobacter swingsii sp. from Colombian agro-industrial wastes. Carbohydrate Polymers, 84(1), 96-102.

Chen, P., Cho, S. Y., \& Jin, H. J. (2010). Modification and applications of bacterial celluloses in polymer science. Macromolecular Research, 18(4), 309-320.

Chisti, Y. (2007). Biodiesel from microalgae. Biotechnology Advances 25(3), 294-306.

Colvin, J. R. (1963). The size of the cellulose micro-fibril. The Journal of cell biology, 17(1), 105109.

Dahman Y. (2009). Nanostructured Biomaterials and Biocomposites from Bacterial Cellulose Nanofibers. Journal of Nanoscience and Nanotechnology, 9(9), 5105-5122.

Dahman, Y., Jayasuriya, K. E., \& Kalis, M. (2010). Potential of biocellulose nanofibers production from agricultural renewable resources: preliminary study. Applied biochemistry and biotechnology, 162(6), 1647-1659.

De Bhowmick, G., Subramanian, G., Mishra, S., \& Sen, R. (2014). Raceway pond cultivation of a marine microalga of Indian origin for biomass and lipid production: A case study. Algal Research, 6, 201-209.

Dien, B. S., Ximenes, E. A., O’Bryan, P. J., Moniruzzaman, M., Li, X. L., Balan, V., \& Cotta, M. A. (2008). Enzyme characterization for hydrolysis of AFEX and liquid hot-water pretreated distillers' grains and their conversion to ethanol. Bioresource Technology, 99(12), 5216-5225. 
Duarte, L. C., Silva-Fernandes, T., Carvalheiro, F., \& Gírio, F. M. (2009). Dilute acid hydrolysis of wheat straw oligosaccharides. Applied biochemistry and biotechnology, 153(1-3), $116-126$

Dutta, D., \& Gachhui, R. (2007). Nitrogen-fixing and cellulose-producing Gluconacetobacter kombuchae sp. Nov., isolated from Kombucha tea. International journal of systematic and evolutionary microbiology, 57(2), 353-357.

El-Saied, H., Basta, A. H., \& Gobran, R. H. (2004). Research progress in friendly environmental technology for the production of cellulose products. Polymer Plastics Technology and Engineering, 43(3), 797-820.

Ezeji, T., \& Blaschek, H. P. (2008). Fermentation of dried distillers' grains and solubles (DDGS) hydrolysates to solvents and value-added products by solventogenic clostridia. Bioresource technology,, 99(12), 5232-5242.

Gilbert, H. J., \& Hazlewood, G. P. (1993). Bacterial cellulases and xylanases. Microbiology, 139(2), 187-194.

Gírio, F. M., Fonseca, C., Carvalheiro, F., Duarte, L. C., Marques, S., \& Bogel-Lukasik, R. (2010). Hemicelluloses for fuel ethanol: a review. Bioresource technology, 101(13), 4775-4800.

Goelzer, F. D. E., Faria-Tischer, P. C. S., Vitorino, J. C., Sierakowski, M. R., \& Tischer, C. A. (2009). Production and characterization of nanospheres of bacterial cellulose from Acetobacter xylinum from processed rice bark. Materials Science and Engineering: C, 29(2), 546-551. 
Grohmann, K. \& Bothast., R. J. (1997). Saccharification of corn fibre by combined treatment with dilute sulphuric acid and enzymes. Process Biochemistry, 32(5), 405-415.

Hamad, W. Y. (2002). Cellulosic materials: fibers, networks and composites.Springer Science and Buisness Media.

Helenius, G., Backdahl, H., Bodin, A., Nannmark, U., Gatenholm, P., \& Risberg, B. (2006). In vivo biocompatibility of bacterial cellulose. Journal of Biomedical Materials Research Part A, 76(2), 431-438.

Hong, F., \&. Qui, K. (2008). An alternative carbon source from konjac powder for enhancing production of bacterial cellulose in static cultures by a model strain Acetobacter aceti subsp. xylinus ATCC 23770. Carbohydrate polymers, 72(3), 545-549.

Iguchi, M., Yamanaka, S., \& Budhiono, A. (2000). Bacterial cellulose-a masterpiece of nature's arts. Journal of Materials Science, 35(2), 261-270.

Ishihara, M., Matsunaga, M., Hayashi, N., \& Tišler, V. (2002). Utilization of D-xylose as carbon source for production of bacterial cellulose. Enzyme and microbial technology, 31(7), 986991

Jiang, L., Luo, S., Fan, X., Yang, Z., \& Guo, R. (2011). Biomass and lipid production of marine microalgae using municipal wastewater and high concentration of $\mathrm{CO}_{2}$. Applied energy, 88(10), 3336-3341. 
Johnson, M. B. (2009). Microalgal Biodiesel Production through a Novel Attached Culture System and Conversion Parameters (Doctoral dissertation, Virginia Polytechnic Institute and State University).

Jonas, R., \& Farah, L. F. (1998). Production and application of microbial cellulose. Polymer Degradation and Stability, 59(1), 101-106.

Karimi, K., Emtiazi, G., \& Taherzadeh, M. J. (2006). Ethanol production from dilute-acid pretreated rice straw by simultaneous saccharification and fermentation with Mucor indicus, Rhizopus oryzae, and Saccharomyces cerevisiae. Enzyme and Microbial Technology, 40(1), 138144.

Keshk, S. M. A. S. , \& Sameshima, K. (2005). Evaluation of different carbon sources for bacterial cellulose production. African Journal of Biotechnology, 4(6), 478-482.

Khan, S. A., Hussain, M. Z., Prasad, S., \& Banerjee, U. C. (2009). Prospects of biodiesel production from microalgae in India. Renewable and Sustainable Energy Reviews, 13(9), 23612372.

Klemm, D., Schumann, D., Udhardt, U., \& Marsch, S. (2001). Bacterial synthesized celluloseartificial blood vessels for microsurgery. Progress in Polymer Science, 26, 1561-1603.

Klemm, D. S. (2001). Bacterial synthesized cellulose—artificial blood vessels for microsurgery. Progress in Polymer Science, 26(9), 1561-1603.

Kongruang, S. (2008). Bacterial cellulose production by Acetobacter xylinum strains from agricultural waste products. Applied Biochemistry and Biotechnology, 148(1-3), 245-256. 
Kuga, S., \& Brown R. M. (1988). Silver labeling of the reducing ends of bacterial cellulose. Carbohydrate Research, 180(2), 345-350.

Kumar, K., Mishra, S. K., Shrivastav, A., Park, M. S., \& Yang, J. W. (2015). Recent trends in the mass cultivation of algae in raceway ponds. Renewable and Sustainable Energy Reviews, 51, $875-885$.

Kurosumi, A., Sasaki, C., Yamashita, Y., \& Nakamura, Y. (2009). Utilization of various fruit juices as carbon source for production of bacterial cellulose by Acetobacter xylinum NBRC 13693. Carbohydrate polymer, 76(2), 333-335.

Kurosumi, A., Sasaki, C., Yamashita, Y., \& Nakamura, Y. (2009). Utilization of various fruit juices as carbon source for production of bacterial cellulose by Acetobacter xylinum NBRC 13693. carbohydrate polymer, 76(2), 333-335.

Lee, J. W., Deng, F., Yeomans, W. G., Allen, A. L., Gross, R. A., \& Kaplan, D. L. (2001). Direct Incorporation of Glucosamine and N-Acetyl glucosamine into Exo-polymers by Gluconacetobacter xylinus (Acetobacter xylinum) ATCC 10245: Production of Chitosan-Cellulose and Chitin-Cellulose Exo-polymers. Applied and Environmental microbiology, 67(9), 3970-3975.

Lee, R. A., \& Lavoie, J. M. (2013). From first-to third-generation biofuels: Challenges of producing a commodity from a biomass of increasing complexity. Animal Frontiers, 3(2), 6-11.

Linnaeus, C. (1800). Species plantarum (Vol. 4). Impensis GC Nauk.

Lundquist, T. J., Woertz, I. C., Quinn, N. W. T., \& Benemann, J. R. (2010). A realistic technology and engineering assessment of algae biofuel production. Energy Biosciences Institute, $1-178$. 
Mikkelsen, D., Flanagan, B. M., Dykes, G. A., \& Gidley, M. J. (2009). Influence of different carbon sources on bacterial cellulose production by Gluconacetobacter xylinus strain ATCC 53524. Journal of applied microbiology,, 107(2), 576-583.

Nakas, J. P., Schaedle, M., Parkinson, C. M., Coonley, C. E., \& Tanenbaum, S. W. (1983). System development for linked-fermentation production of solvents from algal biomass. Applied and environmental microbiology, 46(5), 1017-1023.

Nakatsubo, F., Kamitakahara, H., \& Hori, M. (1996). Cationic ring-opening polymerization of 3, 6-di-O-benzyl- $\alpha$-D-glucose 1, 2, 4-orthopivalate and the first chemical synthesis of cellulose. Journal of the American Chemical Society, 118(7), 1677-1681.

Nguyen, M. T., Choi, S. P., Lee, J., Lee, J. H., \& Sim, S. J. (2009). Hydrothermal acid pretreatment of Chlamydomonas reinhardtii biomass for ethanol production. Journal of microbiology and biotechnology, 19(2), 161-166.

Nguyen, V. T., Gidley, M. J., \& Dykes, G. A. (2008). Potential of a nisin-containing bacterial cellulose film to inhibit Listeria monocytogenes on processed meats. Food Microbiology, 25(3), 471-478.

Nobles, D. R., Romanovicz, D. K., \& Brown, R. M. (2001). Cellulose in cyanobacteria. Origin of vascular plant cellulose synthase?. Plant physiology, 127(2), 529-542.

Palmqvist, E., \& Hahn-Hägerdal, B. (2000). Fermentation of lignocellulosic hydrolysates. II: inhibitors and mechanisms of inhibition. Bioresource technology, 74(1), 25-33.

Pearson, C. (1995). The Diversity and Evolution of Plants. CRC Press, (p. 221). 
Pienkos, P. T., \& Darzins, A. L. (2009, May 28). Biofuels, Bioproducts and Biorefining. The promise and challenges of microalgal-derived biofuels, 3(4), 431- 440.

Playne, M. J. (1984). Increased digestibility of bagasses by pretreatment with alkalis and steam explosion. Biotechnology and Bioengineering, 26(5), 426-433.

Pommet, M., Juntaro, J., Heng, J. Y., Mantalaris, A., Lee, A. F., Wilson, K., \& Bismarck, A. (2008). Surface modification of natural fibers using bacteria: depositing bacterial cellulose onto natural fibers to create hierarchical fiber reinforced nanocomposites. Biomacromolecules, $9(6)$, $1643-1651$.

Potts, T., Du, J., Paul, M., May, P., Beitle, R., \& Hestekin, J. (2012). The production of butanol from Jamaica bay macro algae. Environmental Progress \& Sustainable Energy, 31(1), 29-36.

Qureshi, N., Saha, B. C., Hector, R. E., Hughes, S. R., \& Cotta, M. A. (2008). Butanol production from wheat straw by simultaneous saccharification and fermentation using Clostridium beijerinckii: Part I—Batch fermentation. Biomass and Bioenergy, 32(2), 168-175.

Ross, P., Mayer, R., \& Benziman, M. (1991). Cellulose biosynthesis and function in bacteria. Microbiological reviews, 55(1), 35-58.

Saha, B. C., \& Cotta, M. A. (2006). Ethanol production from alkaline peroxide pretreated enzymatically saccharified wheat straw. Biotechnology Progress, 22(2), 449-453.

Saha, B. C., Iten, L. B., Cotta, M. A., \& Wu, Y. V. (2005). Dilute acid pretreatment, enzymatic saccharification and fermentation of wheat straw to ethanol. Process Biochemistry, 40(12), 36933700. 
Sani, A., \& Dahman, Y. (2010). Improvements in the production of bacterial synthesized biocellulose nanofibers using different culture methods. Journal of Chemical Technology and Biotechnology, 85(2), 151-164.

Sheykhnazari, S., Tabarsa, T., Ashori, A., Shakeri, A., \& Golalipour, M. (2011). Bacterial synthesized cellulose nanofibers; effects of growth times and culture mediums on the structural characteristics. Carbohydrate Polymers, 86(3), 1187-1191.

Singh A., Das K. and Sharma D. K., (1984), "Production of xylose, furfural, fermentable sugars and ethanol from agricultural residues", Journal of Chemical Technology and Biotechnology, Vol. 34(2), pp. 51-61.

Spolaore, P., Joannis-Cassan, C., Duran, E., \& Isambert, A. (2006). Commercial applications of microalgae. Journal of bioscience and bioengineering, 101(2), 87-96.

Sun, Y., \& Cheng, J. (2002). Hydrolysis of lignocellulosic materials for ethanol production: a review. Bioresource technology, 83(1), 1-11.

Svensson, A., Nicklasson, E., Harrah, T., Panilaitis, B., Kaplan, D. L., Brittberg, M., \& Gatenholm, P. (2005). Bacterial cellulose as a potential scaffold for tissue engineering of cartilage. Biomaterials, 26(4), 419-431.

Szengyel Z. and Zacchi G., (2000), "Effect of acetic acid and furfural on cellulase production of Trichoderma reesei RUT C30”, Applied Biochemistry and Biotechnology, Vol. 89(1), pp. 31-42.

Szulczyk, K. R. (2010, October). Renewable and sustainable reviews. Market penetration of biodiesel., 14(8), 2426-2433. 
Talebnia, F., Karakashev, D., \& Angelidaki, I. (2010). Production of bioethanol from wheat straw: an overview on pretreatment, hydrolysis and fermentation.Bioresource Technology, 101(13), 4744-4753.

Tassinari, T. H., Macy, C. F., \& Spano, L. A. (1982). Technology advances for continuous compression milling pretreatment of lignocellulosic for enzymatic hydrolysis. Biotechnology and Bioengineering, 24(7), 1495-1505.

Taylor, F., Craig Jr, J. C., Kurantz, M. J., \& Singh, V. (2003). Corn-milling pretreatment with anhydrous ammonia. Applied biochemistry and biotechnology, 104(2), 141-148.

Teeri, T. T. (1997). Crystalline cellulose degradation: new insight into the function of cellobiohydrolases. Trends in Biotechnology,, 15(5), 160-167.

Thirmal, C., \& Dahman, Y. (2012). Comparisons of existing pretreatment, saccharification, and fermentation processes for butanol production from agricultural residues. The Canadian Journal of Chemical Engineering, 90(3), 745-761.

Trovatti, E., Serafim, L. S., Freire, C. S., Silvestre, A. J., \& Neto, C. P. (2011). Gluconacetobacter sacchari: an efficient bacterial cellulose cell-factory. Carbohydrate Polymers, 86(3), 1417-1420.

Uraki, Y., Morito, M., Kishimoto, T., \& Sano, Y. (2002). Bacterial cellulose production using monosaccharides derived from hemicelluloses in water-soluble fraction of waste liquor from atmospheric acetic acid pulping.Holzforschung, 56(4), 341-347. 
Vandamme, E. J., De Baets, S., Vanbaelen, A., Joris, K., \& De Wulf, P. (1998). Improved production of bacterial cellulose and its application potential.Polymer Degradation and Stability, 59(1), 93-99.

Velasco-Bedrán, H., \& López-Isunza, F. (2007). The unified metabolism of Gluconacetobacter entanii in continuous and batch processes. Process Biochemistry, 42(8), 1180-1190.

Vergara-Fernández, A., Vargas, G., Alarcón, N., \& Velasco, A. (2008). Evaluation of marine algae as a source of biogas in a two-stage anaerobic reactor system. Biomass and Bioenergy, 32(4), 338-344.

Verschuren, P. G., Cardona, T. D., Nout, M. R., De Gooijer, K. D., \& Van den Heuvel, J. C. (2000). Location and limitation of cellulose production by Acetobacter xylinum established from oxygen profiles. Journal of bioscience and bioengineering, 89(5), 414-419.

Ververis, C., Georghiou, K., Danielidis, D., Hatzinikolaou, D. G., Santas, P., Santas, R., \& Corleti, V. (2007). Cellulose, hemicelluloses, lignin and ash content of some organic materials and their suitability for use as paper pulp supplements. Bioresource Technology, 98(2), 296-301.

Wertz, J. L., Mercier, J. P., \& Bedue, O. (2010). Cellulose science and technology. CRC Press.

Wiessner, W., Robinson, D. G., \& Starr, R. C. (Eds.). (2012). Cell walls and surfaces, reproduction, photosynthesis (Vol. 1). Springer Science \& Business Media.

www.res.titech.ac.jp. http://www.res.titech.ac.jp/ junkan/english/cellulose/. 
Yamada, Y., Hoshino, K. I., \& Ishikawa, T. (1997). The phylogeny of acetic acid bacteria based on the partial sequences of $16 \mathrm{~S}$ ribosomal RNA: the elevation of the subgenus Gluconacetobacter to the generic level. Bioscience, biotechnology, and biochemistry, 61(8), 1244-1251.

Yamanaka, S., \& Sugiyama, J. (2000). Structural modification of bacterial cellulose. Cellulose, 7(3), 213-225.

Yang, Y. K., Park, S. H., Hwang, J. W., Pyun, Y. R., \& Kim, Y. S. (1998). Cellulose production by Acetobacter xylinum BRC5 under agitated condition.Journal of fermentation and bioengineering, 85(3), 312-317.

Yan, L., Zhang, H., Chen, J., Lin, Z., Jin, Q., Jia, H., \& Huang, H. (2009). Dilute sulfuric acid cycle spray flow-through pretreatment of corn stover for enhancement of sugar recovery. Bioresource technology, 100(5), 1803-1808.

Yoo, C., Jun, S. Y., Lee, J. Y., Ahn, C. Y., \& Oh, H. M. (2010). Selection of microalgae for lipid production under high levels carbon dioxide. Bio-resource technology, 101(1), 571-574.

Zaar, K. (1977). The biogenesis of cellulose by Acetobacter Xylinum. Cell biology, 16(1), 1-15.

Zabihi, S. A. (2010). Pretreatment of wheat straw using steam, steam/acetic acid and steam/ethanol and its enzymatic hydrolysis for sugar production. Biosystems engineering, 105(3), 288-297.

Zhu, S., Wu, Y., Yu, Z., Zhang, X., Li, H., \& Gao, M. (2006). The effect of microwave irradiation on enzymatic hydrolysis of rice straw. Bio-resource technology, 97(15), 1964-1968. 